Environmental Security Technology Certification Program - Project ER 0630

\title{
Demonstration/Validation of the Snap Sampler Passive Ground Water Sampling Device for Sampling Inorganic Analytes at the Former Pease Air Force Base
}

Louise Parker, Nathan Mulherin, Gordon Gooch, July 2009

William Major, Richard Willey, Thomas Imbrigiotta, Jacob Gibs, and Donald Gronstal

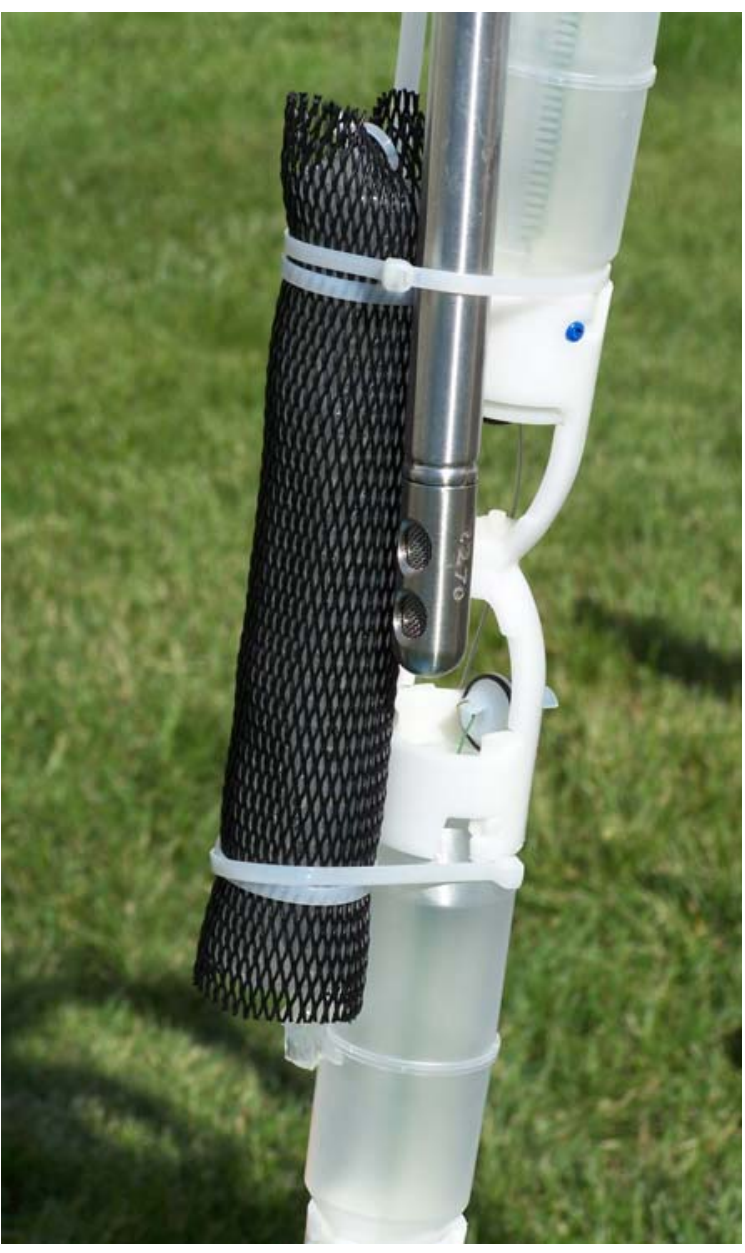





\section{Demonstration/Validation of the Snap Sampler Passive Ground Water Sampling Device for Sampling Inorganic Analytes at the Former Pease Air Force Base}

Louise Parker, Nathan Mulherin, and Gordon Gooch

Cold Regions Research Engineering Laboratory

U.S. Army Engineer Research and Development Center

72 Lyme Road

Hanover, NH 03755-1290

William Major

Naval Facilities Engineer Service Center

1100 23rd Avenue

Port Hueneme, CA 93043-4333

Richard Willey

U.S. Environmental Protection Agency, Region 1

1 Congress Street, Suite 1100

Boston, MA 02114-2023

Thomas Imbrigiotta and Jacob Gibs

U.S. Geological Survey/Water Resources

810 Bear Tavern Road, Suite 206

West Trenton, NJ 08628

Donald Gronstal

U.S. Air Force Real Property Agency

311 Olson Street

McClellan, CA 95652

Final report

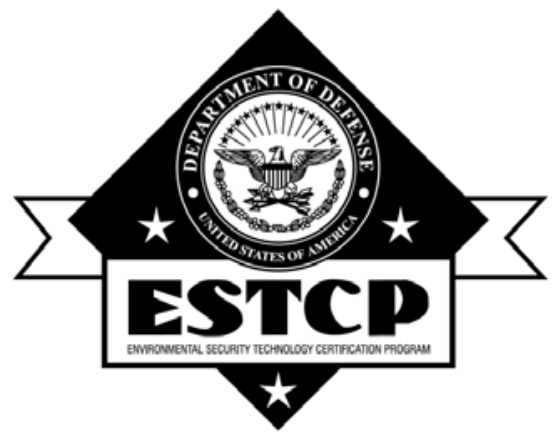

Approved for public release; distribution is unlimited.

Prepared for Environmental Security Technology Certification Program

901 N. Stuart Street - Ste. 303, Arlington, VA 22203

Under ER-0630 


\begin{abstract}
Laboratory studies and a field demonstration were conducted to determine the ability of the Snap Sampler to recover representative concentrations of several types of inorganic analytes from ground water. Analytes included non-metals, transition metals, alkaline earth metals, alkali metals, and a metalloid. In the laboratory studies, concentrations of analytes in Snap Sampler samples were com-parable with concentrations of the analytes in samples collected from a standpipe (i.e., control samples). For the field demonstration, there were sampling events at the former Pease Air Force Base. Samples taken using a Snap Sampler were compared with samples collected using conventional low-flow purging and sampling and a regenerated cellulose passive diffusion sampler. Based upon statistical analyses, analyte concentrations were found to be equivalent to those in the low-flow samples with one exception - unfiltered iron, where concentrations were significantly higher in the Snap Sampler samples. Differences were most pronounced in samples collected from the two stainless steel wells and from wells with higher turbidity levels. Elevated turbidities may have resulted from installing additional sampling equipment (including the baffle, pump, samplers, and bottom weight) in the well before sampling. We will examine this issue further at our next test site.
\end{abstract}

DISCLAIMER: The contents of this report are not to be used for advertising, publication, or promotional purposes. Citation of trade names does not constitute an official endorsement or approval of the use of such commercial products. All product names and trademarks cited are the property of their respective owners. The findings of this report are not to be construed as an official Department of the Army position unless so designated by other authorized documents. 


\section{Table of Contents}

List of Figures and Tables ...........................................................................................................v

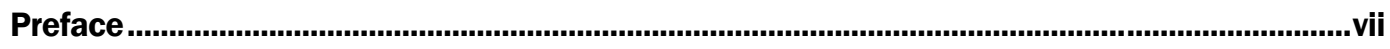

Executive Summary …............................................................................................................................

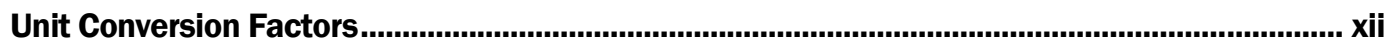

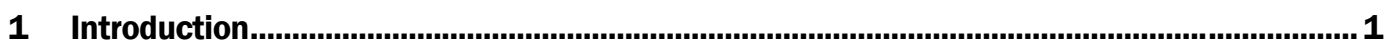

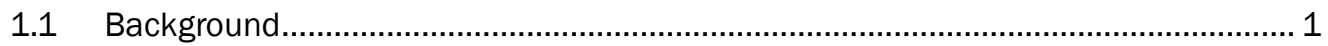

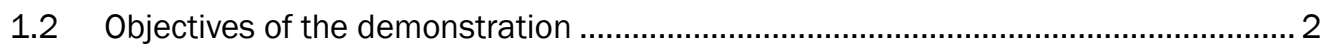

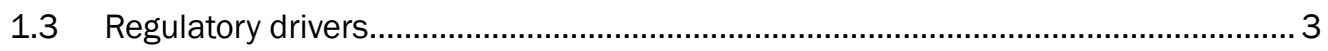

1.4 Stakeholder/end-user issues ............................................................................. 3

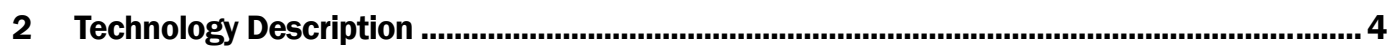

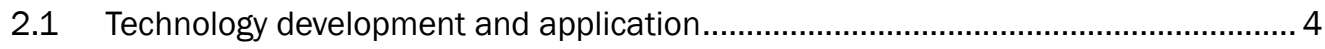

2.2 Previous testing of the technology ........................................................................ 5

2.2.1 Proof of concept: Laboratory tests........................................................................ 5

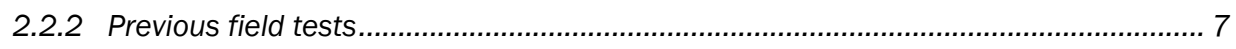

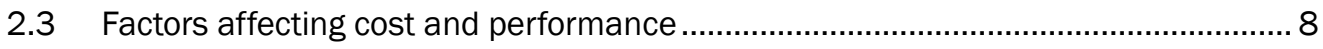

2.4 Advantages and limitations of the technology .................................................... 9

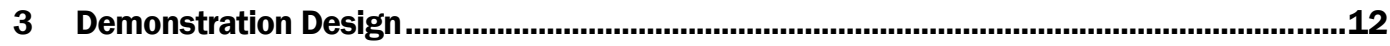

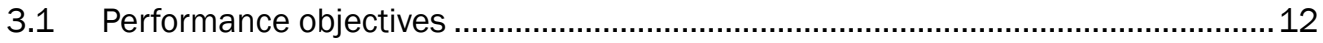

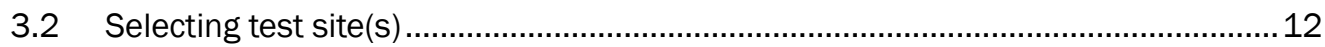

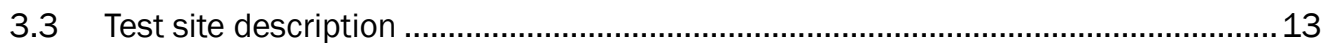

3.3.1 Zone 1

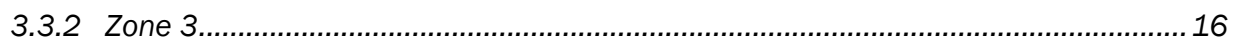

3.4 Pre-demonstration testing and analysis ......................................................... 18

3.4.1 First laboratory study ..................................................................................... 18

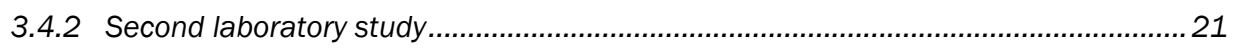

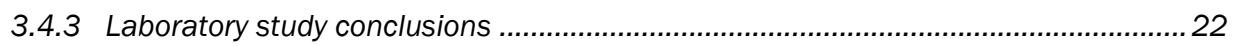

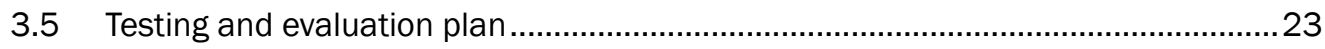

3.5.1 Demonstration installation and start-up................................................................. 23

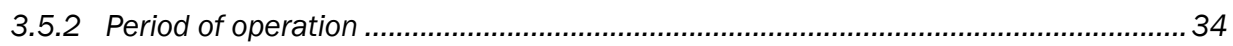

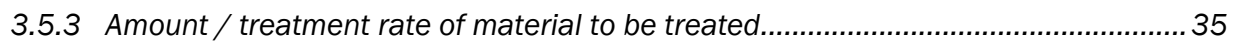

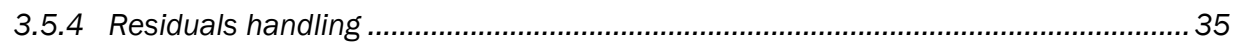

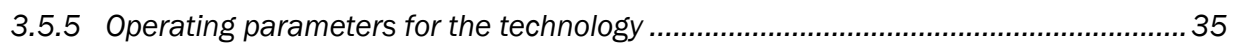

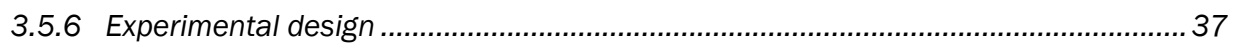

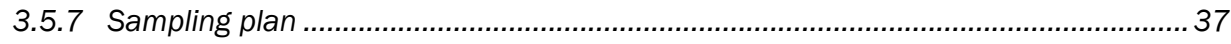

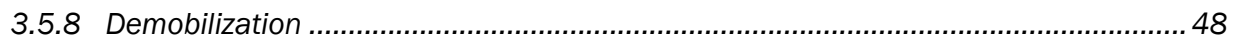

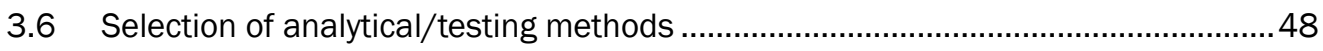

3.7 Selection of analytical/testing laboratory ...........................................................49 
4 Performance Assessment ..................................................................................................50

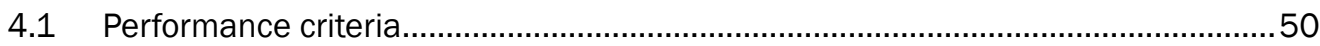

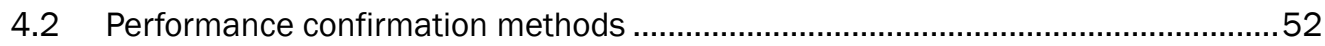

4.3 Data analysis, interpretation and evaluation .....................................................54

4.4 Findings from the field demonstration ................................................................55

4.4.1 Sampler performance and safety issues..................................................................56

4.4.2 Sampling time and personnel requirements............................................................57

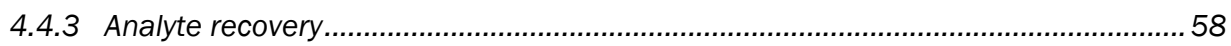

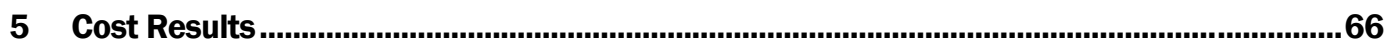

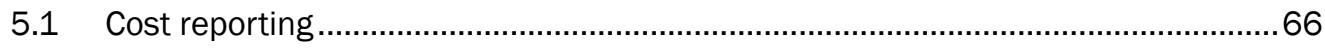

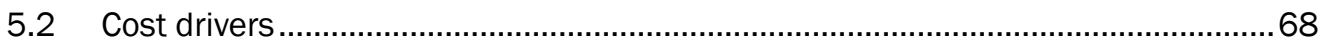

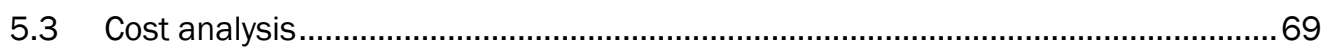

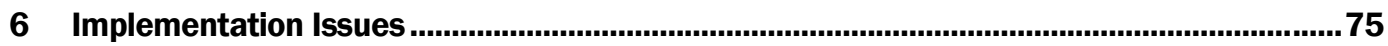

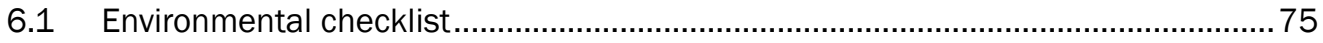

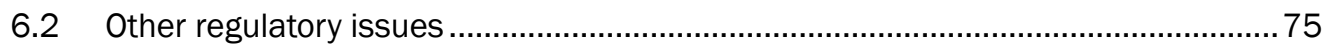

E. End-user issues ............................................................................................ 76

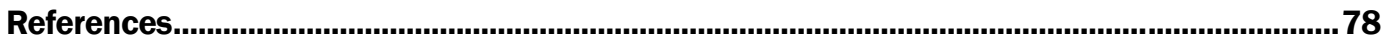

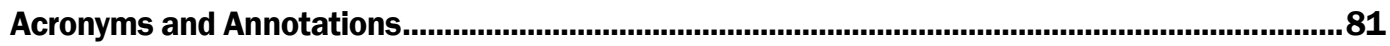

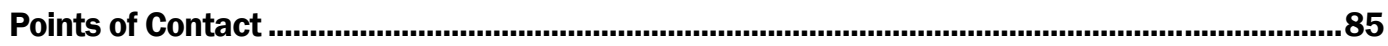

Dated Signature of Project Leader ................................................................................................86

Appendix A: Sampling Methods Supporting the Experimental Design ....................................87

Appendix B: Analytical Methods Supporting the Sampling Plan ................................................88

Appendix C: Quality Assurance Project Plan (QAPP)...........................................................89

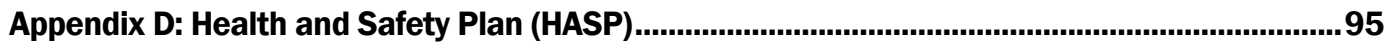

Appendix E: Data Summaries for the Second Laboratory Study. ..................................................96

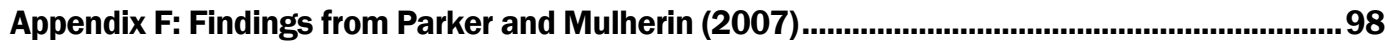

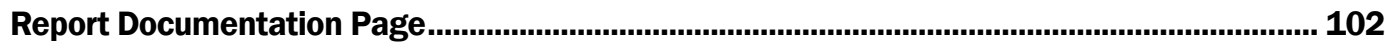




\section{List of Figures and Tables}

\section{Figures}

Figure 1. Snap Sampler deployment procedure.

Figure 2. Map of the state of New Hampshire showing the location of the former Pease AFB.

Figure 3. Map outlining IRP zones at the former Pease AFB (from MWH Americas, Inc. 2004).....

Figure 4. North-south cross section of Zone 3 (Roy F. Weston, Inc. 1992)................................... 17

Figure 5. East-west cross section of Zone 3 (Roy F. Weston, Inc. 1992)........................................ 18

Figure 6. Map of the former base showing the locations of the monitoring wells used in this study.

Figure 7. Diagram showing vertical profiling of well using Snap Samplers. .....................................28

Figure 8. Photo of Snap Sampler, trigger line, and baffle. ................................................................2

Figure 9. Sediment load comparison between two samples from well 32-5020..........................30

Figure 10. Diagram of deployment of sampling equipment in each well. 39

\section{Tables}

Table 1. Performance objectives .......................................................................................... 12

Table 2. Percent recovery of the analytes with time. ..................................................................... 19

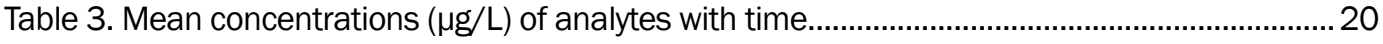

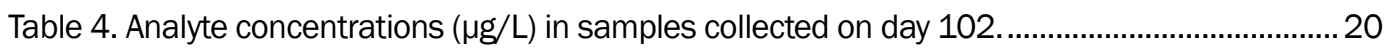

Table 5. Mean percent recovery of the cations with time. ..................................................................2

Table 6. Mean percent recovery of the anions with time.

Table 7. Information on the wells used at the former Pease AFB................................................... 24

Table 8. Ambient (non-pumping) flow testing results...................................................................... 26

Table 9. Active pumping flow testing results..................................................................................... 27

Table 10. Results from the depth profiles of the wells. ……..........................................................

Table 11. Results for the equipment blanks...........................................................................32

Table 12. Results from initial low-flow sampling of the wells.............................................................34

Table 13. Dates for the various demonstration activities..............................................................34

Table 14. Results for field duplicate samples, with relative percent difference calculations........... 45

Table 15. Results from duplicate laboratory analyses, with relative percent difference

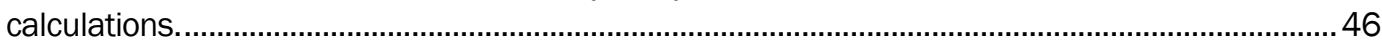

Table 16. Data for matrix spike and matrix spike duplicate samples. ............................................. 47

Table 17. Percent recovery of reference samples. .......................................................................... 48

Table 18. Performance criteria for Snap and RGC samplers vs. low-flow sampling ..........................50

Table 19. Expected performance and performance confirmation methods......................................53 
Table 20. Findings from the field study. 58

Table 21. Purge times and turbidity values ${ }^{*}$ for low-flow sampling during the initial sampling and the field demonstration. 61

Table 22. Cost model for the Snap Sampler: 10-yr period, with quarterly sampling........................66

Table 23. Cost model for low-flow sampling: 10-yr period, with quarterly sampling..........................67

Table 24. Cost model for the RGC sampler: 10-yr period, with quarterly sampling. ..........................68

Table 25. Projected monitoring costs using the Snap Sampler for 10 years. .................................. 71

Table 26. Projected monitoring costs, using low-flow sampling for 10 years................................... 72

Table 27. Projected monitoring costs, using the RGC sampler for 10 years..................................... 73 


\section{Preface}

This report was prepared by the U.S. Army Engineer Research and Development Center (ERDC) - Cold Regions Research and Engineering Laboratory (CRREL) in Hanover, New Hampshire. Funding was provided by the Environmental Security Technology Certification Program (ESTCP) under Project ER-0630: "Demonstration/Validation of the Snap Sampler Passive Ground Water Sampling Device" with Dr. Andrea Leeson as Program Manager for Environmental Restoration.

This report was prepared by Louise V. Parker and Nate Mulherin, Biogeochemical Sciences Branch, and Gordon Gooch, Engineering Resources Branch, at ERDC-CRREL.

The authors' special thanks go to Dr. Andrea Leeson, Dr. Jeffrey Marquesee, and all the ESTCP panel members for the advice and insight they provided. We also wish to thank Michael Daly with Region 1 of the U.S. EPA for providing the historical field data, plus Martin Mistretta and Jim Bryant of URS Corporation at Pease International Tradeport ${ }^{1}$ for access, scheduling, and general assistance at the field site. Special thanks also go to Scott Kelley and Jennifer Lane (Eastern Analytical Inc.) for conducting the chemical analyses, and to Sandy Britt (ProHydro Inc.) for his assistance throughout all stages of this demonstration - especially for help with developing the wells, and for conducting and interpreting the vertical flow testing.

This report was prepared under the general supervision of Dr. Terrence M. Sobecki, Chief, Biogeochemical Sciences Branch; Dr. Thomas J. Tantillo, Chief, Engineering Resources Branch; and Dr. Justin B. Berman, Chief, Research and Engineering Division. Branch.

At the time of publication, Dr. Lance D. Hansen was Deputy Director and Dr. Robert E. Davis was Director, CRREL.

COL Gary E. Johnston was the Commander of ERDC and the Director was Dr. James R. Houston.

1 Pease International Tradeport is located on the site of the former Pease Air Force Base. 


\section{Executive Summary}

This report was completed as a partial fulfillment of the obligations established for ESTCP Demonstration Project ER-0630. The objectives of this project were to demonstrate that the Snap Sampler passive ground water sampling device can provide (1) technically defensible analytical data for the wide spectrum of analytes that are of concern to the Department of Defense (DoD) and (2) offer substantial cost savings in the process. Our research plan was to use this device to collect samples at five sites, for a range of analyte types including: VOCs, explosives, perchlorates, metals, and natural attenuation parameters. The demonstration for this project was conducted at the former Pease Air Force Base in Portsmouth, NH. The analytes of interest were several metals (including two alkali metals, two alkaline-earth metals, and two transition metals) and one metalloid (arsenic).

Prior to conducting this field study, two laboratory studies were conducted to determine the ability of the Snap Sampler to recover representative concentrations of several inorganic analytes including non-metals (bromide, chloride, nitrate, perchlorate, and sulfate); a metalloid (As), and several metals including alkali metals (sodium [Na] and potassium [K]); alkaline earth metals (magnesium $[\mathrm{Mg}]$ and calcium [Ca]); and transition metals (cadmium [Cd], chromium [Cr], manganese [Mg], and iron [Fe]). For these studies, concentrations of analytes in samples taken with the Snap Sampler were compared with known concentrations of the analytes in samples collected from a standpipe (i.e., control samples). These studies clearly demonstrated that the Snap Sampler recovered equivalent concentrations of the inorganic analytes used in these studies, when compared with the control samples.

For the field demonstration, there were 10 sampling events. Inorganic analytes that were found at concentrations above the detection limit at this site included: As, $\mathrm{Ca}, \mathrm{Fe}, \mathrm{Mg}, \mathrm{Mn}, \mathrm{K}$, and $\mathrm{Na}$. Analyte concentrations in samples collected with the Snap Sampler were compared with samples collected using the EPA's low-flow purging and sampling protocol (U.S. EPA Region 1 1996). Both filtered and unfiltered samples were analyzed. Samples were also collected using a Regenerated Cellulose (RGC) passive diffusion sampler and concentrations in these samples were compared as 
well. Using these three sampling technologies allowed us to compare dissolved and colloid-borne contaminants.

This demonstration showed that the Snap Sampler recovered equivalent concentrations of most inorganic analytes, compared to those obtained by using the EPA's low-flow purging and sampling protocol; the exception to this was unfiltered (total) iron where concentrations were higher in the Snap Sampler. Concentrations of unfiltered iron were especially higher in the two stainless steel wells and appear to reflect the turbidity levels in the wells at the time of sampling. Elevated turbidities may have been an artifact of the experimental design that resulted from installing the baffle and additional sampling equipment (including the pump, and RGC and Snap samplers) in the well before sampling. However, because deploying several Snap Sampler bottles in a well may also elevate turbidity in the well, future studies should examine this issue in more depth. Therefore we concluded that for most inorganic analytes, this sampler appears to be a viable alternative to low-flow sampling at this site.

While the RGC sampler can only provide filtered samples, analyte concentrations in these samples were equivalent to those found in the unfiltered low-flow samples. The use of the RGC sampler in conjunction with low-flow sampling and the Snap Sampler demonstrated that colloidal transport of these analytes was not predominant at this site.

Other primary performance criteria used to evaluate the Snap Sampler and RGC sampler included reduced sampling time and/or reduced personnel requirements, ease of use, minimal training required, reduced purge water, sample performance, and sampler reliability. Clearly, both passive methods resulted in reduced personnel requirements (one person could easily sample a well vs. the two typically used for low-flow sampling) and a reduced sampling time (or more wells sampled per day). The RGC sampler was the easiest to use. We found that the Snap Sampler required some training and experience before one could operate the sampler without error. This was especially true with respect to learning to assemble the sampler. Since neither passive sampling method involves purging the well, there is no purge water to dispose of with either method. However, there was a small amount of spent sample to dispose of with use of the RGC sampler. 
Generally, the Snap Samplers performed well by triggering on demand and by providing full samples. Although, there were a few instances where one of the caps did not seal properly because an o-ring did not seat properly and there was some loss of sample in those cases. Also, there were a couple of bottles that had pinhole leaks in the seam, which resulted in losses of sample during shipping and storage. As a result of this issue, the manufacturer has switched to a different polymer that has better weld properties. Because of the issues with the o-rings, we would recommend that an additional Snap Sampler bottle be added to the trigger line as insurance. In contrast, we did not observe any issues with the RGC samplers.

While there were no injuries related to using any of the three sampling technologies, the general consensus was that there are far fewer safety issues associated with using the passive samplers vs. low-flow sampling and all the paraphernalia associated with its use (including a generator, electrical cords, gasoline, etc.).

The long-term costs associated with using these methods were calculated based on the costs of this demonstration. The projected long-term costs were determined for a similar site with 50 wells where quarterly sampling is conducted over 10 years. Based on these calculations, the Snap Sampler can provide a $67 \%$ cost savings vs. using low-flow sampling. If there is only a need to analyze for dissolved species of metals, the RGC sampler could provide a cost savings of $71 \%$. We estimated that the average cost per sample was $\$ 187.70$, using low-flow sampling at this site over 10 years; the similar cost per sample for the Snap Sampler was $\$ 62.40$, and for the RGC sampler was $\$ 53.95$ (without factoring inflation into these costs).

The primary cost drivers for this technology are: the number of analytes and sample volume requirements, depth of the sampling interval, and whether the wells would require reconditioning. However, even if one had to recondition the wells every 5 years and was sampling for a large number of analyte types, our cost analyses indicated this technology can still provide substantial cost savings over low-flow purging and sampling.

We believe this demonstration showed that, when compared to low-flow purging and sampling methods, the Snap Sampler: (1) recovered comparable concentrations of several types of inorganic analytes, (2) offered fewer safety concerns, (3) took considerably less time and 
manpower to collect samples, and (4) was considerably less expensive than low-flow sampling. The primary limitations with this technology were: (1) it may not be suitable for collecting samples to be analyzed for total Fe (and possibly other reactive species), if placing the sampler in the well disturbs the well and elevates turbidity and oxygen levels in the well, (2) it took longer to learn how to collect samples than with a diffusion sampler such as the RGC sampler, and (3) there were issues with sealing a small percentage of the bottles. We will be examining the first issue in subsequent studies.

If one is only interested in determining the dissolved concentrations of these analytes, the RGC sampler is also an economic alternative for sampling for inorganic analytes. 


\section{Unit Conversion Factors}

\begin{tabular}{|l|c|l|}
\hline Multiply & By & To Obtain \\
\hline acres & $4,046.873$ & square meters \\
\hline degrees Fahrenheit & $(\mathrm{F}-32) / 1.8$ & degrees Celsius \\
\hline fathoms & 1.8288 & meters \\
\hline feet & 0.3048 & meters \\
\hline gallons (U.S. liquid) & 3.785412 E-03 & cubic meters \\
\hline horsepower (550 foot-pounds force per second) & 745.6999 & watts \\
\hline inches & 0.0254 & meters \\
\hline inch-pounds (force) & 0.1129848 & newton meters \\
\hline miles (U.S. statute) & $1,609.347$ & meters \\
\hline miles per hour & 0.44704 & meters per second \\
\hline mils & 0.0254 & millimeters \\
\hline ounces (mass) & 0.02834952 & kilograms \\
\hline ounces (U.S. fluid) & $2.957353 \mathrm{E}-05$ & cubic meters \\
\hline pints (U.S. liquid) & $4.73176 \mathrm{E}-04$ & cubic meters \\
\hline pints (U.S. liquid) & 0.473176 & liters \\
\hline
\end{tabular}




\section{Introduction}

\subsection{Background}

Low-flow purging and sampling methods currently in use (Puls and Barcelona 1996; U.S. EPA Region 1 1996; Nielsen and Nielsen 2002; ASTM 2003) are expensive because of the time involved in waiting for purge parameters to stabilize, the capital cost of the dedicated equipment (pumps or costly decontamination of the equipment between sampling events), and in many instances, the costs associated with disposing of the purge water. Low-flow sampling also causes extensive mixing within the well and well bore, and this prevents vertical profiling of the contaminant plume. One recent estimate places the monitoring costs for the U.S. Army for the next 10 years at almost $\$ 500$ million. ${ }^{2}$ Given both the issues of concern and the staggering costs associated with long-term monitoring, finding a sampling method that is less labor-intensive and less costly (but able to yield quality data), is clearly needed.

Passive sampling techniques are gaining acceptance in the scientific community for many ground water sampling applications (ITRC 2004, 2006, 2007; NJDEP 2004). Passive sampling techniques rely on the continuous natural flow through the well screens (Robin and Gillham 1987; Powell and Puls 1993; ASTM 2003). Where the use of passive sampling is appropriate, data-quality improvements and cost reductions include: better delineation of contamination with depth within the screened zone, reduced volumes of purge water waste, reduced labor during sampling, and reduced equipment costs. Parsons (2003) estimated that the potential costsavings using passive techniques for long-term monitoring at Department of Defense (DoD) facilities is on the order of $70 \%$, compared to low-flow ground water sampling.

Although the improvements and potential cost savings associated with passive sampling are significant, most passive sampling devices have limitations. For example, the Polyethylene Diffusion Bag (PDB) sampler can be used only for selected volatile organic compounds (VOCs), and while the Regenerated-Cellulose Dialysis sampler (or RGC sampler) can be used for a broader range of contaminants, there are concerns about the

\footnotetext{
2 www.denix.osd.mil/denix/DOD/Policy/Army/Aerta/tnstop.html
} 
length of time this sampler can be deployed before it starts to undergo biodegradation. Also, because diffusion samplers typically require at least several days for equilibration to occur, they yield a concentration that is a time-weighted average (as compared with samples that are collected in "real time"). In comparison, equilibrated grab-type samplers (such as the HydraSleeve and Snap Samplers) can be used to obtain whole water samples in real time for any type of analyte. These devices are deployed in the well and left to allow time for the well to recover and for the materials to equilibrate with the analytes in the well water prior to collecting a sample. However, unlike the HydraSleeve sampler, the Snap Sampler has an advantage in that the sample is collected and sealed under in-situ conditions, and can remain sealed until the sample is analyzed. There is little or no agitation of the water column as the sample is collected, and no chance of accidentally recovering any of the stagnant water above the well screen as the device is brought to the surface.

\subsection{Objectives of the demonstration}

The objectives of this demonstration/validation project were to demonstrate that the Snap Sampler passive ground water sampling device can provide (1) technically defensible analytical data for the wide spectrum of analytes that are of concern to the DoD and (2) substantial cost savings. A third objective was to facilitate technology transfer and acceptance of this sampling method. The Snap Sampler is an equilibrated grab sampler (ITRC 2006, 2007) that allows one to collect a whole water sample under in-situ conditions without agitating the well during sample collection. Once samples are collected, they can remain in the sampling bottle and do not require additional transfer to another container, thereby reducing the possibility of loss of volatiles, reaction of analytes with the air during transfer, or contamination by the air.

Our demonstration plan was to collect samples at five sites with three sampling technologies: (1) the Snap Sampler, (2) low-flow purging and sampling (U.S. EPA Region 1 1996), and (3) wherever applicable, passive diffusion samplers such as the RGC sampler, PDB sampler, or Rigid Porous Polyethylene (RPP) sampler. Analytes to be included in this demonstration include VOCs, explosives, perchlorate, metals, and natural attenuation parameters. Using these three sampling technologies will allow comparison of dissolved and colloid-borne contaminants (such as metals, and the more hydrophobic organic contaminants, including explosives). 
This particular demonstration took place at the former Pease Air Force Base (AFB) site near Portsmouth, New Hampshire. Inorganic analytes found at detectable levels at this site included one metalloid (As), and several types of metals including alkaline metals ( $\mathrm{Na}$ and $\mathrm{K}$ ), alkaline earth metals ( $\mathrm{Ca}$ and $\mathrm{Mg}$ ), and transition metals ( $\mathrm{Mn}$ and $\mathrm{Fe}$ ). Analyte concentrations in samples taken with the Snap Sampler were compared with those taken using low-flow sampling, and the RGC passive diffusion sampler. Both filtered and unfiltered samples were compared.

\subsection{Regulatory drivers}

Currently, the preferred method for sampling a ground water monitoring well is to use a low-flow purging and sampling method as first outlined by Puls and Barcelona (1996) and now promulgated by others, including the U.S. EPA Region 1 (1996), Nielsen and Nielsen (2002), and the ASTM (2003). However, because low-flow sampling draws water most heavily from the most permeable part of the formation (which may not be the zone of interest), does not allow vertical profiling of the contaminants in the well or plume, and is both time consuming and expensive, finding a sampling method that is less labor-intensive and costly (but able to yield quality data) is clearly needed.

\subsection{Stakeholder/end-user issues}

Many concerns from stakeholders, regulators, and end-users have been addressed by the Interstate Technology and Regulatory Council (ITRC) Passive Sampler team. This team published a protocol document on the use of five passive samplers that includes the Snap Sampler. This document is available free at the ITRC website (ITRC 2007). This document serves as a guide to regulators, technology users, and stakeholders on how to properly deploy and collect samples using this technology. In addition, ITRC has offered free Internet training to any interested party including stakeholders, regulators, and end-users. 


\section{Technology Description}

\subsection{Technology development and application}

While most previous research and development of passive ground water samplers has focused on diffusion-based devices, the Snap Sampler (Figure 1) is a grab-type device that was initially developed by Sanford Britt of ProHydro, Inc. to improve data quality of VOCs. Specifically, the initial objectives were: (1) to collect a sample at discrete levels that would allow profiling contamination with depth within the well, (2) to reduce inconsistencies associated with the sampling methods and personnel, and (3) to reduce losses during sample transfer. However, the applicability of this device to a broad spectrum of analytes was evident immediately because this sampler can collect a whole water sample under in-situ conditions without agitating the well during sample collection and can be used to sample any of the analytes of concern to the DoD. Typically, after these samplers are deployed, the well is then left and given time to re-equilibrate with the natural formation water flowing through the well.

The Snap Sampler consists of the sampler body that holds the sample bottle in place, a sample bottle that is open on both ends, and a trigger line with a trigger. The device is deployed so that both ends of the sample bottle are open, and the trigger releases spring-activated end caps that seal the bottle. The trigger line is attached to a well docking station during deployment ensuring that the sampler remains at the desired depth in the well. Components of the plastic Snap Sampler and its deployment are shown in Figure 1. (If preferred, stainless steel sampler bodies can also be purchased for the Snap Sampler.) This sampler is different from most others in that samples remain in the sampling bottle and do not require additional transfer to another container after they are recovered from the well. During transfer, this feature reduces the possibility of loss of volatiles or reaction of the analytes with the air. Currently, available sampling bottle options include $40-\mathrm{mL}$ glass volatile organic analyte (VOA) vials, $125-\mathrm{mL}$ high-density polyethylene (HDPE), and 350-mL HDPE bottles. The 350$\mathrm{mL}$ bottle fits into 4-in. diameter wells (and larger). The VOA vials and the 125-ml bottles fit into 2-in. diameter wells (or larger). The VOA vials can be used in common laboratory autosampler equipment. Multiple bottles can be deployed in tandem on a single trigger line, or on multiple trigger lines when different types of samples need to be collected or when larger 
sample volumes are required. Up to four Snap Samplers can be deployed in tandem on a single mechanical trigger line. For deep wells, an electronic activator or a pneumatic activator can be used to trigger the samplers. These devices allow one to deploy five or six samplers on a single line.
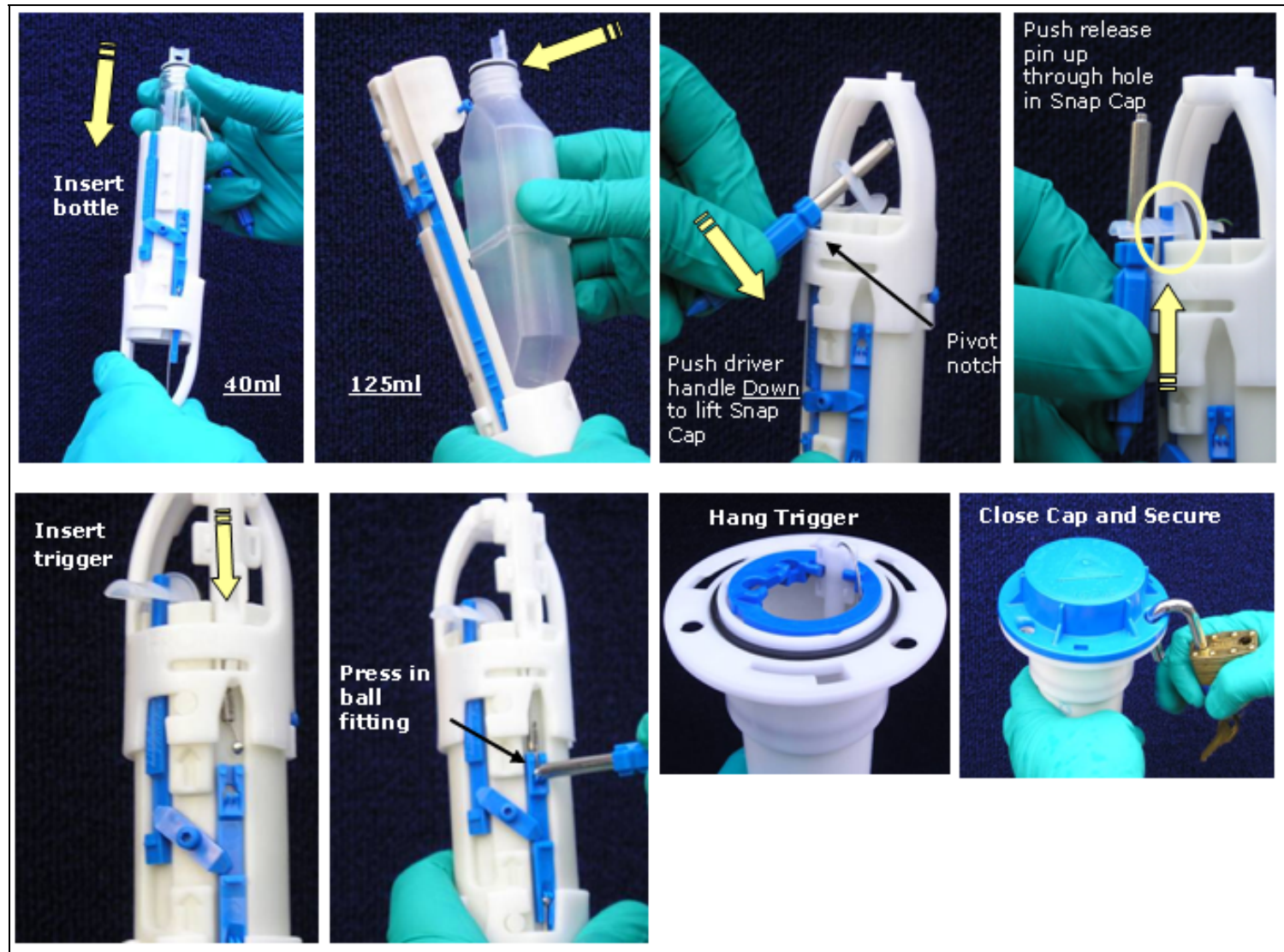

Figure 1. Snap Sampler deployment procedure.

\subsection{Previous testing of the technology}

\subsubsection{Proof of concept: Laboratory tests}

Under the sponsorship of the U.S. Army Corps of Engineers (USACE) Long-Term Monitoring (LTM) Program, Parker and Mulherin (2007) examined the ability of the Snap Sampler to recover representative concentrations of VOCs and explosives, under laboratory conditions and in a limited number of field trials. For the laboratory studies, sampling was conducted in an 8-ft high (8-in. diameter) standpipe that contained known concentrations of a suite of either VOCs or explosives. The samplers were deployed at the same depth as the sampling port on the standpipe, and analyte concentrations in the Snap Sampler samples were compared with 
the concentrations of the various analytes in the control samples collected from the standpipe's sampling spigot.

For the initial studies, the Snap Samplers were left for 24 hours to allow time for the materials in the sampler to equilibrate with the test solution. The two test solutions contained either 7 VOCs or 6 explosives, measured at ppm- and ppb-levels. For all the analytes tested, statistical analyses (paired-t tests at 95\% confidence level) revealed that there was no significant difference between the mean concentrations of the analytes in the Snap Samplers vs. the controls. The data from these studies can be found in Appendix Table F1 and Table F2.

For the previous studies, the samples were analyzed within 24 hours. However for most sampling events, samples are typically shipped to a laboratory and held for several days (or longer) prior to analyses. Given that the Snap Sampler contains a Teflon-coated spring and two Tefloncoated end caps, it is possible there could be significant sorption of the analytes by these materials if the equilibration period was not long enough (Parker and Ranney 1994, 1997, 1998, 2000; Ranney and Parker 1998a). To address this concern, several follow-up studies were conducted to determine if there were additional analyte losses when the samples reached their maximum holding times. For samples containing explosives, typically no preservative is added and the maximum holding time is 7 days. For VOC samples, the maximum holding time is 7 days if the samples are not preserved or 14 days if they are preserved. These studies are summarized below and data are summarized in Appendix Table F3 for the VOCs and Appendix Table F4 for the explosives.

The Snap Samplers were deployed in the standpipe containing the test solution and left to equilibrate for 24 hours, as described in the previous experiments. After collecting the samples, the bottles (for explosives) or vials (for VOCs) were then held for the prescribed maximum holding times. For the VOCs, vials with and without preservative were tested. We found that representative concentrations of explosives could be recovered from the (unpreserved) samples containing explosives after holding the samples for 7 days. However, when this sampler was used to sample VOCs, we found statistically significant losses of VOCs in both the preserved samples (14day holding time) and the unpreserved samples (7-day holding time). For the unpreserved samples, differences in the mean concentrations for the analytes ranged from no loss to a $61 \%$ loss. For samples that were pre- 
served but were held for the full 14-day holding time, the mean losses were not as large, with a maximum loss of $36 \%$. One possible explanation for the observed losses was that a longer equilibration time (greater than 24 hours) is needed.

Two additional holding time studies for the VOCs were then conducted. These studies were similar in design except that the equilibration period was 3 days (rather than 24 hours). For the unpreserved samples, differences were relatively small $(<5 \%)$ for all the analytes except m-xylene (mXYL). For the preserved samples, differences were also relatively small $(<5 \%)$ for all the analytes except mXYL. For mXYL, the mean loss was substantially less than that found in the previous study (with a 24-hr equilibration period) but was still substantial (e.g., the preserved samples loss was $23 \%$ vs. $36 \%$ in the previous study). Therefore, it appears that 3 days is sufficient equilibration time for VOCs, with the possible exception of mXYL.

There have not been any laboratory studies that have examined the ability of the Snap Sampler to recover inorganic analytes. So prior to any field work, this demonstration included plans to test the ability of the Snap Sampler to recover representative concentrations of several types of metals and other inorganic ions in laboratory studies. The results from these studies are given later.

\subsubsection{Previous field tests}

Parker and Mulherin (2007) conducted limited field trials of the Snap Sampler for VOCs and explosives at three locations. Specifically, the Cold Regions Research and Engineering Laboratory (CRREL) site (Hanover, $\mathrm{NH}$ ) contained trichloroethylene (TCE); the Silresim Superfund Site (Lowell, MA) contained benzene, toluene, ethylbenzene, and xylene (BTEX) compounds and several chlorinated VOCs; and the former Louisiana Army Ammunition Plant (Minden, LA) contained several explosives and daughter compounds, including trinitrotoluene (TNT) and cyclotrimethylenetrinitramine (RDX). Concentrations of the analytes in samples collected with the Snap Sampler were compared with those collected using the EPA's low-flow purging and sampling method. Statistical analyses revealed no significant differences that could be associated with the sampling method for either the VOCs or explosives. 
Other field studies include one conducted by Britt, Parker, and Cherry that is currently in review. Another was conducted at the former McClellan Air Force Base (Parsons 2005). Although the McClellan AFB study has not been published in a peer-reviewed journal, the final report is available at the manufacturer's Web site. 3

In the Parsons (2005) study, 6 different passive samplers (including the Snap Sampler), were compared with both a low-flow purging and sampling method and a well-volume purging and sampling method (i.e., the well was purged of 3-5 well volumes, and then a sample was collected using a bailer). For the Snap Sampler, concentrations of VOCs (including 1,4dioxane) and anions were compared. Unfortunately, interpreting the results from this study is difficult. This is due in part to the different methods used, both in sampling and sample handling (including different sampling times and compositing the VOC samples for the other passive sampling methods), the numerous methods that were used to analyze the data, and issues with some of statistical analyses (e.g., the data was pooled for the various analytes prior to conducting the statistical analyses). However, regression plots of the (pooled) VOC data were informative. These plots showed that the Snap Sampler VOC concentrations correlated well with those taken using low-flow sampling ( $\mathrm{r} 2=0.995)$, but were substantially higher (the slope was 1.77). While we might expect these results based on the differences in handling these samples, it is interesting that the concentrations in the samples collected using the well-volume purge method were equivalent to those in the Snap Sampler ( $\mathrm{r} 2=0.90$ with a slope of 1.04). Findings were similar for Snap Sampler concentrations of the anions and 1,4-dioxane, although the slope (1.2) was considerably closer to 1.0.

\subsection{Factors affecting cost and performance}

For this demonstration, the performance of the Snap Sampler was evaluated by comparing analyte concentrations in samples taken using low-flow sampling, the Snap Sampler, and the RGC sampler. Subjective measures such as user-reported ease of use and time to proficiency were also used to determine the over-all performance of the Snap Sampler.

With respect to the performance of the sampler (i.e., its ability to recover a representative sample), various factors can impact the composition of a

\footnotetext{
3 http://www.snapsampler.com/images/McClellan_Report_Highlighted.pdf
} 
ground water sample and therefore the sampler's performance. These factors include the hydrogeology of the site, well construction, well development, and the experience of the field personnel. Different sampling methods may yield different results depending upon these factors. Performance of the various sampling methods may also vary depending upon analyte type, and weather may impact the performance of sampling devices (especially on hot, sunny days). Although low-flow purging and sampling is currently the industry standard, there is currently no sampling method that yields the "correct" result. Therefore, when interpreting the data from this demonstration or similar studies, it is important to understand conceptual differences of each sampling technology and the site hydrogeology.

As for cost, factors such as the initial equipment costs (including any necessary ancillary equipment such as generators, air compressors, etc.), sampling time and personnel requirements, decontamination, and waste disposal clearly affect total cost. Major operating costs consist of the field crew's salary (time) and occasionally, travel costs. For the Snap Sampler, the device's ease of use, the familiarity of the sampling person with the device, and the total sampling time will impact cost.

\subsection{Advantages and limitations of the technology}

Advantages associated with using the Snap Sampler include that it collects a whole water sample under in-situ conditions, does not agitate the well during sample collection, can be used to collect a sample at a discrete depth in the well, and can be used to sample a broad spectrum of analyte types. In addition, samples do not require additional transfer to another container after collection, there is no purge water generated that requires disposal, and there are no power requirements for this sampler. Because samples remain in the original bottle they were collected in, presumably there is a reduced chance for losses of volatiles or changes in concentrations of dissolved gases or analytes subject to oxidation/precipitation reactions (that can occur during transfer). Data uncertainty due to variability in sampling technique (associated with different personnel), hot and/or sunny weather, and exposure to the atmosphere (and any airborne contaminants) also are presumably reduced. 
While the HydraSleeve 4 is similar in many respects (i.e., it can be used to collect a whole water sample, it can be used to sample for any type of analyte), the samples are not necessarily collected at a discrete depth in the well but rather over an interval that is $\sim 1.5$ times the length of the sampler. Also, although the reed valve on the HydraSleeve closes once the sampler is full, the Snap Sampler bottle is sealed tightly at the sampling depth, and there is no need to transfer the sample at the well head with the Snap Sampler as there is with a HydraSleeve sampler.

Because the Snap Sampler is deployed prior to sampling (to allow the well to recover from any disturbance associated with placing it in the well), and because this device collects a whole water sample instantaneously, presumably samples collected with this sampler should not have elevated turbidity (i.e., soil-derived, non-transportable particles) and thus would reflect the true, naturally mobile, colloid-borne contaminants flowing through the well. In contrast, even low-flow sampling has been shown to artificially elevate particle levels in some wells (Bailey et al. 2005), and most diffusion samplers cannot collect colloidal particles because of the small pore sizes of the membranes.

Previous studies by CRREL (Parker and Ranney 1998) have demonstrated that when low-flow purging and sampling is used, sorption by longer lengths of polymer tubing can substantially reduce concentrations of some VOCs. In contrast, there were no losses of these analytes in samples where the Snap Sampler was equilibrated prior to collecting the sample (Parker and Mulherin 2007). However, one of the primary distinctions between low-flow purging and sampling, and using the Snap Sampler, is that the Snap Sampler can be used to collect a sample at a discrete depth in the well, whereas the low-flowing sampling collects a sample that is a flowweighted average over the entire screen.

One final advantage associated with using the Snap Sampler is that it can be used to sample wells with slow recharge. This is also true for other passive (no-purge) samplers whether they are a diffusion sampler (e.g., the PDB sampler), a sorptive sampler (e.g., the Gore Module) or another grabtype device (e.g., the HydraSleeve). In contrast, any purging method that removes all the water from the well will yield suspect samples for volatiles and analytes subject to oxidation/precipitation reactions.

\footnotetext{
4 The HydraSleeve is a disposable, passive, no-purge, ground-water sampler that was developed and is manufactured by Geolnsight of Las Cruces, NM.
} 
The principle limitations with this technology are well diameter and sample volume. The Snap Sampler does not fit into wells with diameters smaller than $2 \mathrm{in}$. While this sampler can be used to sample for any type of analyte, including those parameters typically measured during purging when collecting low-flow samples, analyses of multiple analyte types and QA/QC samples increase sample volume requirements. Sample volume can be increased by using multiple samplers, either on multiple trigger lines or in tandem on the same trigger line. Up to four samplers can be deployed in tandem on the same trigger line (using a conventional trigger line), and five to six samplers can be deployed on lines using an electronic trigger or a pneumatic trigger. Also, in many cases, sample volume requirements can be reduced by working closely with the analytical laboratory. With time, sample volume is expected to become less of an issue for these samplers, as analytical methods improve.

While the volume of samples collected using low-flow purging and sampling typically is not limited (as long as there is adequate flow in the well), several other passive samplers also have similar volume limitations (especially the Rigid Porous Polyethylene [RPP] sampler). Again, multiple samplers can be deployed to circumvent this problem, and some samplers (e.g., the RGC sampler and the HydraSleeve sampler) can be made in longer lengths, to accommodate larger sample volume requirements. 


\section{Demonstration Design}

\subsection{Performance objectives}

The performance objectives are outlined in Table 1 and include qualitative as well as quantitative measures of performance. Specifically, ease of use, reduced sampling time, ability to sample a range of analyte types and concentrations, agreement between analyte concentrations, and a lack of bias associated with the passive samplers were noted.

Table 1. Performance objectives

\begin{tabular}{|c|c|c|c|}
\hline $\begin{array}{l}\text { Type of } \\
\text { Performance } \\
\text { Objective }\end{array}$ & Primary Performance Criteria & $\begin{array}{l}\text { Expected Performance } \\
\text { (Metric) }\end{array}$ & $\begin{array}{l}\text { Actual Performance } \\
\text { Objective Met? }\end{array}$ \\
\hline \multirow{4}{*}{ Qualitative } & 1. Ease of use & Little training required & $\begin{array}{l}\text { Required training \& } \\
\text { some repetition for } \\
\text { smooth operation }\end{array}$ \\
\hline & 2.Ease of use & $\begin{array}{l}\text { Few problems requiring } \\
\text { second attempt to } \\
\text { sample well }\end{array}$ & Yes \\
\hline & 3. Faster sampling & $\begin{array}{l}\text { Less time needed to } \\
\text { sample a well }\end{array}$ & Yes \\
\hline & 4. Ease of Use & Operator acceptance & Yes \\
\hline \multirow{4}{*}{ Quantitative } & $\begin{array}{l}\text { 1. Agreement between sampling } \\
\text { methods for analytes of interest }\end{array}$ & $\begin{array}{l}\text { Lack of statistically } \\
\text { significant differences }\end{array}$ & $\begin{array}{l}\text { Yes, with one } \\
\text { exception }\end{array}$ \\
\hline & 2. Lack of bias with sampling method & $\begin{array}{l}\text { Statistically significant } \\
\text { correlations }\end{array}$ & Yes \\
\hline & $\begin{array}{l}\text { 3. Ability to sample a range of } \\
\text { contaminants at site }\end{array}$ & $\begin{array}{l}\text { Adequate sample } \\
\text { volume for all analyses }\end{array}$ & Yes \\
\hline & $\begin{array}{l}\text { 4. Ability to sample a range of analyte } \\
\text { concentrations }\end{array}$ & $\begin{array}{l}\text { Equivalent sensitivity for } \\
\text { methods }\end{array}$ & Yes \\
\hline
\end{tabular}

\subsection{Selecting test site(s)}

The initial three requirements for a test site were that it (1) contain a variety of inorganic analytes, (2) be within an easy driving distance from our laboratory (since this would be our first demonstration), and (3) have larger diameter ( $\geq 4$ in.) wells. Richard Willey (U.S. EPA Region 1) and Ms. Parker (CRREL) examined EPA databases for New England sites contaminated with metals and metalloids. Subsequent screening included five additional criteria: (1) the wells were monitoring wells (vs. injection and recovery wells used in remediation), (2) the wells met American Society for 
Testing and Materials (ASTM) design criteria, (3) the wells had concentrations at least three times the detection limit for one or more analytes, (4) there be at least five wells that met these criteria, and (5) there be no free product in the wells. After some searching, we found that the former Pease AFB met all the test site qualifications.

\subsection{Test site description}

The former Pease AFB occupies approximately 4,365 acres and is located on a peninsula in southeastern New Hampshire (Figure 2). The former AFB is located in the town of Newington and the City of Portsmouth. The peninsula is bounded on the west and southwest by Great Bay, on the northwest by Little Bay, and on the north and northeast by the Piscataqua River.

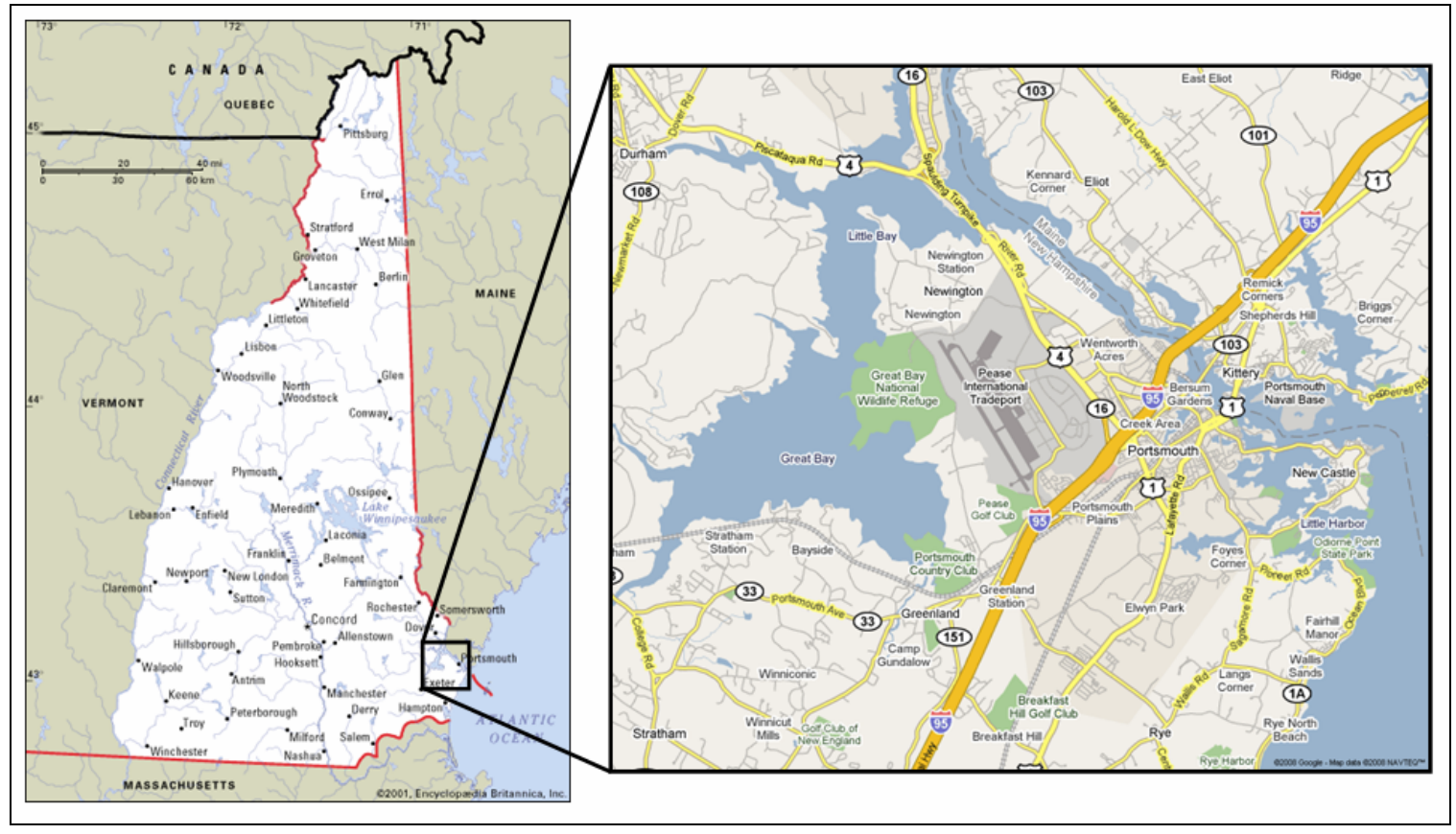

Figure 2. Map of the state of New Hampshire showing the location of the former Pease AFB.

At the onset of World War II, the U.S. Navy used this location as an airport. The Air Force assumed control of the site in 1951, and construction of the base was completed in 1956. Over time, various quantities of fuels, oils, lubricants, solvents, and protective coatings were used, and as a result, contaminants from these substances were released into the environment. Specifically, fuels, organic solvents, polycyclic aromatic hydrocarbons (PAHs), and metals have been found in soils on the base. The ground water has been found to be contaminated with volatile organic compounds 
(VOCs) including trichloroethylene (TCE) and tetrachloroethylene (PCE). PAHs, pesticides, and heavy metals have been found in the sediments from various discharge ditches.

In 1976, the DoD conducted an assessment of the environmental contamination resulting from the past operation and disposal practices. In 1984, a Phase I Problem Identification Search was completed, and the Air Force was designated as the lead agency authority to conduct Comprehensive Environment Response, Compensation and Liability Act (CERCLA) 5 cleanup activities.

In December 1988, Pease AFB was selected for closure as a result of the Secretary of Defense's Base Realignment and Closure (BRAC) Commission. The base was closed as an active installation in March 1991, and the Air Force has transferred most of the property to the Pease Development Authority. The airfield is now a fully operational commercial airport. Other property is currently being used or developed for light commercial and industrial facilities. A portion of the base was transferred to the U.S. Department of Interior for use as a national wildlife refuge, and the Air Force retained 229 acres of the former base for use by the New Hampshire Air National Guard.

The former AFB was listed on the EPA's National Priorities List (NPL) in 1990. In 1991, the Air Force, EPA, and New Hampshire Department of Environmental Services (NHDES) signed a Federal Facility Agreement (FFA), establishing the protocols for conducting the environmental study and cleanup of the former AFB. This agreement established eight Installation Restoration Plan (IRP) zones, for which separate remedial investigation and feasibility study (RI/FS) reports were prepared (Figure 3).

\footnotetext{
${ }^{5}$ CERCLA is commonly known as the Superfund and was enacted in 1980 by the U.S. Congress.
} 


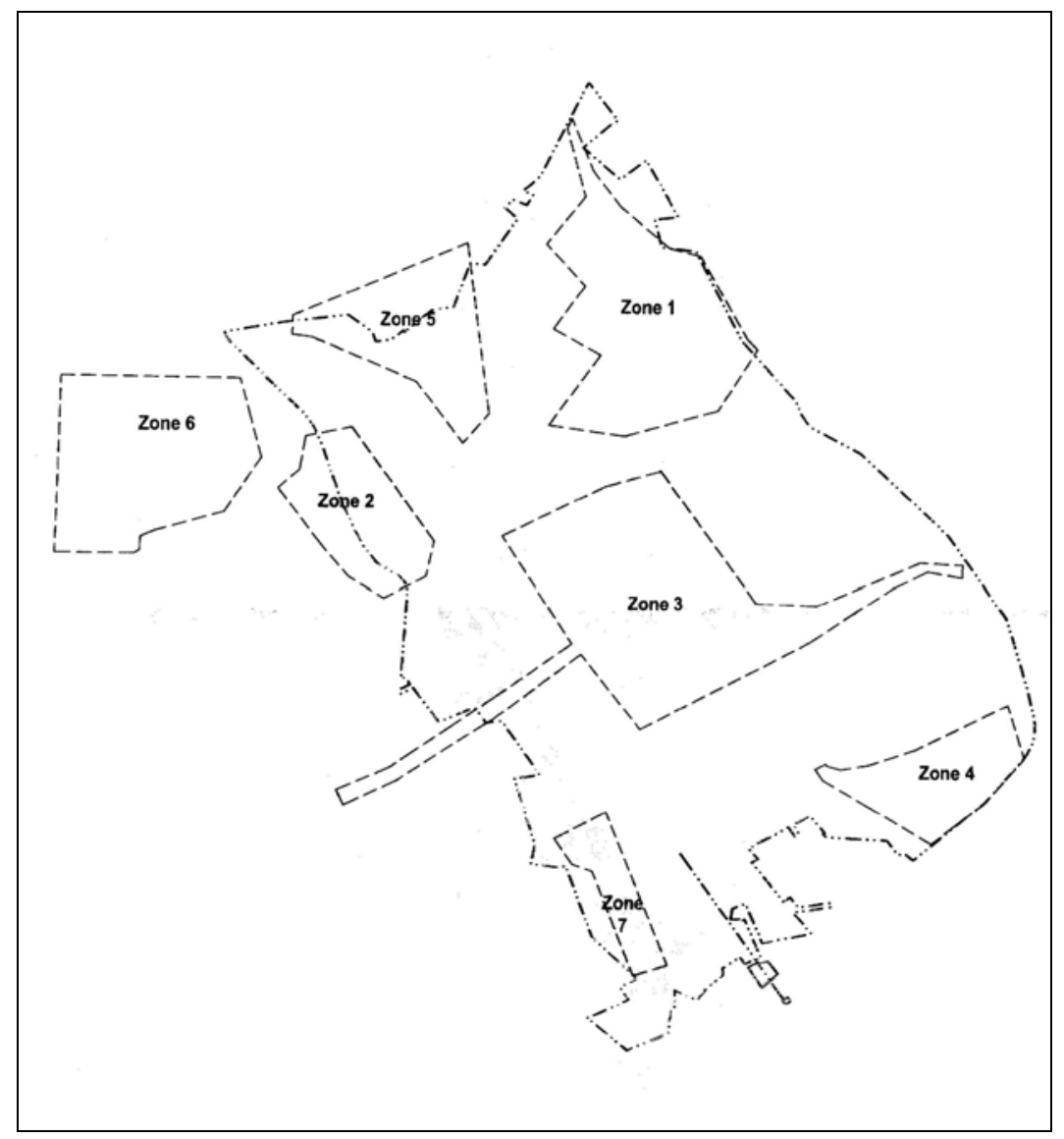

Figure 3. Map outlining IRP zones at the former Pease AFB (from MWH Americas, Inc. 2004).

The eight monitoring wells selected for this demonstration are located in Zones 1 and 3 . Zone 1 is located in the eastern part of the former base; Zone 3 encompasses the area where most of the industrial shops and aircraft maintenance were located. Descriptions of the activity that occurred in these zones and the geology of these zones that follows was taken from the five-year review published in 2004 (MWH Americas, Inc. 2004).

\subsubsection{Zone 1}

Zone 1 is located in the northeastern portion of the former base and contains several IRP sites. These include several landfills, a paint can disposal area, railroad tracks, and a bulk fuel storage area (BFSA), Site 13, where two of the monitoring wells used in this study are located. The BFSA was the main storage area for fuels at the base; it has been in operation from 1953 to the present. The BFSA encompasses approximately 16 acres and is located at the northeastern section of this zone. Currently, the BFSA contains two aboveground and two underground storage tanks, which are sur- 
rounded by earthen berms. Major spills occurred at this site in 1963, 1975, and 1980 .

The overburden deposits across Zone 1 include younger sediments, such as marsh deposits, and older deposits, such as glacial-marine deposits. The unconsolidated stratigraphic units identified at Pease AFB are fill, Upper Sand (US), Marine Clay and Silt (MCS), Lower Sand (LS), and glacial till. One or more of these units may be absent at any particular location.

Across Zone 1, the US unit ranges in thickness from approximately o.6 to $10 \mathrm{ft}$. The LS unit is not present in Zone 1 due to limited presence of the MCS unit. Glacial till is discontinuous across Zone 1.

The topography of the bedrock surface across Zone 1 is accentuated by several prominent highs and one prominent valley, with up to $75 \mathrm{ft}$. of relief zone-wide. A relatively large, broad bedrock high extends from the BFSA north toward Landfill 5. The bedrock consists of rocks of the Eliot Formation, which is generally composed of interbedded phyllite, metagraywacke, and quartzite.

\subsubsection{Zone 3}

Zone 3 is located in the central portion of the former AFB and occupies approximately 440 acres. The zone contains numerous buildings with adjacent paved parking areas, a network of roads, and the flightline area. The aircraft parking apron is a major feature of the base and comprises nearly one-third of the zone. This zone contains seven IRP sites that are buildings and three underground storage tank (UST) sites. The other six wells selected for this demonstration are located at building 113 (site 32). Newfields Ditch, a storm-water drainage swale passes between Buildings 113 (Site 32) and 119 (Site 36). The ditch drains toward the northeast and eventually discharges into Hodgsons Brook.

Building 113 was used between 1955 and 1991 primarily for aircraft munitions systems and avionics maintenance (including some vapor degreasing operations). A 1,200-gallon concrete UST was located near the northeastern corner of the building and received waste TCE from degreasing operations conducted inside the building from 1956 to 1968. Sometime after 1977, use of the UST was discontinued and it was filled with sand. In 1988, the UST was excavated and removed, and an underground overflow discharge pipe associated with the UST was discovered. The soil and ground- 
water contamination at this site is believed to be primarily a result of the historic use of the TCE tank and associated overflow pipe.

The shallow subsurface beneath Zone 3 generally consists of the same lithologic units found in Zone 1. The underlying bedrock is either the Kittery or Eliot formation, depending on the specific site location within Zone 3. The thickness of the overlaying, unconsolidated lithologic units varies across the site as the elevation of the bedrock interface is highly variable. Figure 4 shows a cross-section of the stratigraphy of Zone 3 on a northsouth axis, and Figure 5 shows the stratigraphy on an east-west axis. These cross-sections also are characteristic of the stratigraphy of the entire site.

Regional groundwater flow is to the south-southeast within this zone under static conditions (i.e., when the Haven well is not being used). Localized flow vectors exist at each of the sites, depending upon the season. Groundwater contaminant plumes extending beyond the identified source areas have been delineated at Sites 32 and 36 . The identified contaminant plumes are primarily halogenated hydrocarbons with the most extensive groundwater contaminant plume originating from Site 32.

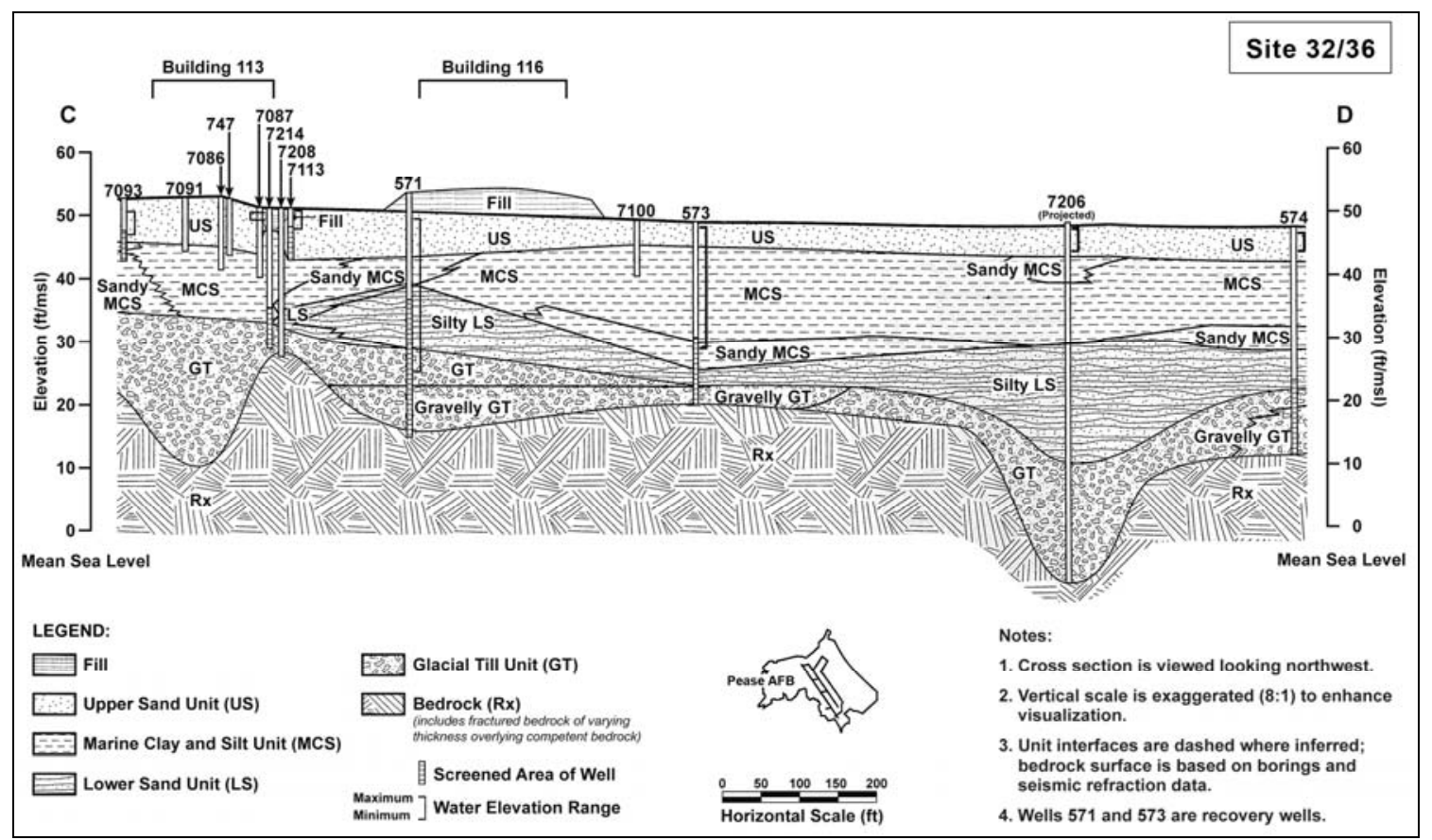

Figure 4. North-south cross section of Zone 3 (Roy F. Weston, Inc. 1992). 


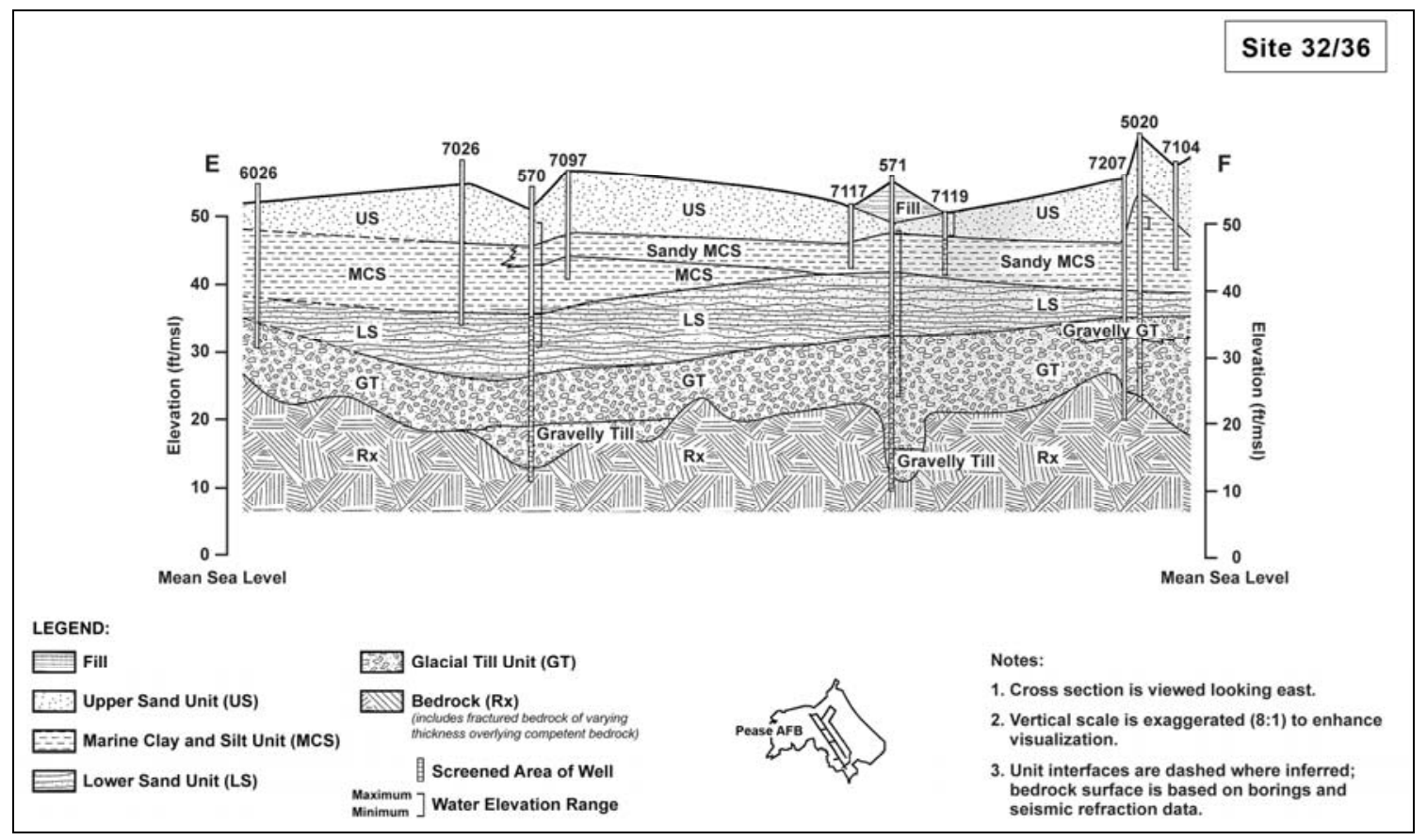

Figure 5. East-west cross section of Zone 3 (Roy F. Weston, Inc. 1992).

\subsection{Pre-demonstration testing and analysis}

Prior to conducting a field trial for inorganic analytes, it was important to demonstrate that the Snap Sampler could also be used to collect inorganic analytes. These studies were conducted to address this question.

\subsubsection{First laboratory study}

For this study, the procedure was similar to that described previously (Section 2.2.1). Five trigger lines of Snap Samplers, with each line containing three Snap Samplers (with 125-mL polypropylene [PP] bottles), were deployed in a standpipe. The test solution was prepared by adding Atomic Adsorption reference solutions with known volumes of $\mathrm{As}, \mathrm{Cd}, \mathrm{Cr}, \mathrm{Ni}$, and $\mathrm{Zn}$ to a 1000-mL glass beaker containing deionized (DI) water. A known weight of lead nitrate was then added to the test solution and the solution was stirred for approximately 2 hours. The concentrated test solution was added to the standpipe (already containing DI water), and the diluted test solution was then circulated for $2^{1 / 2}$ hours to mix it. Concentrations of As, $\mathrm{Cd}, \mathrm{Cr}$, and $\mathrm{Pb}$ were $\sim 200 \mathrm{ppb}$ in the test solution, and concentrations of $\mathrm{Ni}$ and $\mathrm{Zn}$ were $\sim 400 \mathrm{ppb}$. One trigger line (with three bottles) was recovered after 24-hour, 48-hour, and 72-hour equilibrations, and additional samples were collected after 50- and 102-day equilibrations. Samples were acidified and sent to the Engineering Research and Development Center 
Environmental Laboratory at Omaha, Nebraska (ERDC-EL-EP) for analyses by Inductively-Coupled Plasma (ICP), using EPA SW 846 method 6010B (U.S. EPA 1996).

Typically, As and $\mathrm{Cr}$ exist as anions in water while $\mathrm{Cd}, \mathrm{Pb}, \mathrm{Ni}$, and $\mathrm{Zn}$ are found as cations. For the anions, we recovered $100 \%$ of the As and $98 \%$ of the Cr after 24 hours, and 100\% of both analytes after 72 hours (Table 2). Recovery of the Cd cation was also $100 \%$ after 24 hours. In contrast, only 78 to $95 \%$ of the $\mathrm{Zn}, \mathrm{Ni}$, and $\mathrm{Pb}$ cations were recovered after the 24-hour equilibration time. After 72 hours, recovery of these analytes was essentially the same. The results for the $\mathrm{Zn}, \mathrm{Ni}$, and $\mathrm{Pb}$ were not surprising, given that previous studies (Masse, Maessen, and DeGeoeij 1981; Parker, Hewitt, and Jenkins 1990; Hewitt 1992; Ranney and Parker 1998b) have shown that anions are typically not sorbed by polymers such as polyethylene (PE) and polytetrafluoroethylene (PTFE), while cations are.

Table 2. Percent recovery of the analytes with time.

\begin{tabular}{|c|c|c|c|c|c|}
\hline \multirow{2}{*}{ Analyte } & \multicolumn{5}{|c|}{ Equilibration time } \\
\hline & 24-hr & 48-hr & 72-hr & 50-day & 102-day \\
\hline Arsenic & 100.0 & 99.6 & 100.1 & 100.9 & 99.9 \\
\hline Cadmium & 100.7 & 98.0 & 100.5 & 100.7 & 100.6 \\
\hline Chromium & 98.5 & 98.4 & 99.5 & 100.2 & 113.0 \\
\hline Lead & 95.1 & 94.3 & 94.4 & 89.5 & 97.3 \\
\hline Nickel & 94.5 & 91.7 & 91.9 & 93.4 & 103.9 \\
\hline Zinc & 78.3 & 80.9 & 79.6 & 69.2 & 91.2 \\
\hline
\end{tabular}

These results suggested to us that a longer equilibration time may be needed for some of the cations. To address this possibility, one of the two remaining samplers was removed after 50 days. However, even after $5 \mathrm{O}^{-}$ day equilibration, there was no improvement in the recovery of these cations (Table 2).

Since 50 days should have been more than adequate time for equilibration to occur, we examined the actual concentrations of the analytes (vs. the percent recovery). If leaching had occurred, that might explain the lack of equilibration. Table 3 shows the concentrations of the various analytes with time. Concentrations of $\mathrm{Pb}, \mathrm{Ni}$, and $\mathrm{Zn}$ were considerably higher (1.2x $-2.3 \mathrm{x}$ ) after 50 days than they were initially. This suggested that perhaps the metal spigot leached these analytes into the test solution as the control samples were collected. To address this possibility, we decided to collect a 
control sample from inside the standpipe (bottle control) and compare it with control samples taken from the spigot (spigot control).

Table 3. Mean concentrations $(\mu \mathrm{g} / \mathrm{L})$ of analytes with time.

\begin{tabular}{|l|l|l|l|l|l|l|l|l|l|l|}
\hline \multirow{2}{*}{ Analyte } & \multicolumn{2}{c}{ 24-hr } & \multicolumn{2}{c|}{ 48-hr } & \multicolumn{2}{c|}{ 72-hr } & \multicolumn{2}{c|}{ 50-day } & \multicolumn{2}{c|}{ 102-day } \\
\cline { 2 - 12 } & Control & Sample & Control & Sample & Control & Sample & Control & Sample & Control & Sample \\
\hline As & 195 & 195 & 195 & 194 & 194 & 194 & 188 & 190 & 187 & 186 \\
\hline $\mathrm{Cd}$ & 209 & 210 & 210 & 206 & 207 & 208 & 204 & 205 & 204 & 205 \\
\hline $\mathrm{Cr}$ & 196 & 193 & 196 & 193 & 194 & 193 & 192 & 192 & 198 & 224 \\
\hline $\mathrm{Pb}$ & 197 & 188 & 198 & 187 & 199 & 188 & 231 & 207 & 231 & 225 \\
\hline $\mathrm{Ni}$ & 373 & 353 & 387 & 355 & 398 & 365 & 478 & 447 & 478 & 496 \\
\hline $\mathrm{Zn}$ & 438 & 343 & 428 & 346 & 441 & 351 & 1031 & 714 & 1225 & 1117 \\
\hline
\end{tabular}

The last set of samples was collected after 102 days equilibration. To collect the bottle controls, a sample bottle was placed on a stainless steel line (with stainless steel weights), lowered quickly into the standpipe to the depth of the spigot, and allowed to fill. The following sampling order was used. First a bottle control was taken, then a spigot control, then the Snap Sampler was activated closing the sample bottles, then a second bottle control sample was collected, and finally a second spigot control was collected. The results from this trial are given in order in Table 4.

Table 4. Analyte concentrations $(\mu \mathrm{g} / \mathrm{L})$ in samples collected on day 102.

\begin{tabular}{|l|c|c|c|c|c|c|}
\hline Sample & As & Cd & Cr & Pb & Ni & Zn \\
\hline Bottle control 1 & 154 & 170 & 165 & 187 & 399 & 941 \\
\hline Spigot control 1 & 186 & 204 & 198 & 235 & 479 & 1260 \\
\hline Snap sample & 186 & 205 & 224 & 225 & 496 & 1120 \\
\hline Bottle control 2 & 187 & 203 & 198 & 223 & 478 & 1140 \\
\hline Spigot control 2 & 187 & 203 & 198 & 227 & 476 & 1190 \\
\hline Mean bottle control & 171 & 187 & 182 & 205 & 439 & 1040 \\
\hline Snap sample & 186 & 205 & 224 & 225 & 496 & 1120 \\
\hline Mean spigot control & 187 & 204 & 198 & 231 & 478 & 1220 \\
\hline
\end{tabular}

Although this data is somewhat confusing (probably because the standpipe was mixed with each sampling event), it is clear that the concentration of $\mathrm{Zn}$ was higher in both spigot controls than it was in either the bottle control or Snap Sampler sample. These results support our hypothesis that there was leaching of these analytes (especially $\mathrm{Zn}$ ) from the sampling spigot. 
For all the data, the precision of the data (i.e., agreement between the replicate samples) was excellent, with percent relative standard deviations (\%RSDs) that were less than 7.5\%. However, it is interesting that for As, $\mathrm{Cd}$, and $\mathrm{Cr}$, the \%RSDs were always less than $1.5 \%$. In contrast, the \%RSD for the leached analytes ( $\mathrm{Pb}, \mathrm{Ni}$, and $\mathrm{Zn}$ ) were generally greater for the control samples (where the \%RSD ranged from 1.1 to $7.1 \%$ ) than for the Snap Sampler samples (where the \%RSD ranged from 0.3\% to 1.8\%). These findings also support the hypothesis that there was leaching from the sampling valve into the control samples.

To explore this further, we emptied the standpipe and removed the metal spigot from it. When we examined the inner surface of the spigot, we found it showed signs of significant corrosion. Thus, based on these findings and similar earlier findings from studies conducted with stainless steel well casings (Hewitt 1989; Parker, Hewitt, and Jenkins 1990; Hewitt 1992; Hewitt 1994), we concluded that the spigot served as a reservoir for leached metal constituents of $\mathrm{Pb}, \mathrm{Ni}$, and $\mathrm{Zn}$, and that this sampler was able to recover representative concentrations of $\mathrm{As}, \mathrm{Cd}$, and $\mathrm{Cr}$.

\subsubsection{Second laboratory study}

For the second laboratory study, the metal spigot on the standpipe was replaced with an HDPE) spigot. The test solution was prepared by adding calcium nitrate, manganese sulfate (monohydrate), sodium chloride, potassium bromide, and magnesium perchlorate to a 5-gal glass carboy containing DI water. The carboys were filled so that there was minimal headspace and then covered with two layers of tightly fitting aluminum foil. To dissolve the analytes, the solutions were stirred for approximately one hour using a magnetic stirrer (with a Teflon-coated stir bar). After stirring the test solution, the carboy was added to the standpipe that already contained $\sim 4$ gal of DI water. The diluted test solution was then mixed by emptying the standpipe and refilling it. Concentrations of the cations in the test solution ranged from $\sim 8 \mathrm{mg} / \mathrm{L}$ (for $\mathrm{Mg}$ ) to $\sim 42 \mathrm{mg} / \mathrm{L}$ (for $\mathrm{K}$ ). Concentrations of the anions in the test solution ranged from $\sim 13 \mathrm{mg} / \mathrm{L}$ (for nitrate) to $\sim 8 \mathrm{o} \mathrm{mg} / \mathrm{L}$ (for bromide).

The experimental protocol used was similar to that used in the first laboratory study, except that only three Snap Sampler trigger lines were deployed in the standpipe and each line contained only two 125-mL PE Snap Sampler bottles. One trigger line (with two bottles) was recovered after 24hour, 48-hour, and 72-hour equilibrations. Samples were acidified and 
sent to ERDC-EL-MS for analyses by Ion Chromatography, using EPA methods 300.0 (Hautman et al. 1999) and 314.0 for perchlorate (Pfaff 1993).

Tables 5 and 6 summarize our findings by showing the mean percent recovery of the cations and anions by the Snap Sampler, as compared with the control samples. For all the analytes, recovery was greater than $96 \%$ after 24 hours, and greater than 99\% after 48 hours. The data for the anions and cations are summarized in Appendix Table E1 and Appendix Table E2 (respectively). These tables include the mean concentrations and the $\%$ RSD of the analytes for each sampling method, time and analyte.

Table 5. Mean percent recovery of the cations with time.

\begin{tabular}{|l|c|l|c|c|c|}
\multirow{2}{*}{ Sample } & \multicolumn{5}{|c|}{ Mean Recovery (\%) } \\
\cline { 2 - 6 } & Calcium & Potassium & Magnesium & Manganese & Sodium \\
\hline 24-Hr & 98.7 & 100.4 & 97.4 & 98.3 & 99.2 \\
\hline 48-Hr & 100.3 & 102.0 & 99.8 & 99.4 & 100.5 \\
\hline $72-H r$ & 99.0 & 98.5 & 99.9 & 100.0 & 100.0 \\
\hline
\end{tabular}

Table 6. Mean percent recovery of the anions with time.

\begin{tabular}{|l|c|c|c|l|l|}
\hline \multirow{2}{*}{ Sample } & \multicolumn{5}{|c|}{ Mean Recovery (\%) } \\
\cline { 2 - 6 } & Bromide & Chloride & Nitrate & Perchlorate & Sulfate \\
\hline $\mathbf{2 4 - H r}$ & 99.1 & 96.2 & 100.0 & 100.8 & 101.6 \\
\hline $\mathbf{4 8 - H r}$ & 100.6 & 107.0 & 100.8 & 106.1 & 102.4 \\
\hline $\mathbf{7 2}-\mathrm{Hr}$ & 98.8 & 100.8 & 99.6 & 110.9 & 100.8 \\
\hline
\end{tabular}

\subsubsection{Laboratory study conclusions}

Currently the ITRC Passive Sampling team recommends that most passive samplers be left in a well to equilibrate for at least two weeks (ITRC 2006, 2007). This allows the well time to recover from the disturbance caused by placing the sampler in the well and gives time for the formation to reestablish the normal flow pattern in the well. The findings from these studies demonstrate that this is more than enough time for the materials in the Snap Sampler to equilibrate with both anions and cations (including several types of metals) in the well water. 


\subsection{Testing and evaluation plan}

\subsubsection{Demonstration installation and start-up}

The eight ground water monitoring wells used in this study had an inner diameter of $10 \mathrm{~cm}$ (4 in.). These wells are characterized in Table 7 and their location is shown in Figure 6. Most of the wells are located near building 113 (Site 32, Zone 3), which is near an underground storage tank spill of TCE; two wells were located in a BFSA (Site 13, Zone 1). The criteria used to select these wells included well diameter, screen length, sampling depth, and detectable concentrations of the analytes of interest. The tops of the well screens varied in depth from 1.5 to $13.7 \mathrm{~m}$ ( 4 to $45 \mathrm{ft}$ ) below ground surface (bgs), and screen lengths varied from 1.5 to $4.6 \mathrm{~m}$ ( 5 to $15 \mathrm{ft}$ ). All of the screens were located below the water table.

Both before and during this demonstration, we checked with the site manager to be certain that there would not be any discontinuities in the operation of the treatment facility. This was because such discontinuities would affect ground water flow within the formation and the wells.

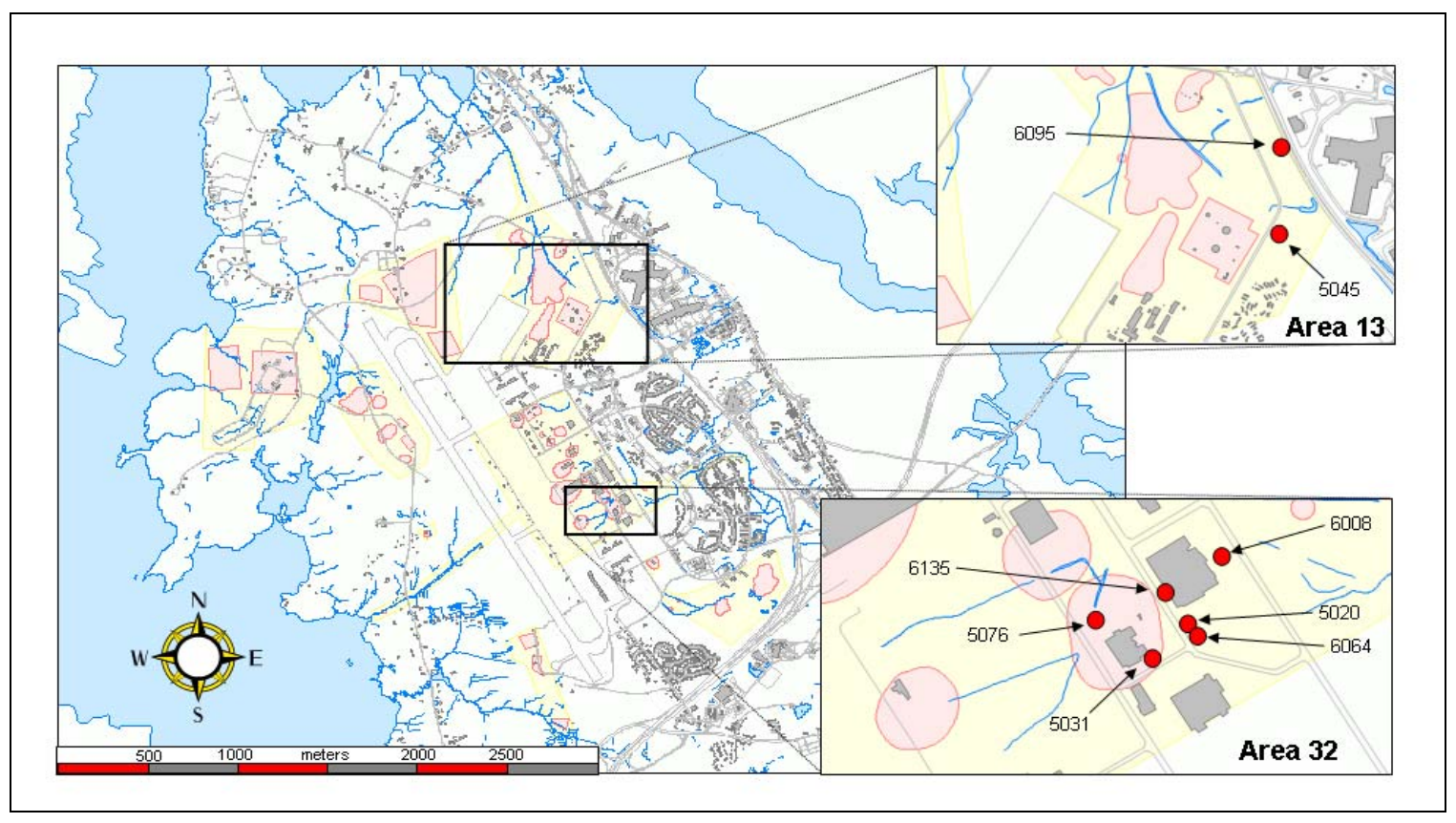

Figure 6. Map of the former base showing the locations of the monitoring wells used in this study. 
Table 7. Information on the wells used at the former Pease AFB.

\begin{tabular}{|c|c|c|c|c|c|c|c|c|}
\hline Well \# & $\begin{array}{l}\text { Well } \\
\text { Diameter } \\
\text { (inches) }\end{array}$ & $\begin{array}{l}\text { Toxics } \\
\text { above } \\
\text { MCLs }\end{array}$ & $\begin{array}{l}\text { VOCs } \\
\text { above } \\
\text { MCLs? }\end{array}$ & $\begin{array}{l}\text { Top of } \\
\text { screen } \\
\text { (ft bgs) }\end{array}$ & $\begin{array}{l}\text { Bottom of } \\
\text { screen } \\
\text { (ft bgs) }\end{array}$ & $\begin{array}{l}\text { Screen } \\
\text { length } \\
\text { (ft) }\end{array}$ & $\begin{array}{l}\text { Approx. } \\
\text { depth } \\
\text { to water } \\
\text { (ft bgs) }\end{array}$ & $\begin{array}{l}\text { Screen } \\
\text { length } \\
\text { in water } \\
\text { table } \\
\text { (ft) }\end{array}$ \\
\hline \multicolumn{9}{|c|}{ Bulk Fuel Storage Area (BFSA - Site 13) } \\
\hline $3-5045$ & 4 & As & yes & 51 & 13 & 8 & 3 & all \\
\hline $13-6095 *$ & 4 & As & no & 11 & 21 & 10 & 6 & all \\
\hline \multicolumn{9}{|c|}{ Building 113 (Site 32) } \\
\hline $32-5020$ & 4 & As & no & 14.7 & 25.35 & 10.65 & 5 & all \\
\hline $32-5031$ & 4 & As & yes & 13 & 18 & 5 & 4 & all \\
\hline $32-5076$ & 4 & As & no & 35 & 45 & 10 & 5 & all \\
\hline $32-6008 *$ & 4 & As & yes & 38 & 52 & 14 & 3 & all \\
\hline $32-6064 *$ & 4 & As & no & 34.5 & 44.5 & 10 & 5 & all \\
\hline $32-6135 *$ & 4 & As & yes & 45 & 60 & 15 & 7 & all \\
\hline
\end{tabular}

* bedrock well

\subsubsection{Well development}

Preliminary assessment of the wells revealed that most had large amounts of silt in them. Since it was important that the wells function properly, we redeveloped all of them prior to conducting any further field work. The wells were redeveloped using a surge-and-purge technique. However, we were not able to obtain clear water in three of the eight wells. Specifically, substantial turbidity remained in the pumped water following redevelopment in wells 32-5020 and 32-6135, and there was slight turbidity in water from well 13-6095. Two of these wells (32-6135 and 13-6095) were bedrock wells. Two of the wells (13-6095 and 32-5020) were relatively shallow wells. Well 32-6135 had the longest screen (15 ft).

\subsubsection{Flow meter testing}

Once the wells were redeveloped, the hydraulics in each well were determined by using a heat pulse flow meter. 6 These tests were conducted under both static and low-flow pumping conditions.

The heat pulse flow meter works by generating a "heat pulse" which is directly transferred to the water surrounding the element. The heated water then travels vertically along with the flow in the well, if any vertical flow is

\footnotetext{
6 The flow meter used was manufactured by Mount Sopris Instruments of Golden, Colorado.
} 
present. Sensors above and below the heating element detect the arrival of the heated water, which is recorded and displayed on the field computer used to run the tests. Travel time of the heat pulse, along with borehole diameter, is used to calculate flow rate within the bore. The flow meter software reports the flow rate in gallons per minute (gpm). In the case where there is no vertical flow in the well, the heated water will slowly approach the upper sensor as a result of the buoyancy of the heated water. This artifact of upward vertical flow can be discerned from true vertical flow by comparing velocities in known locations where there is no vertical flow (e.g., in the blank casing).

Calibrations to "no vertical flow" were conducted in the blank casing in the first well. The calibration was conducted to establish a baseline for appearance of the buoyant heat pulse at the upper sensor under known noflow conditions. Repeated measurements were consistent, showing an upward "flow" of less than 0.01gpm. Arrival of the heat pulse under no-flow conditions was 70-90 sec. This instrument could not detect a flow rate lower than $0.01 \mathrm{gpm}$ in these wells

\section{Ambient vertical flow testing}

For the ambient flow testing, the flow meter was deployed at the middle of the screen. The tool was then left to equilibrate in the well for 10 to 30 minutes. This allowed the water level in the well to be reestablished, following insertion of the probe. Following the equilibration, several readings were collected at each well to determine consistency of the results.

Ambient (non-pumping) flow test data indicated that there was measurable vertical flow in only one of the eight wells, well 32-5031 (Table 8). However, the velocity of the flow in this well was slight, just above the detection capability of this method for this well (0.01 gallons per minute), and was in a negative direction. Thus, under normal ambient conditions (i.e., when the well was not pumped), there is a slight downward vertical flow in this well. Generally, one expects to find vertical flow in the wells with longer screens (especially those that are $20 \mathrm{ft}$ or more), where there is a difference in hydraulic head. Given that the well screens in this study were all less than $20 \mathrm{ft}$ in length, it is not surprising that we did not have vertical flow in most of these wells. However, it is interesting that the one well where we found slight vertical flow was actually the well with shortest screen length $(5 \mathrm{ft})$. 
Table 8. Ambient (non-pumping) flow testing results

\begin{tabular}{|c|c|c|c|}
\hline Well & Screen* & Probe Position* & Vertical Flow \\
\hline $32-6064$ & $36.2-46.2$ & 41.3 & None detected \\
\hline $32-5020$ & $15.8-26.5$ & 21.1 & None detected \\
\hline $32-5031$ & $14.9-19.9$ & 17.4 & $-0.48 \mathrm{~cm} / \mathrm{min}$ \\
\hline $32-5076$ & $38.0-48.0$ & 43.0 & None detected \\
\hline $32-6135$ & $46.9-61.9$ & 54.5 & None detected \\
\hline $32-6008$ & $39.4-53-4$ & 46.4 & None detected \\
\hline $13-5045$ & $6.3-14.3$ & 10.3 & None detected \\
\hline $13-6095$ & $13.2-23.2$ & 18.4 & None detected \\
\hline
\end{tabular}

* Measurements in feet below top of casing

\section{Dynamic vertical flow testing}

After completion of the ambient testing in a well, dynamic (pumping) tests were conducted. The heat pulse flow meter was left at a mid-screen position during the first phase of the dynamic tests. Flow within the screen interval was induced by pumping with a peristaltic pump above the screen interval in each well (all wells had fully submerged well screens- i.e., none of the wells were water table wells). Low-flow rates were used to simulate flow rates anticipated for subsequent low-flow purging and sampling. Flow rates at the wells during the dynamic tests ranged from 170 to 430 $\mathrm{mL} / \mathrm{min}$. Steady-state (no further drawdown) conditions were established prior to collecting measurement data. Several heat pulse measurements were taken at each mid-screen deployment to determine consistency of the measurements.

Following the mid-screen measurements, the flow meter sensor was raised above the screen level. Additional measurements were conducted in the blank casing at the same pumping flow rate. These measurements allowed a calibration of each well's full flow. During steady drawdown conditions, all water being pumped must come from the well screen. Therefore, simple calculations can be made using the mid-screen flow rate and full-screen flow rate, to estimate contribution of the upper and lower portions of the well.

Results from the flow meter testing under pumped conditions are presented in Table 9. The measurements indicated a variety of flow patterns in the test wells. Some wells showed nearly equivalent contributions from the top and bottom portions (e.g., wells 32-5020 and 32-6135). Three of 
the four bedrock wells showed a significant contribution from one portion of the screened interval under pumped conditions. Specifically, wells 326008 and 32-6064 showed significant contributions from the upper zone, and wells 13-6095 and 32-5076 (not a bedrock well) showed significant contributions from the deeper portion of the well. The results for well 325031 were anomalous in that the flow rate for the full casing was less than the flow rate for the bottom half of the well. This well had the only detectible ambient vertical flow and also had the shortest (5-ft) screen. It is unclear what is the mechanism for the discrepancy, but the ambient vertical flow component is likely contributing to the ambiguity in this case. Some of the data for well 13-5045 was lost, which resulted in unreliable wholescreen vs. mid-screen flow rates.

Table 9. Active pumping flow testing results.

\begin{tabular}{|l|l|l|l|l|c|r|}
\hline Well & Date & Screen* & $\begin{array}{l}\text { Probe } \\
\text { Positions* }\end{array}$ & $\begin{array}{l}\text { Flow Rate } \\
\mathrm{ml} / \mathrm{min}\end{array}$ & $\begin{array}{l}\text { Flow \%, } \\
\text { bottom half }\end{array}$ & $\begin{array}{l}\text { Flow \%, } \\
\text { top half }\end{array}$ \\
\hline $32-6064$ & $5 / 21 / 07$ & $36.2-46.2$ & $41.3 / 34.9$ & 400 & 10 & 90 \\
\hline $32-5020$ & $5 / 21 / 07$ & $15.8-26.5$ & $21.1 / 15.0$ & 400 & 55 & 45 \\
\hline $32-5031$ & $5 / 22 / 07$ & $14.9-19.9$ & $17.4 / 13.9$ & 400 & - & - \\
\hline $32-5076$ & $5 / 22 / 07$ & $38.0-48.0$ & $43.0 / 37.0$ & 260 & 70 & 30 \\
\hline $32-6135$ & $5 / 22 / 07$ & $46.9-61.9$ & $54.5 / 46.0$ & 170 & 45 & 55 \\
\hline $32-6008$ & $5 / 23 / 07$ & $39.4-53-4$ & $46.4 / 38.4$ & 430 & 5 & 95 \\
\hline $13-5045$ & $5 / 23 / 07$ & $6.3-14.3$ & $10.3 / 5.8$ & 400 & -- & - \\
\hline $13-6095$ & $5 / 23 / 07$ & $13.2-23.2$ & $18.4 / 12.7$ & 400 & 80 & 20 \\
\hline
\end{tabular}

* Measurements in feet below top of casing

\subsubsection{Profiling contaminant stratification with depth in the wells}

Following completion of the borehole flow meter tests, two Snap Samplers, each on its own trigger line, were deployed in each well (Figure 7). The trigger line for the bottom sampler contained a baffle that divided the well screen in half, yielding an upper and lower zone. The trigger line for the upper sampler also had a baffle that was placed $0.5 \mathrm{ft}$ above the top of the well screen. This was done to separate the screen from the blank casing. Both samplers were placed in the middle of their respective zones. The decision was made not to vertically profile well 32-5031 because the screen was only $5 \mathrm{ft}$ in length and so only one sampler was placed in this well. For all the wells, a baffle was placed above the sampler to separate the screen from the blank casing. The samplers were left in the well for one week prior to collecting the samples. 


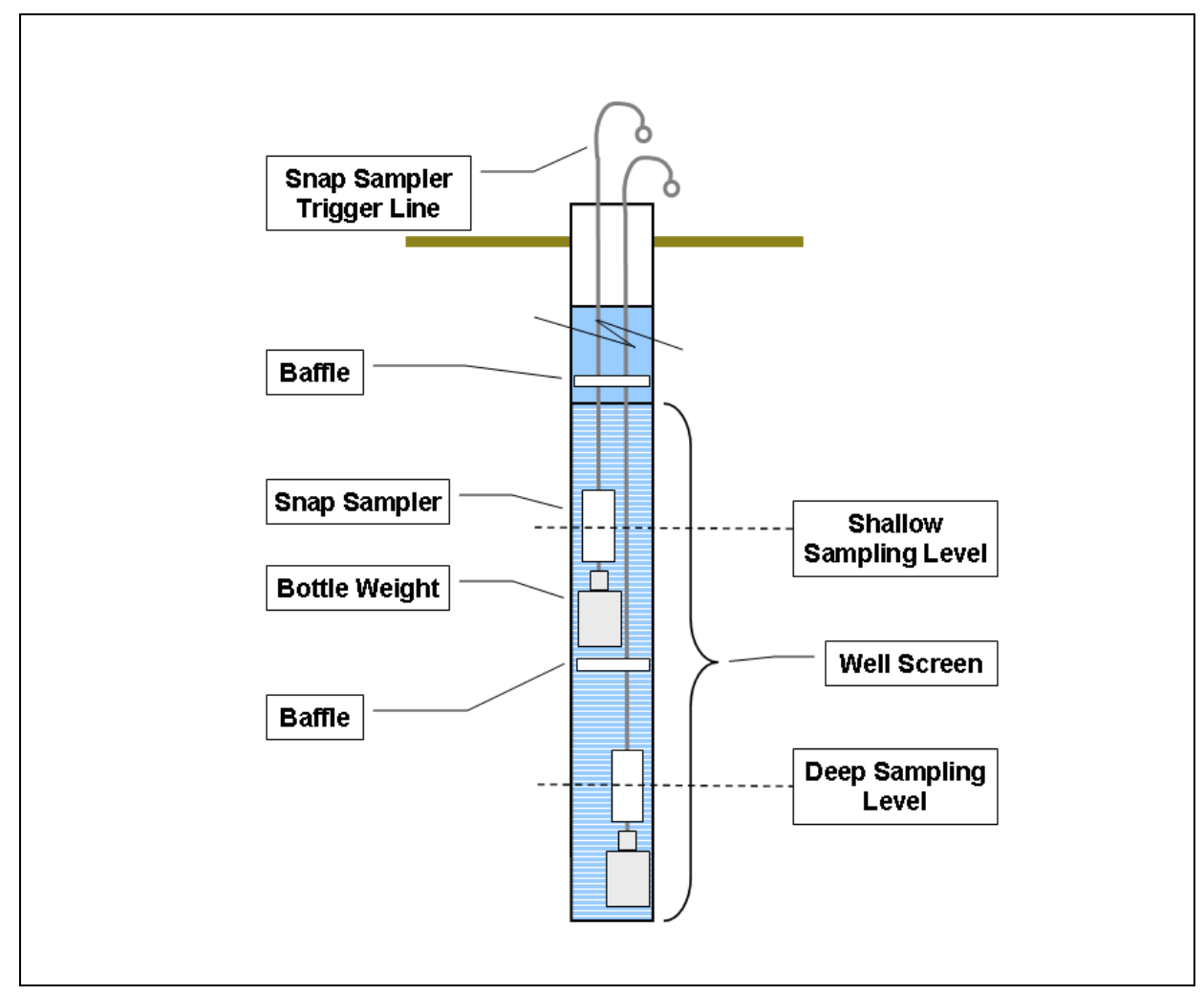

Figure 7. Diagram showing vertical profiling of well using Snap Samplers.

The baffles consisted of two circular discs of 0.030-in-thick PE, sized slightly larger than the inside diameter of the well. Around the outside of the disc, slits were cut to allow the baffles to deform slightly so that the baffle fit tightly within the well. The slits in the two discs were misaligned to limit water exchange. The discs are attached to the Snap Sampler trigger line with plastic snap-on grips ("Herbie" clamps). Figure 8 shows a photo of a trigger line with a baffle. Because of the relatively light weight of the samplers and the resistance to lowering the samplers in the well caused by the baffles, we had to add a weight to the bottom. For each string of samplers, we added a 1-liter plastic water bottle filled with sand as a bottom weight.

Once the samples were collected, they were placed on ice, acidified, and sent by overnight courier to the laboratory for analyses. 


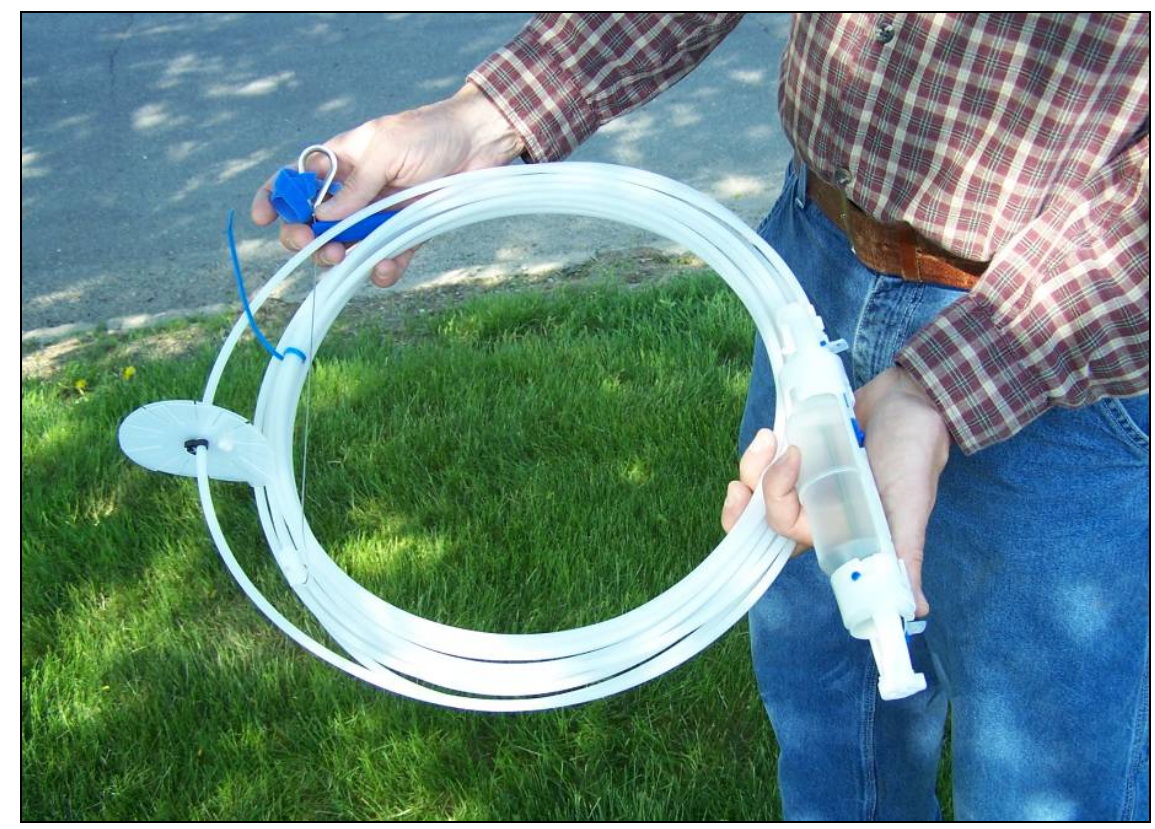

Figure 8. Photo of Snap Sampler, trigger line, and baffle.

Table 10 shows the results from vertically profiling analyte concentrations in the wells. For most of the wells, there was no substantial difference between the analyte concentrations in the sample collected from the shallow vs. the deeper portion of the well. The most notable exception was well 325020 , where concentrations of all the analytes (except $\mathrm{Na}$ ) were higher in the deeper part. However, this difference was believed to be caused by the heavier sediment load found in the deeper sample (Figure 9). This is one of the wells we were not able to successfully redevelop, and we suspect that the filter pack and/or screen for this well may not have been correctly sized and thus was unable to prevent fines from entering the well. Two of the bedrock wells also showed concentration gradients with depth for As and Fe. Wells 32-6064 and 13-6095 both had slightly higher concentrations of these analytes in the shallow portion of the well. 


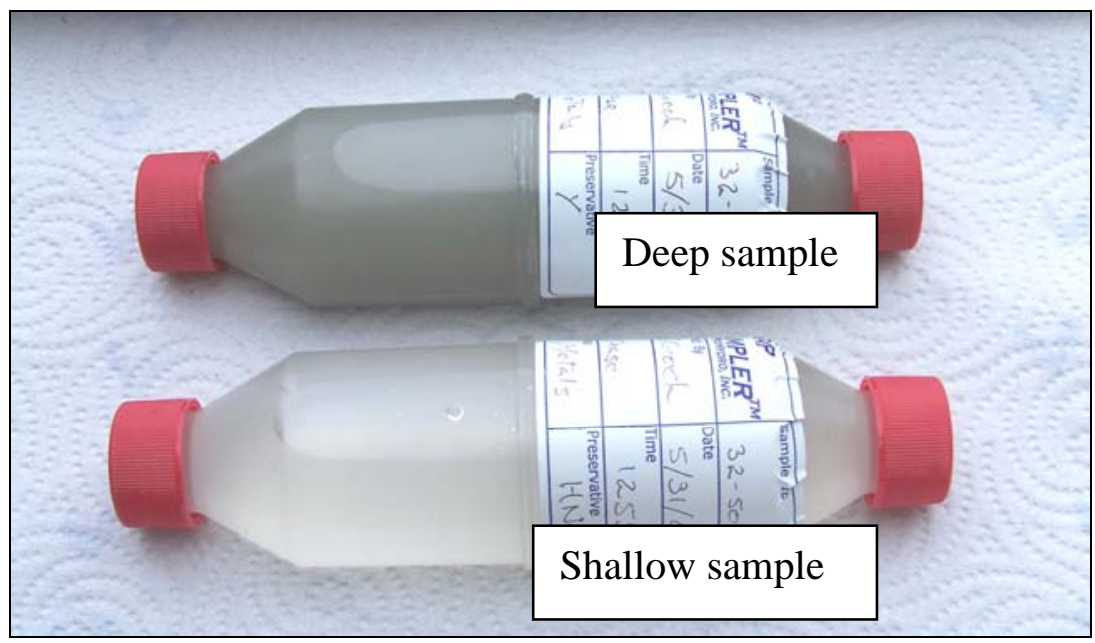

Figure 9. Sediment load comparison between two samples from well 32-5020.

Table 10. Results from the depth profiles of the wells.

\begin{tabular}{|c|c|c|c|c|c|c|c|c|}
\hline \multirow{2}{*}{ Well } & \multirow{2}{*}{ Depth } & \multicolumn{7}{|c|}{ Concentration $(\mathrm{mg} / \mathrm{L})$} \\
\hline & & As & $\mathrm{Ca}$ & $\mathrm{Fe}$ & $\mathrm{Mg}$ & $\mathrm{Mn}$ & K & $\mathrm{Na}$ \\
\hline $13-5045$ & shallow & 0.15 & 67 & 17 & 11 & 5.4 & 2.5 & 80 \\
\hline $13-5045$ & deep & 0.14 & 61 & 17 & 12 & 6 & 2.9 & 110 \\
\hline $13-6095$ & shallow & 0.14 & 29 & 7.9 & 6.3 & 3.9 & 1.2 & 10 \\
\hline $13-6095$ & deep & 0.065 & 28 & 3.7 & 5.9 & 3.7 & 1.1 & 11 \\
\hline $32-5020$ & shallow & 0.15 & 190 & 9.8 & 44 & 0.53 & 8.4 & 60 \\
\hline $32-5020$ & deep & 0.25 & 230 & 160 & 82 & 2.9 & 33 & 60 \\
\hline $32-5031$ & single depth & 0.11 & 89 & 12 & 21 & 0.4 & 5.2 & 30 \\
\hline $32-5076$ & shallow & 0.093 & 65 & 7.4 & 14 & 0.39 & 4.6 & 30 \\
\hline $32-5076$ & deep & 0.089 & 52 & 8.8 & 14 & 0.36 & 4.9 & 30 \\
\hline $32-6008$ & shallow & 0.066 & 65 & 1.5 & 24 & 0.15 & 7.3 & 70 \\
\hline $32-6008$ & deep & 0.057 & 69 & 1.2 & 24 & 0.15 & 7.2 & 70 \\
\hline $32-6008$ & deep dupl. & 0.060 & 65 & 1.3 & 24 & 0.15 & 7.2 & 80 \\
\hline $32-6064$ & shallow & 0.11 & 150 & 2.6 & 42 & 0.27 & 9.2 & 50 \\
\hline $32-6064$ & deep & 0.030 & 140 & 0.2 & 40 & 0.34 & 9.0 & 60 \\
\hline $32-6135$ & shallow & 0.022 & 3.7 & 2.1 & 1.6 & 0.038 & 6.2 & 120 \\
\hline $32-6135$ & deep & 0.021 & 4.5 & 2.9 & 1.6 & 0.059 & 6.4 & 130 \\
\hline
\end{tabular}




\subsubsection{Equipment blanks}

A small diameter ( $3 / 4$ in.) bladder pump (the Mini Bladder Pump 7 ) was installed in each of the wells used in the field study. However, prior to deploying these pumps in the wells, equipment blanks were drawn. This testing was conducted in our laboratory. The pumps were placed in a 94-cmtall x 16.5-cm-dia (37 in. x 6.5 in.) pipette washer containing house distilled water. All the pumps were connected to the pump controller at the same time via a manifold of Teflon tubing and left pumping overnight. During this time, the pumps were pressurized for $1 \mathrm{sec}$ and exhausted for 1 sec at a gauge pressure of approximately 6-8 psi. Pumped water was drained into the sink while the pipette cleaner was continuously replenished with house distilled water. After 22 hours of pumping, the water supply was switched to the DI water system, and they were left to pump at the same rate for another 1.5 hours. The pumps were then shut off for $\sim 4$ hours, after which the pipette cleaner was emptied and refilled with fresh DI water. After another 45 minutes of pumping continuously-replenished DI water, sample blanks were pumped through $6.35 \mathrm{~mm}$-diameter Teflonlined polyethylene tubing (each $\sim 0.75 \mathrm{~m}$ in length) into 125-mL, HDPE bottles containing nitric acid as a preservative. After the pumps were removed from the pipette cleaner, two samples of the water in the pipette cleaner were drawn off through the bottom stopcock. The water in the pipette washer was then drained and refilled with fresh DI water and a trigger line with two Snap Samplers (with 125-mL PP bottles) was placed in the pipette washer. After 10 minutes, the samplers were triggered, recovered, and acidified with $0.5 \mathrm{~mL}$ of nitric acid. All samples were stored in a refrigerator at $4^{\circ} \mathrm{C}$ overnight, packed on ice the next morning, and were transported to the contract lab for analysis ( $\sim 1$ hour away). The samples were analyzed for total metals. (A description of the handling and analyses of the samples is given in detail in Section 3.5.7.2.)

Additional blank equipment samples for the Snap Samplers and the RGC samplers were collected as follows. Two trigger lines, each with one Snap Sampler (125-mL PP bottle) were deployed in the pipette cleaner filled with DI water. At the same time, one RGC sampler was deployed in a widemouthed 5-L HDPE bottle filled with DI water. After leaving the samplers for two weeks, the Snap Samplers were triggered and the RGC sampler was removed from its container. The RGC sample was transferred to a 125mL PE bottle with nitric acid preservative. The Snap Samplers were re-

\footnotetext{
7 The pump used is manufactured by Durham-Geo Slope Indicator (DGSI) of Stone Mountain, GA.
} 
moved from the pipette washer one at a time. The first sample was not acidified. The second sample was preserved with nitric acid. Two samples of water were then drawn directly from the pipette cleaner through the stop cock at the bottom of the washer into (125-mL) PE bottles, containing nitric acid as a preservative. These samples were stored in a refrigerator (at $4^{\circ} \mathrm{C}$ ) for the weekend. The following Monday morning, the samples were placed on ice in a cooler, and they were then picked up by a courier and delivered to the laboratory. The unacidified samples were analyzed for dissolved metals and the acidified samples were analyzed for total metals. (Again, a description of the handling and analyses of the samples is given in detail in Section 3.5.7.2.)

Generally, concentrations for the blank samples indicated that leaching of constituents from the test equipment was not a concern. For the Snap Sampler, concentrations in the equipment blanks were at or below the detection limit for the unfiltered samples. Concentrations of most of the analytes in the RGC blanks were also at or near the detection limit, with the exception of $\mathrm{Ca}$ for which the concentration was very slightly elevated. The results for the pumps indicated that there were no issues with analytes leaching from the pumps (Table 11). For all analytes except for Fe, concentrations were either at or below the detection limit. Concentrations of Fe were also generally below the detection limit, with a few exceptions. The concentration of $\mathrm{Fe}$ in the water from the pipette washer was equivalent to that found in a few of the pumps and in the filtered Snap Sampler sample. This indicates that the pumps and Snap Sampler were not the source of the elevated iron.

Table 11. Results for the equipment blanks.

\begin{tabular}{|c|c|c|c|c|c|c|c|}
\hline \multirow{2}{*}{ Pump No. } & \multicolumn{7}{|c|}{ Concentration $\mathrm{mg} / \mathrm{L}$} \\
\hline & As & $\mathrm{Ca}$ & $\mathrm{Fe}$ & $\mathrm{Mg}$ & $\mathrm{Mn}$ & K & $\mathrm{Na}$ \\
\hline 1470 & $<0.001$ & $<0.05$ & $<0.05$ & $<0.05$ & $<0.005$ & $<0.05$ & $<5$ \\
\hline 2269 & $<0.001$ & $<0.05$ & $<0.05$ & $<0.05$ & $<0.005$ & $<0.05$ & $<5$ \\
\hline 2272 & $<0.001$ & $<0.05$ & $<0.05$ & $<0.05$ & $<0.005$ & $<0.05$ & $<5$ \\
\hline 1472 & $<0.001$ & $<0.05$ & $<0.05$ & $<0.05$ & $<0.005$ & $<0.05$ & $<5$ \\
\hline 2292 & $<0.001$ & $<0.05$ & 0.07 & $<0.05$ & 0.006 & $<0.05$ & $<5$ \\
\hline 2271 & $<0.001$ & $<0.05$ & 0.20 & $<0.05$ & $<0.005$ & $<0.05$ & $<5$ \\
\hline 2291 & $<0.001$ & $<0.05$ & $<0.05$ & $<0.05$ & $<0.005$ & $\mid<0.05$ & $<5$ \\
\hline 2116 & $<0.001$ & $<0.05$ & $<0.05$ & $<0.05$ & $<0.005$ & $<0.05$ & $<5$ \\
\hline 2270 & $<0.001$ & $<0.05$ & 0.15 & $<0.05$ & $<0.005$ & $<0.05$ & $<5$ \\
\hline 1400 & $<0.001$ & $<0.05$ & 0.08 & $<0.05$ & $<0.005$ & $<0.05$ & $<5$ \\
\hline
\end{tabular}




\begin{tabular}{|c|c|c|c|c|c|c|c|}
\hline \multirow{2}{*}{ Other equipment } & \multicolumn{7}{|c|}{ Concentration $\mathrm{mg} / \mathrm{L}$} \\
\hline & As & $\mathrm{Ca}$ & $\mathrm{Fe}$ & $\mathrm{Mg}$ & $\mathrm{Mn}$ & $\mathrm{K}$ & $\mathrm{Na}$ \\
\hline Pipette bucket & $<0.001$ & $<0.05$ & 0.19 & $<0.05$ & $<0.005$ & $<0.05$ & $<5$ \\
\hline Snap Sampler & $<0.001$ & $<0.05$ & $<0.05$ & $<0.05$ & $<0.005$ & $<0.05$ & $<5$ \\
\hline Dup. Snap Sampler & $<0.001$ & $<0.05$ & $<0.05$ & $<0.05$ & $<0.005$ & $<0.05$ & $<5$ \\
\hline RGC (unfiltered) & $<0.001$ & 0.13 & $<0.05$ & $<0.05$ & $<0.005$ & 0.07 & $<5$ \\
\hline Snap (unfiltered) & $<0.001$ & $<0.05$ & $<0.05$ & $<0.05$ & $<0.005$ & $<0.05$ & $<5$ \\
\hline Snap (filtered) & $<0.001$ & $<0.05$ & 0.05 & $<0.05$ & $<0.005$ & $<0.05$ & $<5$ \\
\hline Pump (unfiltered) & $<0.001$ & $<0.05$ & $<0.05$ & $<0.05$ & $<0.005$ & $<0.05$ & $<5$ \\
\hline $\begin{array}{l}\text { Pump (unfiltered) } \\
\text { Lab Duplicate }\end{array}$ & $<0.001$ & $<0.05$ & $<0.05$ & $<0.05$ & $<0.005$ & $<0.05$ & $<5$ \\
\hline Pump (filtered) & $<0.001$ & $<0.05$ & 0.19 & $<0.05$ & $<0.005$ & $<0.05$ & $<5$ \\
\hline Lab Filter Blank & $<0.001$ & $<0.05$ & $<0.05$ & $<0.05$ & $<0.005$ & $<0.05$ & $<5$ \\
\hline
\end{tabular}

\subsubsection{Initial low-flow sampling of the wells}

After the bladder pumps were deployed in the wells, preliminary unfiltered low-flow samples were collected from all the wells. This was done for four reasons: (1) to determine the initial analyte concentrations, (2) to confirm the flow rate to be used would not cause excessive drawdown in the wells, (3) to determine the sampling time for low-flow sampling (needed for the cost analyses), and (4) to equilibrate materials in the pump and tubing with analytes in the well water (to reduce possible losses due to sorption that might occur).

The samples were collected using the EPA's low-flow purging and sampling protocol (U.S. EPA Region 1 1996). The purge parameters were monitored using a Horiba (MDL W-22XD) probe and a flow-through cell. Purge parameters included turbidity, DO, conductivity, salinity, $\mathrm{pH}$, total dissolved solids (TDS), redox potential (ORP), and temperature. Whenever possible, turbidity was monitored until the readings were 10 nephelometric turbidity units (NTU) or less. The other parameters were monitored until three successive readings varied by no more than $\pm 10 \%$. The Horiba probe was calibrated each morning using the Horiba calibration solution. This solution is used to calibrate the meter for $\mathrm{pH}$, conductivity, turbidity, and DO. (The other purge parameters are calculated based on these measurements.) Equipment used to monitor purge parameters was checked approximately one month before we began the project and, again, just before beginning the field work. 
The samples were collected in 125-mL acid-cleaned HDPE bottles containing diluted nitric acid (as described previously). After the sample bottles were filled, they were placed on ice in a cooler, and then shipped to the contract laboratory for analyses.

Table 12 gives the results of the initial low-flow sampling. In all cases, concentrations of the analytes of interest were well above the detection limit and well above any blank values that could have interfered with data analyses.

Table 12. Results from initial low-flow sampling of the wells.

\begin{tabular}{|l|l|l|l|l|l|l|l|}
\hline \multirow{2}{*}{ Well No. } & \multicolumn{7}{|c|}{ Concentration $\mathrm{mg} / \mathrm{L}$} \\
\cline { 3 - 9 } & As & $\mathrm{Ca}$ & $\mathrm{Fe}$ & $\mathrm{Mg}$ & $\mathrm{Mn}$ & $\mathrm{K}$ & $\mathrm{Na}$ \\
\hline $32-6064$ & 0.072 & 160 & 1.1 & 47 & 0.36 & 9.0 & 60 \\
\hline $32-5020$ & 0.15 & 210 & 3.4 & 50 & 0.56 & 6.6 & 60 \\
\hline $32-5031$ & 0.088 & 51 & 5.2 & 16 & 0.37 & 3.8 & 50 \\
\hline $32-5076$ & 0.058 & 46 & 1.6 & 11 & 0.42 & 3.4 & 30 \\
\hline $32-6135$ & 0.022 & 3.1 & 0.42 & 1.3 & 0.032 & 5.8 & 130 \\
\hline $13-5045$ & 0.15 & 42 & 11 & 9.3 & 6.5 & 2.0 & 100 \\
\hline $32-6008$ & 0.060 & 89 & 0.60 & 32 & 0.23 & 7.4 & 80 \\
\hline $13-6095$ & 0.055 & 25 & 3.0 & 5.6 & 5.9 & 1.1 & 10 \\
\hline $13-6095$ (Dup.) & 0.058 & 29 & 3.3 & 6.4 & 5.6 & 1.2 & 10 \\
\hline
\end{tabular}

\subsubsection{Unanswered questions concerning long-term use of Snap Sampler}

One unanswered question with respect to using passive sampling methods is whether the wells that are sampled using this technology will require more frequent re-development than with low-flow sampling.

\subsubsection{Period of operation}

Table 13. Dates for the various demonstration activities.

\begin{tabular}{|l|l|l|}
\hline Task & Start Date & Finish date \\
\hline Preliminary site visit & 13-Mar-07 & 13-Mar-07 \\
\hline Well development & 23-Apr-07 & 2-May-07 \\
\hline Flowmeter testing & 21-May-07 & 23-May-07 \\
\hline Profile contamination in wells & 24-May-07 & 31-May-07 \\
\hline Equipment blanks - pumps & 29-May-07 & 30-May-07 \\
\hline Preliminary Low-Flow sampling & 5-Jun-07 & 7-Jun-07 \\
\hline
\end{tabular}




\begin{tabular}{|l|l|l|}
\hline Task & Start Date & Finish date \\
\hline Deploy samplers for round 1 (8 wells) & 4-Jun-07 & 7-Jun 07 \\
\hline Round 1 sampling & 18-Jun-07 & 29-Jun-07 \\
\hline Equipment blanks - Snap \& RGC samplers & 15-Jun-07 & 18-Jun-07 \\
\hline Deploy samplers for round 2 (2 wells) & 6-July 07 & 6-July 07 \\
\hline Round 2 sampling & 23-Jul-07 & 23-Jul-07 \\
\hline
\end{tabular}

\subsubsection{Amount / treatment rate of material to be treated}

Not applicable.

\subsubsection{Residuals handling}

The only wastes that were generated were the purge water and the spent disposable water from the RGC samplers. After transferring an aliquot from each of the RGC samplers, they were placed in a plastic garbage bag and disposed of as directed by the site manager. The purge water was containerized and taken to the onsite treatment plant for disposal.

\subsubsection{Operating parameters for the technology}

An equilibration time is required for all diffusion passive samplers and is recommended for all equilibrated-grab passive samplers. Thus, the Snap Samplers and the RGC samplers needed to be deployed prior to the sampling day. The RGC samplers typically require an equilibration time of $\sim 7$ days for metals. While the Snap Sampler does not require as long an equilibration time for most analytes as do other diffusion samplers, the Snap Samplers were deployed at the same time so that the lines could be tethered (to reduce tangling of the lines). To allow for adequate equilibration for both types of passive samplers, the samplers were left in the well for at least 10 days prior to sample collection.

For this study, two trips to the field were required, one to deploy the samplers and one to retrieve them. However, for routine monitoring, the second trip to the field could be eliminated for the Snap Sampler. This could be accomplished by placing new bottles in the Snap Sampler after removing the sample bottles from the sampler and then placing the sampler (with the new bottles) back into the well and leaving them until the next sampling event. However, it is not possible to eliminate a second trip to 
the field for the RGC samplers because they are subject to biodegradation and cannot be left in the wells for quarterly (or longer) sampling events.

Labor requirements for the Snap Samplers included: (a) moving the equipment needed for sampling to the site (relatively little needed), (b) assembling the samplers and placing them in the wells, (c) measuring the depth to water and decontaminating the water-level probe after removing it from the well, (d) retrieving the samplers from the well, (e) removing the bottle from the sampler, (f) adding preservative, (g) labeling the samples, (h) placing the samples on ice and preparing them for shipment to the laboratory, and (i) site clean-up.

Labor requirements for the RGC Samplers included: (a) constructing the samplers (prior to going to the field), (b) moving the equipment needed for sampling to the site (relatively little needed), (c) placing the samplers in the well, (d) measuring the depth to water and decontaminating the waterlevel probe after removing it from the well, (e) retrieving the samplers, (f) transferring aliquots of sample to sample bottles (already containing preservative), (g) labeling the samples, (h) placing them on ice and preparing them for shipment to the laboratory, (i) disposing of the spent sampler wastes (minimal volume), and (j) site clean-up.

Labor requirements for low-flow sampling included: (a) cleaning the bladder pumps (a one-time event), (b) placing the pumps in the wells (a onetime event), (c) checking the equipment (used to monitor the purge parameters) prior to going into the field, (d) calibrating the purge-parameter equipment, (e) moving a considerable amount of equipment to the site (including a generator and air compressor), (f) measuring the depth to water and the purge parameters until stabilization occurred, (g) collecting the samples in sample bottles (containing the acid preservative), (h) labeling the samples and placing them on ice, (i) preparing the samples for shipment to the laboratory, $(\mathrm{j})$ disposing of the purge water, $(\mathrm{k})$ decontaminating the purge-parameter equipment, and (l) site clean-up.

Because many types of samples were collected at the same time, two individuals were needed for the field study. However, only one individual would be needed to conduct the sampling using either of the passive methods. While the same is true for low-flow sampling, typically most contractors would send a field crew of two to conduct this kind of sampling. Note that if only one person conducted the low-flow sampling, it would 
definitely take longer (than using a crew of two) because of the effort involved in setting up and tearing down equipment at the site.

\subsubsection{Experimental design}

The objectives for this demonstration/validation project were to demonstrate that the Snap Sampler passive ground water sampling technology can provide (1) technically defensible analytical data for the wide spectrum of analytes that are of concern to the DoD and (2) substantial cost savings. The initial experimental plan included collecting samples at five sites for a range of analyte types including VOCs, explosives, perchlorate, metals, and natural attenuation parameters. At each site, samples were to be collected with (1) the Snap Sampler, (2) low-flow purging and sampling (EPA Region 1, 1996), and (3) passive diffusion samplers such as the RGC or PDB samplers. Using these three sampling technologies allowed us to compare dissolved and colloid-borne contaminants (such as metals and the more hydrophobic organic contaminants). The site selected for this demonstration was the former Pease AFB where the analytes of interest were inorganic analytes, including several types of metals including the Alkali metals (Ca, Mg), alkaline earth metals ( $\mathrm{Na}, \mathrm{K}$ ), and transition metals (Mn, $\mathrm{Fe}$ ).

The initial hypothesis tested was that there were no statistically significant differences between the analyte concentrations in samples taken with the three sampling methods. That is, concentrations of the analytes in samples taken with the Snap Sampler were similar to those taken using low-flow sampling, and those taken using the Snap Sampler were similar to those taken using the RGC sampler, and those taken using the RGC sampler were similar to those taken using the low-flow sampling. However, when comparing these sampling methods, it is important to remember that currently there is no sampling method that yields the true analyte concentrations in the formation. Each of these sampling methods attempts to determine the analyte concentrations differently. The findings from this demonstration will be used to better define the appropriate use of each passive method.

\subsubsection{Sampling plan}

There were 10 sampling events in this demonstration. A sampling event consisted of collecting samples from the same well using the Snap Sampler, low-flow purging and sampling (U.S. EPA Region 1 1996), and the RGC sampler. There were eight wells on the test site that met our require- 
ments for this study. Therefore, all were sampled during the first round of sampling, and two of these wells were sampled a second time (i.e., for the second sampling round). Analytes of interest included $\mathrm{As}, \mathrm{Ca}, \mathrm{Fe}, \mathrm{Mg}, \mathrm{Mn}$, $\mathrm{K}$, and Na.

Two sets of Snap Sampler and low-flow samples were collected from each well: (1) whole-water samples and (2) samples that were filtered in the laboratory. Only one RGC sampler was collected from each well as those samples are already pre-filtered by the RGC membrane, which has a pore size of $18 \AA$. The intent of having both filtered and unfiltered samples was to allow comparison of colloidal-borne and dissolved metal species. Additional quality assurance (QA) / quality control (QC) samples were also collected and will be discussed later.

Two 125-mL PP Snap Sampler bottles were deployed in each well. The RGC Samplers that were deployed in the Pease wells were constructed the morning before departure for the field site. After construction, they were placed in 1-gal plastic, zip-closure bags filled with distilled, de-ionized water, and placed in a cooler with ice for transport to the field. Early the next morning, four samplers were placed in a wide-mouth, 5-L HDPE screwcap bottle that was filled with DI water so that the samplers were fully immersed. Nitrogen gas was then fed under low pressure via tubing to the bottom of the container, and the samplers were sparged for at least 90 minutes. Once work was complete at that site, the tank was disconnected and a replacement RGC sampler was added to the bottle. The sparging process was then repeated at the next site. The samplers were not sparged overnight, but the same process was followed each morning. For the second round of sampling, four RGC samples were sparged for two hours in the lab before taking them to the field. The samplers were then sparged for at least another hour prior to deployment in the well.

The Snap and RGC samplers were deployed at the same depth in the well as the intake of the bladder pump used to collect the low-flow sampling. A small-diameter (3/4-in.) pump was used in these studies so that all the equipment could be placed in the well at the same depth at the same time. The pump was placed at approximately the midpoint of the well screen. The baffle was positioned $0.5 \mathrm{ft}$ above the top of the well screen. The two Snap Samplers were deployed in tandem on the same trigger line, one just above the pump intake and one just below the pump intake (Figure 10). In the first round of sampling, the RGC samplers were attached to the side of 
the pump (so they didn't cover the pump inlet) and the Snap samplers were deployed separately. In the second round of sampling, the three pieces of sampling equipment were bundled together (again making certain that the pump inlet was not covered with other equipment). Again, a 1-liter plastic water bottle filled with sand was added to the string of samplers and was used as a weight to facilitate deployment of the equipment and the baffle in the well. The samplers were left to equilibrate in the well for at least two weeks prior to sampling the wells.

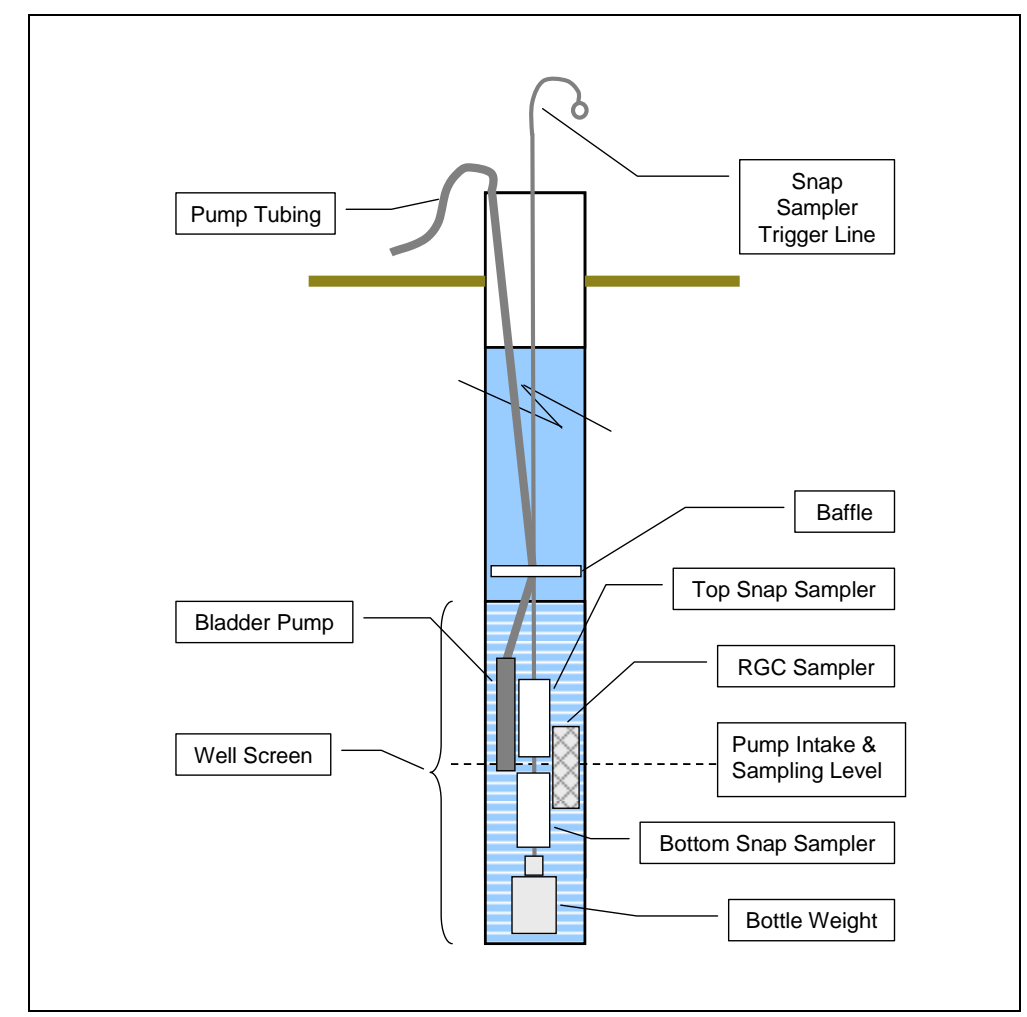

Figure 10. Diagram of deployment of sampling equipment in each well.

\subsubsection{Sample collection}

The dates of the sampling events were given previously in Table 13. The low-flow samples were collected using the EPA's low-flow purging and sampling protocol (U.S. EPA Region 1 1996). The purge parameters were monitored as described previously in section 3.5.1.5. It typically took between 30 and 90 minutes for the purge parameters to stabilize, although some wells took considerably longer to stabilize.

The following sampling order (as outlined in the Demonstration Plan) was developed to reduce the influence of the various samplers on each other, and to minimize the impact of sampling on sample quality (integrity). The 
Snap Sampler was to be triggered first. Then the low-flow samples would be collected as described by the U.S. EPA Region 1 (1996). Once the lowflow samples were collected, the RGC Sampler would be removed from the well and an aliquot transferred to a sample bottle. Finally, the Snap Sampler would be removed from the well and the sample bottles removed from the Snap Sampler. The flow rate, the purge parameter readings, and the time for all the events during sampling were recorded in a bound green field notebook. Because prolonged exposure to air can allow oxygen to diffuse through the RGC membrane thereby impacting some metal concentrations that are subject to oxidation/precipitation reactions and because the Snap Sampler samples remain sealed under in-situ conditions during this time, the RGC sample was transferred to a sample bottle prior to handling the Snap Sampler samples.

However, because of concerns by one of our reviewers about the possible impact the bladder pump might have on the RGC Sampler (i.e., that it might draw water into the sampler) we decided to collect the RGC samples prior to collecting the low-flow samples. So, for the first two wells sampled, the following sample order was used. The Snap Sampler was triggered first. Then the pump and RGC sampler were removed from the well (they were bundled together) and an aliquot from the RGC sampler was transferred to a sample bottle. Next, the Snap Sampler was removed from the well, and the sample bottles were removed from the Snap Sampler. Once these samples were processed, the pump was returned to the well and the well was allowed to settle for at least 30 minutes before purging the well. The well was then purged according to the EPA's low-flow sampling protocol at a flow rate that was determined during our preliminary sampling event. Subsequently, the depth to water was monitored during low-flow sampling to insure that excessive drawdown did not occur. Purging continued until the purge parameters stabilized. Parameters that were monitored included water level, turbidity, temperature, dissolved oxygen, redox potential, and specific conductance. After the purge parameters stabilized, the low-flow samples were collected.

As we had initially suspected, we found that this protocol disturbed the wells and it took several hours for the turbidity readings in these wells to drop to the desired range (i.e., < 10 NTU). Since these wells were being sampled for several types of metals (and metal concentrations in the unfiltered samples would be affected by turbidity), we decided to conduct all the subsequent sampling events using the originally planned sampling or- 
der. For the second sampling round, the first two wells were again sampled and this time, the originally developed sampling order was used. By sampling these two wells using two different sampling orders, we could compare the effect of sampling order on the analyte concentrations in the RGC samples in two wells. Because passive diffusion samplers rely on diffusion (which takes days for equilibration to occur), the time it takes to collect the low-flow samples presumably should not significantly impact analyte concentrations in these samplers.

Sample collection for the RGC sampler involved piercing the membrane with a Pasteur pipet and transferring an aliquot to an acid-cleaned 125-mL HDPE bottle containing 1:1 nitric acid as a preservative. The bottle was then capped, labeled, and placed on ice. For the Snap Sampler samples, the Snap Sampler bottles were removed from the Snap Sampler body and the bottom caps were placed on both bottles. Next, the upper bottle was capped on the top and the lower bottle was acidified and then capped. Both samples were then labeled and placed on ice. For the two low-flow samples, the whole water sample was collected in an acid-cleaned, $125-\mathrm{mL}$ HDPE bottle containing acid, and the sample to be filtered in the lab was collected in a similar bottle containing no preservative.

Waterproof sample container labels and permanent markers were used to label the samples. All samples were marked with the sampling date, sampling individual, whether they were filtered, and given a sample number that will identify the site, well, and sampling method to the sampling personnel but not the laboratory. All sample numbers were recorded in a bound green field notebook. All samples were placed on ice in a cooler and kept cold until we delivered them to the laboratory for analyses. When the samples were ready to be shipped, they were placed on fresh ice, the chainof custody forms were filled out, and the coolers were sealed prior to shipment.

Initially the demonstration plan specified that Louise Parker and Nathan Mulherin (ERDC-CRREL) would conduct the sampling at this site. However, because of Ms. Parker's health issues, Gordon Gooch (ERDC-CRREL) assisted Mr. Mulherin in the sampling, and Ms. Parker was present to supervise most of the sampling events. 


\subsubsection{Sample analysis.}

The samples were transported by automobile to Eastern Analytical Inc. in Concord, NH (approximately one hour away) for analyses. Eastern Analytical is an EPA-certified National Environmental Laboratory Accreditation Conference (NELAC) facility. Upon arrival at the laboratory, any samples that were to be filtered were filtered with a $0.45 \mu$ Chromafil ${ }^{\circledR}$ Polyamide (Nylon) filter into a 2-oz HDPE container containing $200 \mu \mathrm{L}$ of a 1:1 trace-metals grade Nitric Acid/DI water solution.

For the unfiltered samples, the samples were digested prior to analyses. This was accomplished by adding $1 \mathrm{~mL}$ of trace-metals grade, concentrated nitric acid to $50 \mathrm{~mL}$ of the test solution and then digesting the sample on a bloc heater at $85^{\circ} \mathrm{C}$ until the volume was reduced by half. The sample was then cooled to room temperature and brought back to a $50-\mathrm{mL}$ volume by adding reagent-grade water.

Analyses were conducted using Inductively Coupled Plasma /Mass Spectrometry (ICP/MS) using EPA method 200.8 (Creed et al. 1994) according to EPA SW 846 method 6020B (U.S. EPA, 1996). All samples were analyzed within the specified holding times.

For the statistical analyses, the concentration data were analyzed on an analyte-by-analyte basis. Analytes with measurable concentrations that allowed statistical analyses included $\mathrm{As}, \mathrm{Ca}, \mathrm{Fe}, \mathrm{Mg}, \mathrm{Mn}, \mathrm{K}$, and $\mathrm{Na}$. In the few instances where analyte concentrations were below the detection limit, half the detection limit was used in the statistical analyses. The filtered and unfiltered data sets were treated separately. Specifically, analyte concentrations in the filtered Snap Sampler samples, the filtered low-flow samples, and the RGC samplers were compared. Concentrations in the unfiltered Snap Sampler samples, the unfiltered low-flow samples, and the RGC samples were also compared.

Standard statistical analyses were used to analyze the data. The data sets were first analyzed to determine if the data were normally distributed and if the variances were homogenous. Whenever possible, conventional parametric analyses were used. In instances where conventional parametric tests can not be used, non-parametric (ranked) tests were used. Specifically, for normally distributed data, Repeated Measures Analysis of Variance (RM-ANOVA) was used to determine if there were significant differences between the analyte concentrations in the samples collected with 
different sampling methods. Differences between the treatment methods were determined using the Holm-Sidak method for pair-wise multiple comparisons. In cases where non-parametric tests had to be used, the Friedman RM-ANOVA on Ranks test was used to determine if there is a significant difference between the treatments. In the instances where a significant difference was found, the Tukey test was used to determine which treatments differed from each other.

\subsubsection{Experimental controls}

In order for the statistical analyses to be as robust as possible, it is important to minimize any extraneous factors that could influence the data quality. These factors could include the following.

- Improperly functioning wells, i.e., wells that were never adequately developed or wells needing redevelopment

- Flow patterns within the wells, e.g., vertical flow within the well

- Contaminant gradients in the well

- Differences in sampling depth of samplers

- Flow induced changes caused by a sampler

- Contaminant concentrations that are too low to measure

To address these concerns, we included the following provisions in the design of this demonstration in an effort to either quantify their impact or reduce it.

- All the wells were sampled prior to the demonstration to determine that analyte concentrations were within the desired range, that there is adequate flow in the well, and whether the wells needed redevelopment based on turbidity readings.

- All the wells were redeveloped because they contained high levels sediment.

- The flow patterns in each of the wells were determined.

- Samples were collected at two depths in the wells (using a baffles) to determine if there was contaminant stratification in the wells.

- The sampling depth for each passive sampler was matched with that of the pump intake (used for low-flow sampling).

- We developed a sampling order that reduced sampler impacts on subsequent sampling events.

\subsubsection{Data quality parameters.}

To insure data validity, standard laboratory practices for analyses included the following: 
- receiving, log-in, and storage of field samples

- chain-of-custody documentation

- standards preparation and analysis

- instrument calibration

- instrumentation QC

- duplicate field samples

- matrix spike samples

- field and laboratory blanks

Prior to deploying any of the samplers or pumps, equipment blanks were collected. The latter process was described previously in more detail, in section 3.5.1.4.

Standard QC samples included duplicates and duplicates for (laboratory) spiked recoveries to determine matrix affects, and trip blanks. A minimum of $5 \%$ of the samples were analyzed in duplicate to give a measure of the precision of the laboratory and analytical method. Certified reference samples were used by the laboratory to ensure proper calibration and thus accuracy of the analyses. One out of 40 samples was a certified reference sample (2.5\%). One out of 20 samples was a calibration standard (5\%). For each round of sampling, there was also was filter blank sample that was analyzed for contamination of dissolved metals samples.

At least one duplicate field sample was collected each sampling day. During the course of the field sampling, duplicate samples were collected for all three sampling methods (low-flow, Snap, and RGC). The results from these analyses provide a measure of the precision (repeatability) of the field sampling methods.

Duplicate samples for spiked recoveries were collected for $5 \%$ (or 1 of 20) of the total number of samples for the purposes of preparing Matrix Spikes (MS) and Matrix Spike Duplicates (MSD). They were identified with the suffixes MS and MSD on the Chain-of-Custody Forms. These samples were used to identify matrix effects on spiked analytes of known quantity and the laboratory's precision in recognizing matrix effects.

\subsubsection{Data quality indicators}

Laboratory blanks were prepared by the contract laboratory using analytefree reagent water. One laboratory blank was performed for every 20 samples (i.e., $5 \%$ of the samples). In all cases, analyte concentrations of the 
primary analytes (As, $\mathrm{Ca}, \mathrm{Fe}, \mathrm{Mg}, \mathrm{Mn}, \mathrm{K}$, and $\mathrm{Na}$ ) in these samples were below the detection limit.

The relative percent difference (RPD) was used to determine the degree of agreement between the sampling methods (for the analyte concentrations). The RPD was calculated for each well and analyte according to the following formula:

$\mathrm{RPD}=[$ [ | Conc. Sampler A - Conc. Sampler B| ] / [Mean Conc. Sampler A \& B] ] 100

The number of wells where the RPD was $25 \%$ or less for concentrations at or above $50 \mu \mathrm{g} / \mathrm{L}$ (or $50 \%$ for concentrations less than $50 \mu \mathrm{g} / \mathrm{L}$ ) was determined, and the percent agreement between the two sampling methods was determined from the total number of wells.

The agreement between the field duplicate samples and the original samples was excellent with RPDs $15 \%$ or less for all the samples, and in all but four instances the RPD was less than 10\% (Table 14). This is well below our guideline of a $25 \%$ RPD.

Table 14. Results for field duplicate samples, with relative percent difference calculations.

\begin{tabular}{|c|c|c|c|c|c|c|c|}
\hline \multirow{2}{*}{ Sample type } & \multicolumn{7}{|c|}{ Concentration $(\mathrm{mg} / \mathrm{L})$} \\
\hline & As & $\mathrm{Ca}$ & $\mathrm{Fe}$ & Mg & $\mathrm{Mn}$ & K & $\mathrm{Na}$ \\
\hline low flow & 0.095 & 170 & 1.8 & 52 & 0.37 & 11 & 71 \\
\hline low flow & 0.10 & 180 & 2.1 & 52 & 0.40 & 12 & 73 \\
\hline RPD (\%) & 5.1 & 5.7 & 15 & 0.0 & 7.8 & 8.7 & 2.8 \\
\hline low flow & 0.054 & 58 & 2.3 & 13 & 0.52 & 3.8 & 26 \\
\hline low flow & 0.052 & 62. & 2.1 & 13 & 0.54 & 4.0 & 27 \\
\hline RPD (\%) & 3.8 & 6.7 & 9.1 & 0.0 & 3.8 & 5.1 & 3.8 \\
\hline low flow & 0.16 & 72 & 15 & 12 & 7.3 & 2.8 & 140 \\
\hline low flow & 0.16 & 70 & 15 & 12 & 7.8 & 2.7 & 160 \\
\hline RPD (\%) & 0.0 & 2.8 & 0.0 & 0.0 & 6.6 & 3.6 & 13 \\
\hline low flow & 0.093 & 110 & 1.8 & 38 & 0.20 & 9.0 & 53 \\
\hline low flow & 0.088 & 110 & 1.8 & 38 & 0.21 & 9.4 & 56 \\
\hline RPD (\%) & 5.5 & 0.0 & 0.0 & 0.0 & 4.9 & 4.3 & 5.5 \\
\hline
\end{tabular}




\begin{tabular}{|l|l|l|l|l|l|l|l|}
\hline \multirow{2}{*}{ Sample type } & As & Ca & Fe & Mg & Mn & K & Na \\
\hline & 0.055 & 25 & 3.0 & 5.6 & 5.9 & 1.1 & 10 \\
\hline low flow & 0.058 & 29 & 3.3 & 6.4 & 5.6 & 1.2 & 10 \\
\hline low flow & 5.3 & 15 & 9.5 & 13 & 5.2 & 8.7 & 0.0 \\
\hline RPD (\%) & 5.3 &
\end{tabular}

Five percent of the samples were analyzed in duplicate to give a measure of the precision of the analyses (laboratory duplicates). The agreement between the concentrations of the analytes in these samples was also good. The RPD was less than $10 \%$ in all but three instances, was less than $15 \%$ in all but one instance, and was less than the guideline of $25 \%$ in all cases (Table 15).

Table 15. Results from duplicate laboratory analyses, with relative percent difference calculations.

\begin{tabular}{|c|c|c|c|c|c|c|c|}
\hline \multirow{2}{*}{ Sample type } & \multicolumn{7}{|c|}{ Concentration $(\mathrm{mg} / \mathrm{L})$} \\
\hline & As & $\mathrm{Ca}$ & $\mathrm{Fe}$ & $\mathrm{Mg}$ & $\mathrm{Mn}$ & K & $\mathrm{Na}$ \\
\hline Snap & 0.054 & 42.0 & 2.40 & 8.0 & 7.80 & 1.60 & 14 \\
\hline Snap & 0.052 & 41.0 & 2.40 & 7.5 & 7.60 & 1.50 & 14 \\
\hline RPD (\%) & 3.7 & 2.4 & 0.0 & 6.3 & 2.6 & 6.3 & 0.0 \\
\hline low flow & 0.056 & 42.0 & 3.30 & 7.6 & 6.40 & 1.50 & 14 \\
\hline low flow & 0.058 & 44.0 & 3.30 & 7.8 & 7.90 & 1.50 & 14 \\
\hline RPD (\%) & -3.5 & -4.7 & 0.0 & -2.6 & -21 & 0.0 & 0.0 \\
\hline low flow & 0.059 & 98.0 & 0.62 & 34.0 & 0.220 & 10.0 & 95 \\
\hline low flow & 0.057 & 93.0 & 0.60 & 33.0 & 0.200 & 9.7 & 90 \\
\hline RPD (\%) & 3.4 & 5.2 & 3.3 & 3.0 & 9.5 & 3.0 & 5.4 \\
\hline Snap & 0.054 & 42.0 & 2.40 & 8.0 & 7.80 & 1.60 & 14 \\
\hline Snap & 0.052 & 41.0 & 2.40 & 7.5 & 7.60 & 1.50 & 14 \\
\hline RPD (\%) & 3.8 & 2.4 & 0.0 & 6.5 & 2.6 & 6.5 & 0.0 \\
\hline low flow & 0.068 & 140 & $<0.05$ & 38.0 & 0.430 & 7.10 & 57 \\
\hline low flow & 0.068 & 150 & $<0.05$ & 43.0 & 0.450 & 7.50 & 66 \\
\hline RPD (\%) & 0.0 & -6.9 & 0.0 & -12 & -4.5 & -5.5 & -15 \\
\hline low flow & 0.093 & 110 & 1.80 & 38.0 & 0.200 & 9.00 & 53 \\
\hline low flow & 0.087 & 110 & 1.70 & 41.0 & 0.200 & 8.60 & 55 \\
\hline RPD (\%)e & 6.7 & 0.0 & 5.7 & -7.6 & 0.0 & 4.5 & -3.7 \\
\hline
\end{tabular}


For the Matrix Spike and Matrix Spike Duplicate samples, there generally was close agreement between the duplicates (Table 16). Recovery of the spiked analytes was $100 \% \pm 10 \%$ for $\mathrm{Ca}, \mathrm{Fe}, \mathrm{Mn}, \mathrm{K}$, and $\mathrm{Na}$ and recovery of As was only slightly higher at $112 \%$.

Table 16. Data for matrix spike and matrix spike duplicate samples.

\begin{tabular}{|c|c|c|c|c|c|c|c|}
\hline \multirow{2}{*}{ Sample } & \multicolumn{7}{|c|}{ Percent Recovery of Spike } \\
\hline & As & $\mathrm{Ca}$ & $\mathrm{Fe}$ & $\mathrm{Mg}$ & $\mathrm{Mn}$ & K & $\mathrm{Na}$ \\
\hline MS & 104 & 108 & 97 & 108 & 82 & 101 & 106 \\
\hline MSD & 106 & 103 & 102 & 104 & 84 & 100 & 107 \\
\hline MS & 110 & 111 & 96 & 99 & 95 & 91 & 117 \\
\hline MSD & 100 & 101 & 93 & 96 & 88 & 90 & 111 \\
\hline MS & 111 & 99 & 103 & 95 & 93 & 91 & 95 \\
\hline MSD & 111 & 93 & 98 & 90 & 87 & 93 & 99 \\
\hline MS & 121 & 127 & 99 & 110 & 97 & 107 & 111 \\
\hline MSD & 115 & 123 & 100 & 104 & 94 & 106 & 109 \\
\hline MS & 115 & 126 & 94 & 119 & 101 & 122 & 123 \\
\hline MSD & 113 & 130 & 94 & 119 & 101 & 115 & 113 \\
\hline MS & 119 & 85 & 105 & 120 & 101 & 118 & 124 \\
\hline MSD & 119 & 96 & 103 & 121 & 103 & 116 & 123 \\
\hline MS & 110 & 96 & 98 & 92 & 102 & 96 & 95 \\
\hline MSD & 108 & 96 & 97 & 95 & 104 & 96 & 96 \\
\hline Mean & 112 & 107 & 99 & 105 & 95 & 103 & 109 \\
\hline $\begin{array}{l}\text { Standard } \\
\text { Deviation }\end{array}$ & 5.98 & 14.5 & 3.72 & 11.2 & 7.41 & 11.1 & 10.3 \\
\hline Mean RSD \% & 5.4 & 13.6 & 3.8 & 10.6 & 7.8 & 10.7 & 9.4 \\
\hline
\end{tabular}

\subsubsection{Calibration procedures, quality control checks, and corrective action}

All laboratory data was reviewed for completeness, detection and quantitation limits, QA/QC analyses, and the adequacy of the holding times. 
The analytical laboratory used standard EPA protocols for calibrating the analytical instrumentation, including calibration curves for at least three standards at different concentrations, internal and external standards, and testing blanks. Any issues were to be reported to the PI immediately, but there were none. Certified reference samples were used by the laboratory to ensure proper calibration and accuracy of the analyses. In all cases, the certified reference samples were within 10\% of the known values, well within the $20 \%$ guideline (Table 17 ).

Table 17. Percent recovery of reference samples.

\begin{tabular}{|r|r|r|r|r|r|r|}
\hline \multicolumn{7}{|c|}{ Percent Recovery } \\
\hline As & Ca & Fe & Mg & Mn & K & Na \\
\hline 101 & 109 & 95 & 104 & 90 & 94 & 105 \\
\hline 104 & 109 & 101 & 98 & 91 & 102 & 95 \\
\hline 102 & 100 & 108 & 95 & 100 & 106 & 96 \\
\hline 107 & 103 & 110 & 108 & 109 & 102 & 110 \\
\hline 106 & 103 & 99 & 105 & 99 & 108 & 105 \\
\hline 107 & 103 & 110 & 108 & 109 & 102 & 110 \\
\hline 110 & 104 & 109 & 104 & 104 & 105 & 106 \\
\hline
\end{tabular}

\subsubsection{Demobilization}

After sampling was complete, the RGC samplers were placed in garbage bags and disposed as trash (per guidelines of the site manager). The Snap Sampler was packaged in zip-locking plastic bags and returned to our laboratory (CRREL) for decontamination. The bladder pumps were removed from the sampling tubing, bagged, and returned to CRREL for decontamination. The sampling tubing (for the bladder pump), sampling lines (for the RGC samplers) and trigger lines (for the Snap Sampler) were placed in garbage bags and disposed of as trash (per instructions from the site manager).

\subsection{Selection of analytical/testing methods}

Analyses were conducted using standard EPA methods: i.e., Inductively Coupled Plasma /Mass Spectrometry (ICP/MS) using EPA method 200.8 (Creed et al. 1994) according to EPA SW 846 method 6020B (U.S. EPA, 1996). 


\subsection{Selection of analytical/testing laboratory}

Our primary criteria for a laboratory were that it be (1) able to conduct the required analyses within the time frame needed, (2) an EPA NELACcertified laboratory (NH certificate number 101208), and (3) a local contractor that was willing to come on site to pick up samples. We also preferred to have a laboratory with a proven record. 


\section{Performance Assessment}

\subsection{Performance criteria}

The criteria for the evaluating the performance of the Snap and RGC samplers is given in Table 18 .

Table 18. Performance criteria for Snap and RGC samplers vs. low-flow sampling.

\begin{tabular}{|c|c|c|}
\hline Performance Criteria & Description & Primary or Secondary \\
\hline $\begin{array}{l}\text { Mechanical performance of } \\
\text { Snap Samplers }\end{array}$ & $\begin{array}{l}\text { Samplers work as described } \\
\text { without problems, reliable, ease of } \\
\text { use, training required, etc. }\end{array}$ & Primary \\
\hline $\begin{array}{l}\text { Mechanical performance of } \\
\text { Snap Samplers }\end{array}$ & Reduced time needed to sample. & Primary \\
\hline Ease of use of Snap Sampler & $\begin{array}{l}\text { Easy to use, number of people } \\
\text { required to operate sampler, } \\
\text { training required. }\end{array}$ & Primary \\
\hline $\begin{array}{l}\text { Mechanical performance of } \\
\text { RGC sampler }\end{array}$ & $\begin{array}{l}\text { Samplers work as described } \\
\text { without problems, reliable, ease of } \\
\text { use, training required, etc. }\end{array}$ & Primary \\
\hline $\begin{array}{l}\text { Mechanical performance of } \\
\text { RGC sampler }\end{array}$ & Reduced time needed to sample. & Primary \\
\hline Ease of use of RGC sampler & $\begin{array}{l}\text { Easy to use, number of people } \\
\text { required to operate sampler, } \\
\text { training required. }\end{array}$ & Primary \\
\hline $\begin{array}{l}\text { Factors Affecting Technology } \\
\text { Performance of Snap Sampler }\end{array}$ & $\begin{array}{l}\text { Describe how technology } \\
\text { performance is affected by } \\
\text { operating conditions (e.g., ground } \\
\text { water flow in wells, turbidity, } \\
\text { temperature, etc.). Describe how } \\
\text { matrix effects (e.g., soil type, well } \\
\text { construction, presence of particles, } \\
\text { pH, DO, contaminants, etc.) may } \\
\text { affect technology performance. }\end{array}$ & Primary \\
\hline $\begin{array}{l}\text { Factors Affecting Technology } \\
\text { Performance of RGC sampler }\end{array}$ & $\begin{array}{l}\text { Describe how technology } \\
\text { performance is affected by } \\
\text { operating conditions (e.g., ground } \\
\text { water flow in wells, turbidity, } \\
\text { temperature, etc.). Describe how } \\
\text { matrix effects (e.g., soil type, well } \\
\text { construction, presence of particles, } \\
\text { pH, DO, contaminants, etc.) may } \\
\text { affect technology performance. }\end{array}$ & Primary \\
\hline
\end{tabular}




\begin{tabular}{|c|c|c|}
\hline Performance Criteria & Description & Primary or Secondary \\
\hline $\begin{array}{l}\text { Reduced purge water with Snap } \\
\text { Samplers }\end{array}$ & $\begin{array}{l}\text { Document volume and time } \\
\text { required for disposal of purge water } \\
\text { for low-flow sampling }\end{array}$ & Primary \\
\hline $\begin{array}{l}\text { Reduced purge water with RGC } \\
\text { samplers }\end{array}$ & $\begin{array}{l}\text { Document volume and time } \\
\text { required for disposal of purge water } \\
\text { for low-flow sampling. Document } \\
\text { volume discarded from RGC } \\
\text { sampler. }\end{array}$ & Primary \\
\hline $\begin{array}{l}\text { Equivalent analyte recovery } \\
\text { Snap Sampler \& low-flow }\end{array}$ & $\begin{array}{l}\text { According to performance criteria } \\
\text { (statistical tests, RPDs less than } \\
25 \% \text { ) }\end{array}$ & Primary \\
\hline $\begin{array}{l}\text { Equivalent analyte recovery low- } \\
\text { flow samples \& RGC sampler }\end{array}$ & $\begin{array}{l}\text { According to performance criteria } \\
\text { (statistical tests, RPDs less than } \\
25 \% \text { ) }\end{array}$ & Primary \\
\hline $\begin{array}{l}\text { Equivalent analyte selectivity of } \\
\text { Snap Sampler }\end{array}$ & $\begin{array}{l}\text { Compile analyses of performance } \\
\text { criteria for all the analytes }\end{array}$ & Primary \\
\hline $\begin{array}{l}\text { Equivalent analyte selectivity of } \\
\text { RGC sampler }\end{array}$ & $\begin{array}{l}\text { Compile analyses of performance } \\
\text { criteria for all the analytes }\end{array}$ & Primary \\
\hline $\begin{array}{l}\text { Equivalent analyte recovery } \\
\text { Snap Sampler \& RGC sampler }\end{array}$ & $\begin{array}{l}\text { According to performance criteria } \\
\text { (statistical tests, RPDs less than } \\
25 \% \text { ) }\end{array}$ & Secondary \\
\hline Reliability of Snap Samplers & $\begin{array}{l}\text { Breakdown of equipment, leakage } \\
\text { from sampler; sensitivity to } \\
\text { environmental conditions. }\end{array}$ & Secondary \\
\hline Reliability of RGC samplers & $\begin{array}{l}\text { Breakdown of equipment, leakage } \\
\text { from sampler, sensitivity to } \\
\text { environmental conditions. }\end{array}$ & Secondary \\
\hline Versatility of Snap Sampler & $\begin{array}{l}\text { Describe whether the technology } \\
\text { can be used for any other } \\
\text { application(s) and whether it can be } \\
\text { used at other locations. If not, could } \\
\text { it be adapted? To what extent } \\
\text { would the technology have to be } \\
\text { adapted so that it can be used in } \\
\text { other settings? }\end{array}$ & Secondary \\
\hline Versatility of RGC sampler & $\begin{array}{l}\text { Describe whether the technology } \\
\text { can be used for any other } \\
\text { application(s) and whether it can be } \\
\text { used at other locations. If not, could } \\
\text { it be adapted? To what extent } \\
\text { would the technology have to be } \\
\text { adapted so that it can be used in } \\
\text { other settings? }\end{array}$ & Secondary \\
\hline
\end{tabular}




\begin{tabular}{|c|c|c|}
\hline Performance Criteria & Description & Primary or Secondary \\
\hline $\begin{array}{l}\text { Hazardous Materials Snap } \\
\text { Sampler }\end{array}$ & $\begin{array}{l}\text { Identify any hazardous materials } \\
\text { that will remain or might be } \\
\text { introduced by the Snap Sampler. }\end{array}$ & Secondary \\
\hline $\begin{array}{l}\text { Hazardous Materials } \\
\text { RGC sampler }\end{array}$ & $\begin{array}{l}\text { Identify any hazardous materials } \\
\text { that will remain or might be } \\
\text { introduced by the RGC sampler. }\end{array}$ & Secondary \\
\hline Process Waste for Snap Sampler & $\begin{array}{l}\text { Identify any process waste } \\
\text { produced by the technology. If there } \\
\text { is such a waste, describe its } \\
\text { volume, any hazards that are } \\
\text { associated with it, and how it will be } \\
\text { handled. }\end{array}$ & Secondary \\
\hline Process Waste for RGC sampler & $\begin{array}{l}\text { Identify any process waste } \\
\text { produced by the technology. If there } \\
\text { is such a waste, describe its } \\
\text { volume, any hazards that are } \\
\text { associated with it, and how it will be } \\
\text { handled. }\end{array}$ & Secondary \\
\hline $\begin{array}{l}\text { Scale-up constraints for } \\
\text { Snap Sampler }\end{array}$ & $\begin{array}{l}\text { Determine if there are any scale-up } \\
\text { constraints for full-scale use. }\end{array}$ & Secondary \\
\hline $\begin{array}{l}\text { Scale-up constraints for } \\
\text { RGC sampler }\end{array}$ & $\begin{array}{l}\text { Determine if there are any scale-up } \\
\text { constraints for full-scale use. }\end{array}$ & Secondary \\
\hline
\end{tabular}

\subsection{Performance confirmation methods}

Performance criteria, metrics, and confirmation methods that were used for this demonstration are presented in Table 19. The primary quantitative criteria included equivalent analyte recoveries, equivalent analyte selectivity, and reduced purge water volume. The primary qualitative criteria included reduced sampling time, relatively few problems encountered when using these samplers, and that these samplers were easy to use with little training. Secondary performance criteria include scale-up considerations. Chemical analyses and associated statistical methods and records from the demonstration were used to confirm whether or not the expected performance metrics were met. 
Table 19. Expected performance and performance confirmation methods.

\begin{tabular}{|c|c|c|c|}
\hline Performance Criteria & $\begin{array}{l}\text { Expected Performance Metric } \\
\text { (pre demo) }\end{array}$ & $\begin{array}{l}\text { Performance } \\
\text { Confirmation } \\
\text { Method }\end{array}$ & $\begin{array}{l}\text { Actual (post } \\
\text { demo) }\end{array}$ \\
\hline \multicolumn{4}{|c|}{$\begin{array}{l}\text { PRIMARY CRITERIA (Performance Objectives) } \\
\text { (Qualitative) }\end{array}$} \\
\hline $\begin{array}{l}\text { Mechanical Performance of Snap } \\
\text { Sampler }\end{array}$ & $\begin{array}{l}\text { Few problems encountered using } \\
\text { sampler }\end{array}$ & $\begin{array}{l}\text { Records from } \\
\text { demonstration }\end{array}$ & Future \\
\hline $\begin{array}{l}\text { Mechanical Performance of Snap } \\
\text { Sampler }\end{array}$ & Reduced time needed to sample & $\begin{array}{l}\text { Records from } \\
\text { demonstration }\end{array}$ & Future \\
\hline Ease of Use of Snap Sampler & $\begin{array}{l}\text { Easy to use, requires little } \\
\text { training }\end{array}$ & $\begin{array}{l}\text { Records from } \\
\text { demonstration }\end{array}$ & Future \\
\hline $\begin{array}{l}\text { Mechanical Performance of RGC } \\
\text { samplers }\end{array}$ & $\begin{array}{l}\text { Few problems encountered using } \\
\text { sampler }\end{array}$ & $\begin{array}{l}\text { Records from } \\
\text { demonstration }\end{array}$ & Future \\
\hline $\begin{array}{l}\text { Mechanical Performance of RGC } \\
\text { sampler }\end{array}$ & Reduced time needed to sample & $\begin{array}{l}\text { Records from } \\
\text { demonstration }\end{array}$ & Future \\
\hline Ease of Use of RGC samplers & $\begin{array}{l}\text { Easy to use, requires little } \\
\text { training }\end{array}$ & $\begin{array}{l}\text { Records from } \\
\text { demonstration }\end{array}$ & Future \\
\hline \multicolumn{4}{|c|}{$\begin{array}{l}\text { PRIMARY CRITERIA (Performance Objectives) } \\
\text { (Quantitative) }\end{array}$} \\
\hline $\begin{array}{l}\text { Reduced purge water with passive } \\
\text { samplers }\end{array}$ & $\begin{array}{l}\text { Document purge volume and } \\
\text { disposal time }\end{array}$ & $\begin{array}{l}\text { Records from } \\
\text { demonstration }\end{array}$ & Future \\
\hline $\begin{array}{l}\text { Equivalent analyte recovery for Snap } \\
\text { Sampler \& low-flow samples }\end{array}$ & $\begin{array}{l}\text { Analyte concentrations equivalent } \\
\text { between sampling methods }\end{array}$ & $\begin{array}{l}\text { Statistical } \\
\text { analyses, RPDs }\end{array}$ & Future \\
\hline $\begin{array}{l}\text { Equivalent analyte recovery for RGC } \\
\text { samplers \& Low-flow samples }\end{array}$ & Analyte concentrations equivalent & $\begin{array}{l}\text { Statistical } \\
\text { analyses, RPDs }\end{array}$ & Future \\
\hline $\begin{array}{l}\text { Equivalent analyte selectivity of } \\
\text { Snap Sampler }\end{array}$ & $\begin{array}{l}\text { Samplers can recover same } \\
\text { analytes as low-flow sampling }\end{array}$ & $\begin{array}{l}\text { Compile analyses } \\
\text { of performance } \\
\text { criteria }\end{array}$ & Future \\
\hline $\begin{array}{l}\text { Equivalent analyte selectivity of RGC } \\
\text { samplers }\end{array}$ & $\begin{array}{l}\text { Samplers can recover same } \\
\text { analytes as low-flow sampling }\end{array}$ & $\begin{array}{l}\text { Compile analyses } \\
\text { of performance } \\
\text { criteria }\end{array}$ & Future \\
\hline \multicolumn{4}{|l|}{$\begin{array}{l}\text { SECONDARY PERFORMANCE CRITERIA } \\
\text { (Qualitative) }\end{array}$} \\
\hline $\begin{array}{l}\text { Scale-up considerations for the Snap } \\
\text { Sampler }\end{array}$ & $\begin{array}{l}\text { Determine any scale-up } \\
\text { constraints for this sampler }\end{array}$ & $\begin{array}{l}\text { Based upon } \\
\text { records \& } \\
\text { analyses }\end{array}$ & Future \\
\hline $\begin{array}{l}\text { Scale-up constraints for RGC } \\
\text { samplers }\end{array}$ & $\begin{array}{l}\text { Determine any scale-up } \\
\text { constraints for this sampler }\end{array}$ & $\begin{array}{l}\text { Based upon } \\
\text { records \& } \\
\text { analyses }\end{array}$ & Future \\
\hline \multicolumn{4}{|l|}{$\begin{array}{l}\text { SECONDARY PERFORMANCE CRITERIA } \\
\text { (Quantitative) }\end{array}$} \\
\hline $\begin{array}{l}\text { Equivalent analyte recovery for Snap } \\
\text { Sampler \& RGC samplers }\end{array}$ & $\begin{array}{l}\text { Analyte concentrations equivalent } \\
\text { between sampling methods }\end{array}$ & $\begin{array}{l}\text { Statistical } \\
\text { analyses, RPDs }\end{array}$ & Future \\
\hline
\end{tabular}


Data quality procedures outlined in the project QAPP were followed for sampling and analyses. These procedures included using the EPA's lowflow purging and sampling protocol and the EPA's standard analytical methods. Equipment blanks were collected prior to their deployment in the field. To insure data validity, standard laboratory procedures for sample handling and analyses (as outlined in the QAPP) were strictly followed including the use of certified reference samples and certified reference standards. All data was reviewed by the laboratory supervisor to ensure that all calculations were correct and to detect any transcription errors. Any issues (including lack of agreement with reference samples) were to be reported to the PI immediately but there were not any incidents that needed to be reported.

Standard QC samples were taken at each site including field and laboratory duplicate samples, duplicates for spiked recoveries by the lab (to determine matrix affects including matrix spikes and matrix spike duplicates), laboratory blanks, and trip blanks. Laboratory duplicates give a measure of the precision of the laboratory and the related analytical methods. The results from the analyses of duplicate field samples provide a measure of the precision (repeatability) of the field sampling methods. Matrix Spikes and Matrix Spike Duplicates samples help identify matrix effects on spiked analytes of known quantity, as well as the laboratory's precision in recognizing matrix effects. The results of these analyses are detailed in sections 3.5.7.4 and 3.7.5.5.

Standard statistical analyses were used to evaluate the concentration data generated by each sampling method. These methods are given in more detail below.

\subsection{Data analysis, interpretation and evaluation}

Standard statistical analyses were used to determine if there were statistically significant differences between the concentrations of the inorganic analytes in samples collected using the Snap Sampler, the RGC sampler, and low-flow purging and sampling. In all cases, these analyses were conducted on an analyte-by-analyte basis. Analytes with measurable concentrations that allowed statistical analyses included As, Ca, Fe, Mg, Mn, K, and $\mathrm{Na}$. In the few instances where analyte concentrations were below the detection limit, half the detection limit was used in the statistical analyses. 
In instances where the data were normally distributed and the variances were homogenous, a Repeated Measures Analysis of Variance (RMANOVA) test was used. If the data were not normally distributed and/or the variances were not homogeneous, the data were log transformed and retested for normality and homogeneity. If the log-transformed data met the requirements for normality and homogeneity, then the logtransformed data were tested using the RM-ANOVA test. If neither the raw data nor the log-transformed data met the requirements for normality and homogeneity, then a Freidman Repeated Measures Analysis of Variance on Ranks test was used.

Filtered and unfiltered samples were analyzed separately. Specifically, analyte concentrations in the filtered Snap Sampler samples, the filtered low-flow samples, and the RGC samplers were compared. Concentrations in the unfiltered Snap Sampler samples, the unfiltered low-flow samples, and the RGC samples were also compared.

\subsection{Findings from the field demonstration}

The purpose of this field demonstration was to determine if the Snap Sampler recovered samples with equivalent concentrations of inorganic analytes to those recovered in samples collected using low-flow purging and sampling. In addition, we also wanted to examine the relationship between analyte concentrations of metals in samples collected using the Snap Sampler, low-flow sampling, and a diffusion sampler (i.e., the RGC sampler). We anticipated that the concentrations of metals in whole water samples (collected either with the Snap Sampler or low-flow sampling) would most likely be higher than concentrations in a diffusion sampler (which would be naturally filtered by the membrane) if colloidal transport was significant in these wells.

The various types of metals that were found in measurable concentrations in these wells included: $\mathrm{Ca}, \mathrm{Fe}, \mathrm{Mg}, \mathrm{Mn}, \mathrm{K}$, and $\mathrm{Na}$. These analytes typically occur as cations in groundwater. In addition, these wells contained measurable concentrations of As which is usually present as an anion in ground water.

Given that there were not large differences in analyte concentrations with depth in these wells, we would predict that we would not expect to find large differences between analyte concentrations in the Snap Sampler samples vs. those collected using low-flow purging and sampling. 


\subsubsection{Sampler performance and safety issues}

For the Snap Sampler there was no purge water or other waste water than had to be disposed of. For the RGC sampler, there also was no purge water to dispose of but there were small amounts of residual sample water that required disposal.

Generally, the Snap Samplers performed well by triggering on demand and providing full samples. Out of the 41 samples collected, there were four instances when one of the caps did not seal properly because the o-ring did not seat properly. In instances where the o-ring was on the bottom of the sampler, there was leakage of some of the sample as it was withdrawn from the well. In two cases, there was excessive sediment in the samples; these particles may have prevented the o-rings from seating properly. Later, the laboratory discovered that two bottles had pinhole leaks in the seam and there was some loss of sample during shipping and storage. (These bottles were returned to the developer after the sampling was complete so that they could be examined. The developer has since changed the polymer that the bottles are made out of from PP to HDPE, which has better weld properties.) There also was one instance where we found the top cap of one of the samplers deployed prematurely, and there was one instance during deployment where the ball connector had pulled off the trigger line. In these instances the samplers had to be redeployed. Because there were issues with some of the samples collected, we would recommend deploying an additional bottle as insurance.

There are no moving parts on the RGC samplers so the only problems that might occur would be tearing, causing loss of the sampler or degradation of the membrane. However, no problems were encountered during this demonstration.

With respect to safety issues, there were no injuries related to using any of the three sampling technologies. Generally, there were fewer safety concerns with the passive samplers. For the RGC sampler, possible issues include spilling acid from the sample bottle, and exposure to the sample's contaminants during transfer or during disposal. There are also relatively few issues with using the Snap Sampler. These include, injury from piercing the septum (to add acid to the sample bottle), spilling acid while adding acid to the sample bottle, and exposure to the sample's contaminants if transferring the sample to another container. In contrast, for low-flow sampling there numerous safety concerns. These include electrical con- 
cerns with using the sampling equipment (especially in the rain); spillage and fire hazards associated with working with gasoline and running a generator; possible burns from generator's muffler; strained or pulled muscles from moving heavy equipment in and out of the vehicle; prolonged exposure to the sample's contaminants during purging, sampling, and waste disposal; spilling acid from the sample bottles; and tripping over electrical cords.

\subsubsection{Sampling time and personnel requirements}

The sampling time for both the Snap Sampler and the RGC sampler was considerably less than that needed for low-flow sampling. We also determined that, during normal sampling events, the sampling time the Snap Sampler would be less than that for the RGC sampler. This is because only one trip to the field would be needed for the Snap Sampler whereas the RGC sampler would require two trips to the field; one to deploy the sampler and one to recover the sampler. In contrast, a new Snap Sampler can be deployed in the well at the end of a sampling event and left in the well until the next sampling event. Time savings are given in more detail in costs (Section 5).

For both the Snap and RGC samplers, sampling can be easily accomplished with one individual. While one individual can also conduct lowflow sampling, generally a field crew of two is preferred. These differences also figure into the cost of the sampling methods (see Section 5).

With respect to the training time needed to become proficient with the sampling method, the Snap Sampler required a longer training time than did the RGC sampler. For the Snap Sampler, it takes several minutes of training and some practice to become proficient. In contrast, there is not much to learn to deploy the RGC sampler. With respect to constructing the RGC samplers, the guidance on their construction was easy to follow. The only issue that we encountered was that there was no guidance about what width of dialysis tubing or diameter of support tubing to order. Also, for the size of the dialysis tubing, the manufacturer only lists the flat width of the tubing. Therefore, it is important to calculate correctly the diameter of dialysis tubing so that the support tubing will fit inside the dialysis membrane. 


\subsubsection{Analyte recovery}

The findings for this study can be found in Table 20. Generally, concentrations of the analytes in the Snap Sampler were equivalent to those found using low-flow sampling.

Table 20. Findings from the field study.

\begin{tabular}{|c|c|c|c|c|c|c|c|}
\hline \multirow[t]{2}{*}{ Analyte } & \multirow[t]{2}{*}{ Well } & \multicolumn{3}{|c|}{$\begin{array}{c}\text { Filtered Samples } \\
\text { Mean Concentration (mg/L) }\end{array}$} & \multicolumn{3}{|c|}{$\begin{array}{c}\text { Unfiltered Samples } \\
\text { Mean Concentration (mg/L) }\end{array}$} \\
\hline & & Low-flow & RGC & Snap & Low-flow & RGC & Snap \\
\hline \multirow{10}{*}{ As } & $13-5045$ & 0.097 & 0.16 & 0.12 & 0.16 & 0.16 & 0.16 \\
\hline & 13-6095 & 0.044 & 0.059 & 0.054 & 0.056 & 0.059 & 0.058 \\
\hline & $32-5020$ & 0.074 & 0.15 & 0.053 & 0.15 & 0.15 & 0.15 \\
\hline & $32-5020$ & 0.068 & 0.094 & 0.045 & 0.11 & 0.094 & 0.10 \\
\hline & $32-5031$ & 0.031 & 0.11 & 0.024 & 0.063 & 0.11 & 0.13 \\
\hline & $32-5076$ & 0.026 & 0.062 & 0.019 & 0.054 & 0.062 & 0.051 \\
\hline & $32-6008$ & 0.051 & 0.055 & 0.041 & 0.059 & 0.055 & 0.069 \\
\hline & 32-6064 & 0.060 & 0.092 & 0.022 & 0.095 & 0.092 & 0.14 \\
\hline & 32-6064 & 0.070 & 0.10 & 0.043 & 0.093 & 0.10 & 0.11 \\
\hline & 32-6135 & 0.025 & 0.023 & 0.027 & 0.023 & 0.023 & 0.027 \\
\hline As & Mean & $0.055^{a}$ & $0.091^{b}$ & $0.045^{a}$ & $0.086^{c}$ & $0.091^{\circ}$ & 0.100 \\
\hline \multirow{10}{*}{$\mathrm{Ca}$} & $13-5045$ & 69 & 71 & 70 & 72 & 71 & 66 \\
\hline & 13-6095 & 43 & 43 & 42 & 42 & 43 & 41 \\
\hline & $32-5020$ & 230 & 250 & 230 & 230 & 250 & 190 \\
\hline & $32-5020$ & 140 & 130 & 150 & 150 & 130 & 150 \\
\hline & $32-5031$ & 72 & 86 & 93 & 75 & 86 & 97 \\
\hline & $32-5076$ & 62 & 58 & 60 & 58 & 58 & 53 \\
\hline & $32-6008$ & 97 & 98 & 96 & 98 & 98 & 100 \\
\hline & 32-6064 & 170 & 170 & 170 & 170 & 170 & 180 \\
\hline & 32-6064 & 110 & 110 & 110 & 110 & 110 & 110 \\
\hline & 32-6135 & 4.5 & 4.4 & 4.6 & 4.3 & 4.4 & 5.1 \\
\hline $\mathrm{Ca}$ & Mean & $100^{a}$ & $102^{a}$ & $103^{a}$ & $101^{c}$ & $102^{c}$ & $99.0^{c}$ \\
\hline \multirow[t]{7}{*}{$\mathrm{Fe}$} & $13-5045$ & 9.1 & 14 & 9.4 & 15 & 14 & 14 \\
\hline & $13-6095$ & 1.5 & 3.1 & 2.4 & 3.3 & 3.1 & 3.7 \\
\hline & $32-5020$ & $<0.05$ & 4.4 & $<0.05$ & 5.0 & 4.4 & 13 \\
\hline & $32-5020$ & $<0.05$ & 2.6 & 0.14 & 3.6 & 2.6 & 4.1 \\
\hline & 32-5031 & $<0.05$ & 9.0 & $<0.05$ & 4.4 & 9.0 & 20 \\
\hline & $32-5076$ & $<0.05$ & 4.4 & $<0.05$ & 2.3 & 4.4 & 6.3 \\
\hline & $32-6008$ & $<0.05$ & 0.79 & $<0.05$ & 0.62 & 0.79 & 1.4 \\
\hline
\end{tabular}




\begin{tabular}{|c|c|c|c|c|c|c|c|}
\hline \multirow[t]{2}{*}{ Analyte } & \multirow[t]{2}{*}{ Well } & \multicolumn{3}{|c|}{$\begin{array}{c}\text { Filtered Samples } \\
\text { Mean Concentration (mg/L) }\end{array}$} & \multicolumn{3}{|c|}{$\begin{array}{c}\text { Unfiltered Samples } \\
\text { Mean Concentration (mg/L) }\end{array}$} \\
\hline & & Low-flow & RGC & Snap & Low-flow & RGC & Snap \\
\hline & $32-6064$ & $<0.05$ & 1.8 & $<0.05$ & 1.8 & 1.8 & 4.5 \\
\hline & 32-6064 & $<0.05$ & 2.1 & $<0.05$ & 1.8 & 2.1 & 2.6 \\
\hline & $32-6135$ & $<0.05$ & 0.25 & $<0.05$ & 0.26 & 0.25 & 4.5 \\
\hline $\mathrm{Fe}$ & Mean & $1.1^{\mathrm{a}}$ & $4.2^{b}$ & $1.2^{a}$ & $3.8^{c}$ & $4.2^{\mathrm{c}}$ & $7.4^{d}$ \\
\hline \multirow{10}{*}{$\mathrm{Mg}$} & $13-5045$ & 12 & 12 & 13 & 12 & 12 & 12 \\
\hline & $13-6095$ & 8.1 & 7.7 & 8 & 7.6 & 7.7 & 7.5 \\
\hline & $32-5020$ & 53 & 52 & 53 & 53 & 52 & 47 \\
\hline & $32-5020$ & 38 & 36 & 40 & 36 & 36 & 41 \\
\hline & $32-5031$ & 18 & 21 & 22 & 18 & 21 & 25 \\
\hline & $32-5076$ & 13 & 13 & 13 & 13 & 13 & 12 \\
\hline & 32-6008 & 35 & 34 & 33 & 34 & 34 & 33 \\
\hline & 32-6064 & 49 & 52 & 51 & 52 & 52 & 50 \\
\hline & 32-6064 & 43 & 40 & 38 & 38 & 40 & 36 \\
\hline & 32-6135 & 1.9 & 1.8 & 1.9 & 1.8 & 1.8 & 2.2 \\
\hline $\mathrm{Mg}$ & Mean & $27^{a}$ & $27^{a}$ & $27^{a}$ & $27^{c}$ & $27^{c}$ & $27^{c}$ \\
\hline & & & & & & & \\
\hline \multirow{10}{*}{$\mathrm{Mn}$} & $13-5045$ & 8.0 & 7.8 & 7.8 & 7.3 & 7.8 & 7.4 \\
\hline & $13-6095$ & 8.0 & 7.9 & 7.8 & 7.9 & 7.9 & 7.7 \\
\hline & $32-5020$ & 0.70 & 0.71 & 0.70 & 0.71 & 0.71 & 0.77 \\
\hline & $32-5020$ & 0.43 & 0.44 & 0.49 & 0.46 & 0.44 & 0.54 \\
\hline & $32-5031$ & 0.23 & 0.46 & 0.44 & 0.23 & 0.46 & 0.75 \\
\hline & $32-5076$ & 0.53 & 0.56 & 0.53 & 0.52 & 0.56 & 0.55 \\
\hline & $32-6008$ & 0.22 & 0.22 & 0.21 & 0.22 & 0.22 & 0.22 \\
\hline & 32-6064 & 0.37 & 0.41 & 0.38 & 0.37 & 0.41 & 0.44 \\
\hline & $32-6064$ & 0.20 & 0.21 & 0.21 & 0.20 & 0.21 & 0.21 \\
\hline & $32-6135$ & 0.018 & 0.024 & 0.022 & 0.024 & 0.024 & 0.13 \\
\hline $\mathrm{Mn}$ & Mean & $1.9^{a}$ & $1.9^{a}$ & $1.9^{a}$ & $1.8^{c}$ & $1.9^{c}$ & $1.9^{c}$ \\
\hline \multirow[t]{8}{*}{$\mathrm{K}$} & $13-5045$ & 2.8 & 2.7 & 2.7 & 2.8 & 2.7 & 2.6 \\
\hline & $13-6095$ & 1.6 & 1.6 & 1.6 & 1.5 & 1.6 & 1.5 \\
\hline & $32-5020$ & 8.6 & 8.4 & 8.6 & 8.8 & 8.4 & 8.7 \\
\hline & $32-5020$ & 7.1 & 6.4 & 7 & 7.1 & 6.4 & 7.6 \\
\hline & $32-5031$ & 5.3 & 4.6 & 4.8 & 5.4 & 4.6 & 6.8 \\
\hline & $32-5076$ & 4.0 & 3.8 & 3.9 & 3.8 & 3.8 & 4.0 \\
\hline & $32-6008$ & 10 & 9.8 & 10 & 10 & 9.8 & 10 \\
\hline & $32-6064$ & 11 & 12 & 11 & 11 & 12 & 12 \\
\hline
\end{tabular}




\begin{tabular}{|c|c|c|c|c|c|c|c|}
\hline \multirow[t]{2}{*}{ Analyte } & \multirow[t]{2}{*}{ Well } & \multicolumn{3}{|c|}{$\begin{array}{c}\text { Filtered Samples } \\
\text { Mean Concentration (mg/L) }\end{array}$} & \multicolumn{3}{|c|}{$\begin{array}{c}\text { Unfiltered Samples } \\
\text { Mean Concentration (mg/L) }\end{array}$} \\
\hline & & Low-flow & RGC & Snap & Low-flow & RGC & Snap \\
\hline & $32-6064$ & 9.8 & 9.7 & 9.2 & 9.0 & 9.7 & 8.9 \\
\hline & $32-6135$ & 8.2 & 8.4 & 8.3 & 7.9 & 8.4 & 8.2 \\
\hline K & Mean & $6.8^{a}$ & $6.7^{a}$ & $6.7^{a}$ & $6.7^{c}$ & $6.7^{\circ}$ & $7.0^{c}$ \\
\hline \multirow{10}{*}{$\mathrm{Na}$} & $13-5045$ & 120 & 98 & 99 & 140 & 98 & 88 \\
\hline & $13-6095$ & 15 & 14 & 14 & 14 & 14 & 14 \\
\hline & $32-5020$ & 73 & 72 & 72 & 72 & 72 & 62 \\
\hline & $32-5020$ & 57 & 54 & 62 & 56 & 54 & 62 \\
\hline & $32-5031$ & 59 & 34 & 34 & 60 & 34 & 32 \\
\hline & $32-5076$ & 27 & 26 & 27 & 26 & 26 & 23 \\
\hline & $32-6008$ & 99 & 92 & 94 & 95 & 92 & 91 \\
\hline & $32-6064$ & 68 & 69 & 70 & 71 & 69 & 68 \\
\hline & $32-6064$ & 61 & 58 & 55 & 53 & 58 & 55 \\
\hline & $32-6135$ & 160 & 160 & 160 & 180 & 160 & 170 \\
\hline $\mathrm{Na}$ & Mean & $74^{a}$ & $68^{b}$ & $69^{a, b}$ & $77^{c}$ & $68^{c}$ & $67^{c}$ \\
\hline
\end{tabular}

\subsubsection{Total analyte concentrations (unfiltered samples)}

There were no statistically significant differences in the concentrations of these analytes between the low-flow samples vs. the RGC samples or the Snap Sampler samples with one exception, and that is the Fe levels in the Snap Sampler. We believe that exception occurred for two reasons: (1) the small pore size of ( $18 \AA$ or $1.8 \times 10^{-3} \mu$ ) of the cellulose membrane prevented all but the very smallest of colloidal particles from entering the RGC sampler and (2) the low-flow and Snap Sampler samples were whole water samples. These findings indicate that colloidal transport of this contaminant is not a predominant transport mechanism at this site.

We believe that the Fe concentrations in the Snap Sampler represented the conditions in the well at the time of sampling and are an indication of the higher levels of particulates present in the well at the time of sampling. We believe that placing the baffles and additional sampling equipment in the well (i.e., the pump, Snap and RGC samplers, and bottle weight) acted as a surge block in the well and elevated turbidity and oxygen levels (which caused oxidation/precipitation reactions to occur with the iron in the 
well), and thereby falsely elevated concentrations of Fe. (When we placed the equipment in the wells, we actually heard a sound similar to a plunger in a toilet bowl.) Apparently some of the wells never fully recovered, even after leaving this equipment in the wells for two weeks.

Although we did not measure the turbidity in the Snap Sampler samples ${ }^{8}$, the initial turbidity values at the start of low-flow sampling (Table 21) indicated that, generally, turbidity was considerably less during the preliminary round of sampling than it was during the field demonstration. This supports our hypothesis that deploying all this equipment in the well elevated the turbidity. The most affected wells included 32-5020, 32-5031, and 32-5076. We discuss this in more detail in Section 4.4.3.4which provides an analysis of data on a well-by-well basis.

\subsubsection{Dissolved analytes (filtered samples)}

For the filtered samples, there were no statistically significant differences between the analyte concentrations in the Snap Sampler samples and the low-flow samples for any of the analytes. There also was not a statistically significant difference between the concentrations of $\mathrm{Ca}, \mathrm{Mg}, \mathrm{Mn}$ and $\mathrm{K}$ in the RGC samples compared with the filtered low-flow samples. However, there was a statistically significant difference between the concentrations of As, Fe, and Na in the RGC samples and the filtered, low-flow samples; concentrations of As and Fe were higher and concentrations of Na were lower in the RGC samples. These anomalies can best be understood by comparing the concentrations in the filtered and unfiltered low-flow samples.

Table 21. Purge times and turbidity values ${ }^{*}$ for low-flow sampling during the initial sampling and the field demonstration.

\begin{tabular}{|l|c|c|c|c|c|c|c|c|c|c|c|}
\hline \multicolumn{10}{|c|}{ Initial sampling } \\
\hline Well No. & $32-6064$ & $32-6064$ & $32-5020$ & $32-5020$ & $32-5031$ & $32-5076$ & $32-6135$ & $13-5045$ & $32-6008$ & $13-6095$ \\
\hline Pump No. & 2291 & 2291 & 2269 & 2269 & 1470 & 2271 & 2270 & 2292 & 1472 & 1400 \\
\hline Purge time (minutes) & 88 & & 37 & & 61 & 79 & 91 & 61 & 63 & 50 \\
\hline Initial turbidity & 2 & & 4 & & 14 & 11 & 27 & 8 & 31 & 9 \\
\hline Final turbidity & 1 & & 4 & & 11 & 8 & 20 & 8 & 32 & 11 \\
\hline
\end{tabular}

8 This can be done by collecting an additional sampler and then measuring the sample with a turbidity meter. 


\begin{tabular}{|l|c|c|c|c|c|c|c|c|c|c|}
\hline \multicolumn{10}{|c|}{ Field demonstration } \\
\hline Well No. & $32-6064$ & $32-6064$ & $32-5020$ & $32-5020$ & $32-5031$ & $32-5076$ & $32-6135$ & $13-5045$ & $32-6008$ & $13-6095$ \\
\hline Round & 1 & 2 & 1 & 2 & & & & & & \\
\hline Purge time (minutes) & 99 & 86 & 62 & 223 & 121 & 214 & 81 & 81 & 63 & 93 \\
\hline Initial turbidity & 15 & 7 & 40 & 11 & 490 & 38 & 22 & 11 & 9 & 14 \\
\hline Final turbidity & 5 & 4 & $42 * *$ & $26 * *$ & 11 & 20 & $6.5^{*}$ & 9 & 9 & 7 \\
\hline
\end{tabular}

* All turbidity values taken with Horiba probe unless noted otherwise. Value measured with LaMotte turbidity meter.

** Issues with meter and with particles collecting in flow-through cell.

\subsubsection{Comparing the filtered vs. unfiltered low-flow samples}

When the low-flow filtered samples were compared with the low-flow unfiltered samples, there was a statistically significant difference between the treatments for As and Fe, but not for the other cations. If colloidal transport is not responsible for these differences (as shown previously), then the filtered samples must have a falsely low bias. Since these samples were filtered in the laboratory, it is reasonable to assume that there were losses of iron due to the precipitation of hydrous iron oxides that occurred during shipping and storage (prior to filtration) and that the losses of the As anion resulted from co-precipitation with the hydrous iron oxides. Several studies (Korte and Fernando 1991; Korte et al. 1976; Jenne 1968) have shown that anions are more readily removed by iron oxides than cations, and that the most important mechanism for the accumulation of arsenic in sediment is adsorption on and coprecipitation with hydrous iron oxides (Aggett and O’Brien 1985; Aggett and Roberts 1986 [as given by Mok and Wai 1990]; Korte 1991). The findings between the filtered and unfiltered Snap Sampler samples were also similar.

Initially, we had considered using in-line filtration for the low-flow samples. However, the Snap Sampler samples could not be filtered using an inline filter, and we wanted to use the same filtration equipment for both sampling methods. We considered filtering the samples in the field using a suction or hand filtration apparatus, but were concerned that this might add more bias than simply shipping the samples to the laboratory for filtration. Given our findings, field filtration of the samples would have been prudent because the sample handling clearly affected filtered concentrations of both Fe and As. 


\subsubsection{Well-by-well comparisons using unfiltered sample data}

While the statistical analyses clearly indicate there is no consistent (significant) bias associated with using the Snap Sampler when compared with low-flow purging and sampling (for any of the analytes except unfiltered iron), we also examined the unfiltered data on a well-by-well basis to see if there were any wells where there appeared to be a large difference in the results for the different sampling methods.

The flow testing showed that for four of the wells (32-6008, 32-6064, 136095, and 32-5076), there was a significant contribution from one portion of the well under pumped conditions, but there was no vertical flow under ambient conditions. We expected that we might find poor agreement between the concentrations in the Snap Sampler vs. the pumped samples for those wells if there also was a concentration gradient in those wells. For two of those wells, 32-5076 (10-ft screen) and 32-6008 (14-ft screen), there was no apparent concentration gradient with depth, so we would not expect any difference with these wells. For the other two wells, there was a concentration gradient for some analytes with depth. For well 13-6095 (10-ft screen), the concentrations of As and Fe were slightly higher ( 2x) in the shallow portion of the well screen. The findings for well 32-6064 (10-ft screen) were similar, with slightly larger differences in concentrations ( $\sim 3 \mathrm{x}$ for As and 10x for Fe). However, there was excellent agreement between the analyte concentrations in the low-flow samples vs. the Snap Sampler samples in those wells.

In contrast, the wells with perhaps the poorest agreement between the concentrations in the unfiltered samples taken with the Snap Sampler vs. low-flow sampling were well numbers 32-6135 and 32-5031. For well 326135 , in the Snap Sampler, the concentration of Fe was $\sim 10 x$ higher and the Mn concentration was $\sim 5 x$ higher. For Well 32-5031 in the Snap Sampler, there were higher concentrations of three analytes (As, Fe, and Mn); specifically, As was 2x higher, Fe was 5x higher, and Mn concentrations were $\sim 3 x$ higher. Both of these wells are stainless steel wells. (The other six wells were made with PVC casing and screen.) Although we might expect Fe and Mn concentrations to be higher in stainless steel wells as a result of leaching (Parker, Hewitt, and Jenkins 1990; Hewitt 1989, 1992, 1994), arsenic is not a component of stainless steel so there is no reason to expect elevated concentrations of As in these wells. Thus, we suspect that much of these elevated concentrations of analytes resulted from higher turbidities in these wells. Higher turbidities may be the result of installation of all the 
sampling equipment in the well (as mentioned previously), from poor well-construction methods, or from degradation (corrosion) of the well screens, resulting in an increased slot size. (The improper selection of the slot size of the screen and/or the grain size of the filter pack can result in larger fines entering a well.) We were not able to successfully redevelop well 32-6135. Thus, this may be an example of a well with an elevated native turbidity that resulted from poor well construction design or degradation of the screen. In contrast, well 32-5031 appears to have been dramatically affected by the installation of all the equipment in the well; the initial low-flow turbidity reading for this well was $35 \mathrm{x}$ higher in this sampling event than it was in the preliminary sampling round (Table 21). As mentioned previously, agitating the well can result in coprecipitation of the As, which would explain the elevated concentration of this analyte in this well.

Other wells where there were elevated Fe levels included numbers 325076, 32-5020, and 32-6064. These wells also appear to have been affected by the installation of the sampling equipment in the well as the initial turbidity reading for these sampling events were 2-10x higher than during the preliminary sampling round (Table 21).

Generally, in the RGC samplers concentrations of Fe were similar to those found in the low-flow samples, except for wells 32-5031 and 32-5076, where the concentrations of Fe were elevated but not as much as the concentrations found in the Snap Sampler. Concentrations of As and Mn were also similarly elevated in the RGC samples from well 32-5031. These data support the hypothesis that the Snap Sampler concentrations were elevated because of higher turbidities in these wells.

In contrast to the occasionally higher concentrations of other analytes found in the Snap Sampler, lower concentrations of unfiltered Na were found in the Snap Sampler samples collected from wells 32-5031 and 135045, where concentrations were approximately one-half those found in the low-flow samples. This may be because low-flow pumping brought in more saline water from the surrounding estuary. These were the two shallowest wells.

Again, for most of the analytes from most wells, there was close agreement between concentrations of inorganic analytes in both the Snap Sampler samples and the low-flow samples. The one analyte where we did observe a statistically significant difference was unfiltered Fe where the concentra- 
tions were higher in the Snap Sampler. These levels appear to reflect the turbidity of the well at the time of sampling and for most of the wells it appears that the disturbance caused by adding the baffle and other sampling equipment to the well was responsible for these elevated levels.

Subsequent studies should examine: (a) whether the Snap Sampler raises turbidity in wells under normal deployment conditions (i.e., without the baffle and the other equipment used this study) (b) if so, which types of wells are affected, and (c) whether analyte concentrations in shallow wells are more apt to be affected by the sampling method (i.e., pumping vs. passive). 


\section{Cost Results}

\subsection{Cost reporting}

The cost models that were used for estimating the cumulative quarterly sampling costs over a 10-year period are given in Table 22 for the Snap Sampler, Table 23 for the low-flow purging and sampling, and Table 24 for the RGC sampler. These models include the costs associated with initial startup, the materials needed for sampling (including both equipment and consumables), equipment installation, labor costs, and inflation.

Table 22. Cost model for the Snap Sampler: 10-yr period, with quarterly sampling.

\begin{tabular}{|c|c|c|c|}
\hline Cost Element & $\begin{array}{l}\text { Data Tracked During } \\
\text { the Demonstration }\end{array}$ & Details & Cost (\$) \\
\hline Initial Startup & $\begin{array}{l}\text { Planning fieldwork, equipment, } \\
\text { supplies, and personnel }\end{array}$ & Project Technician (1) & $\$ 60 / \mathrm{hr}$ \\
\hline Materials & Equipment \& consumables & $\begin{array}{l}\text { Snap Sampler lines, holders, } \\
\text { trigger mechanism, bottles, } \\
\text { etc. }\end{array}$ & $\begin{array}{l}\text { purchase } \\
\text { price }\end{array}$ \\
\hline \multirow{2}{*}{ Installation } & First-time sampler deployment & Project Technician (1) & $\$ 60 / \mathrm{hr}$ \\
\hline & Materials & Supplies & $\begin{array}{l}\text { purchase } \\
\text { price }\end{array}$ \\
\hline \multirow{2}{*}{$\begin{array}{l}\text { Quarterly } \\
\text { Sampling }\end{array}$} & $\begin{array}{l}\text { Quarterly sampling, redeployment of } \\
\text { new samplers, \& clean up }\end{array}$ & Project Technician (1) & $\$ 60 / \mathrm{hr}$ \\
\hline & Materials & $\begin{array}{l}\text { Replacement sampler } \\
\text { bottles, etc. }\end{array}$ & $\begin{array}{l}\text { purchase } \\
\text { price }\end{array}$ \\
\hline \multirow{13}{*}{$\begin{array}{l}\text { Long-term } \\
\text { Monitoring }\end{array}$} & \multirow{3}{*}{ Total Costs } & After Year 1, no inflation & \\
\hline & & After 5 years, no inflation & \\
\hline & & After 10 Years, no inflation & \\
\hline & $\begin{array}{l}\text { Cumulative Costs, assuming OMB's } \\
2.2 \% \text { annual inflation average: } \\
\text { After Year } 1\end{array}$ & $\begin{array}{l}\text { Yearly sampling costs } \\
+ \text { cumulative inflation }\end{array}$ & Total Costs \\
\hline & After Year 2 & & \\
\hline & After Year 3 & & \\
\hline & After Year 4 & & \\
\hline & After Year 5 & & \\
\hline & After Year 6 & & \\
\hline & After Year 7 & & \\
\hline & After Year 8 & & \\
\hline & After Year 9 & & \\
\hline & After Year 10 & & \\
\hline
\end{tabular}


Table 23. Cost model for low-flow sampling: 10-yr period, with quarterly sampling.

\begin{tabular}{|c|c|c|c|}
\hline Cost Element & $\begin{array}{l}\text { Data Tracked During the } \\
\text { Demonstration }\end{array}$ & Details & Cost (\$) \\
\hline Initial Startup & $\begin{array}{l}\text { Planning fieldwork, equipment, } \\
\text { supplies, personnel, etc. }\end{array}$ & Project Technician (1) & $\$ 60 / \mathrm{hr}$ \\
\hline Materials & Equipment \& consumables & $\begin{array}{l}\text { Bladder pumps, tubing, } \\
\text { controller, generator, air } \\
\text { compressor, air hose, etc.; Purge } \\
\text { parameter equipment, } \\
\text { calibration standards, etc.; } \\
\text { Decon equipment. }\end{array}$ & $\begin{array}{l}\text { Purchase } \\
\text { price }\end{array}$ \\
\hline \multirow[b]{2}{*}{ Installation } & \multirow[b]{2}{*}{ First-time equipment deployment } & Project Technician (2) & $\$ 120 / \mathrm{hr}$ \\
\hline & & Supplies & $\begin{array}{l}\text { Purchase } \\
\text { price }\end{array}$ \\
\hline \multirow[b]{2}{*}{$\begin{array}{l}\text { Quarterly } \\
\text { Sampling Costs }\end{array}$} & \multirow{2}{*}{$\begin{array}{l}\text { Quarterly sampling \& clean up: } \\
\text { including field set up, purge } \\
\text { stabilization, sampling time, sample } \\
\text { preparation, decon of equipment, } \\
\text { purge water disposal, breakdown of } \\
\text { field site }\end{array}$} & Project Technician (2) & $\$ 120 / \mathrm{hr}$ \\
\hline & & $\begin{array}{l}\text { Supplies, standards for purge } \\
\text { parameters, DI water for decon, } \\
\text { gasoline, etc. }\end{array}$ & $\begin{array}{l}\text { Purchase } \\
\text { price }\end{array}$ \\
\hline \multirow{14}{*}{$\begin{array}{l}\text { Long-term } \\
\text { Monitoring }\end{array}$} & \multirow{3}{*}{ Total costs, no inflation } & After Year 1 & \\
\hline & & After Year 5 & \\
\hline & & After Year 10 & \\
\hline & $\begin{array}{l}\text { Cumulative Costs, assuming OMB's } \\
2.2 \% \text { annual inflation avg. }\end{array}$ & $\begin{array}{l}\text { Yearly sampling costs } \\
+ \text { cumulative inflation }\end{array}$ & Total Costs \\
\hline & After Year 1 & & \\
\hline & After Year 2 & & \\
\hline & After Year 3 & & \\
\hline & After Year 4 & & \\
\hline & After Year 5 & & \\
\hline & After Year 6 & & \\
\hline & After Year 7 & & \\
\hline & After Year 8 & & \\
\hline & After Year 9 & & \\
\hline & After Year 10 & & \\
\hline
\end{tabular}


Table 24. Cost model for the RGC sampler: 10-yr period, with quarterly sampling.

\begin{tabular}{|c|c|c|c|}
\hline Cost Element & $\begin{array}{l}\text { Data Tracked During } \\
\text { the Demonstration }\end{array}$ & Details & Cost $(\$)$ \\
\hline Initial Startup & $\begin{array}{l}\text { Planning fieldwork, equipment, } \\
\text { supplies, personnel, etc. }\end{array}$ & Project Technician (1) & $\$ 60 / \mathrm{hr}$ \\
\hline \multirow{3}{*}{ Materials } & $\begin{array}{l}\text { Equipment \& consumables } \\
\text { (each quarter) }\end{array}$ & $\begin{array}{l}\text { Membrane, support \& } \\
\text { protective mesh, etc. }\end{array}$ & $\begin{array}{l}\text { Purchase } \\
\text { price }\end{array}$ \\
\hline & $\begin{array}{l}\text { One time equipment and } \\
\text { consumables }\end{array}$ & Weights & $\begin{array}{l}\text { Purchase } \\
\text { price }\end{array}$ \\
\hline & Sampler construction (ea. quarter) & Project Technician (1) & $\$ 60 / \mathrm{hr}$ \\
\hline \multirow[b]{2}{*}{ Installation } & \multirow[t]{2}{*}{ Sampler deployment (each quarter) } & Project Technician (1) & $\$ 60 / \mathrm{hr}$ \\
\hline & & $\begin{array}{l}\text { Supplies (ice for samplers, } \\
\text { nitrogen for degassing } \\
\text { samplers, etc.) }\end{array}$ & $\begin{array}{l}\text { Purchase } \\
\text { price }\end{array}$ \\
\hline $\begin{array}{l}\text { Sampler } \\
\text { Retrieval }\end{array}$ & $\begin{array}{l}\text { Sampler retrieval (second trip ea. } \\
\text { quarter); includes: retrieval of } \\
\text { sampler, sample transfer, sample } \\
\text { labeling, site clean up, disposal of } \\
\text { wastes. }\end{array}$ & Project Technician (1) & $\$ 60 / \mathrm{hr}$ \\
\hline \multirow{13}{*}{$\begin{array}{l}\text { Long-term } \\
\text { Monitoring }\end{array}$} & Total Costs & After Year 1 & \\
\hline & & After Year 5 & \\
\hline & & After Year 10 & \\
\hline & $\begin{array}{l}\text { Cumulative Costs, assuming OMB's } \\
2.2 \% \text { annual inflation average } \\
\text { After Year } 1\end{array}$ & $\begin{array}{l}\text { Yearly sampling costs + } \\
\text { cumulative inflation }\end{array}$ & Total Costs \\
\hline & After Year 2 & & \\
\hline & After Year 3 & & \\
\hline & After Year 4 & & \\
\hline & After Year 5 & & \\
\hline & After Year 6 & & \\
\hline & After Year 7 & & \\
\hline & After Year 8 & & \\
\hline & After Year 9 & & \\
\hline & After Year 10 & & \\
\hline
\end{tabular}

\subsection{Cost drivers}

We concluded that the following items comprise the major cost drivers for the Snap Sampler. (Please note that all the values used in this analysis are adjusted for inflation.)

- The number of analytes. The more analytes that need to be sampled, the more Snap Sampler bottles that will be needed, which drives up the cost of sampling. As an example, if we had also sampled for 
VOCs, that would have required adding at least two more samplers to the string of samplers and purchasing two additional VOC bottles per well (plus 10\% QA/QC samples). The estimated savings over 10 years using only Snap Sampler for the inorganic analytes would have been $67 \%$, for an estimated cost of $\sim \$ 296 \mathrm{~K}$. By contrast, the estimated cost savings would have been only $57 \%$ if one had monitored for both VOCs and inorganics, for an estimated 10-year cost of $\$ 390.5 \mathrm{~K}$.

- Sample volume requirements. Large sample volume requirements can also increase the number of sampler bottles used. As an example, if we had to sample for low levels of explosives at this site (instead of inorganics) then we would need $500 \mathrm{~mL}$ of sample. To do this, we would need four 125-mL bottles, rather the two bottles used in this study. The cost savings in this case would be similar to the previous example, $57 \%$ for an estimated 10 -year cost of $\sim \$ 390.5 \mathrm{~K}$.

- Depth of the sampling interval. At this site, the wells were relatively shallow and a manual trigger line could be used. At one of our other sites, the former McClellan AFB, the wells were much deeper and required an electronic trigger. However, the electronic trigger is a onetime cost that is fairly modest when compared with the total cost of sampling. This cost would be divided by the anticipated length of time for long-term monitoring (LTM) and the number of sampling events each year.

- Reconditioning of the wells. It is not known how often the wells will have to be redeveloped or reconditioned. Given time and financial constraints, this is often an issue that currently is disregarded by sampling teams using conventional sampling methods. However, even if one assumed that the wells sampled with the Snap Sampler will need to be reconditioned every 5 years, the estimated cost savings from using this technology would still be over $50 \%$. The projected long-term cost would be $\sim \$ 422 \mathrm{~K}$, with an estimated cost savings of $53.5 \%$ over lowflow sampling (with no well conditioning).

- Replacing Snap Sampler hardware. Given the materials used in the Snap Sampler (mostly rigid plastics), we would not anticipate that the equipment would require replacement during the 10-year deployment period. However, even if the equipment had to be replaced every 5 years, the estimated 10-year monitoring cost using the Snap Sampler would be $\sim \$ 375 \mathrm{~K}$, and the cost savings would still be substantial at $58 \%$ (vs. the initial cost savings of $\sim \$ 296 \mathrm{~K}$, for an estimated cost savings of $67 \%)$.

\subsection{Cost analysis}

The cost analyses for each of these sampling technologies were calculated over a 10-year period, based upon the costs incurred at this site, but extrapolated for a typical site that consisting of 50 monitoring wells. The following considerations were included: capital costs; startup costs, opera- 
tions and maintenance costs, and waste disposal costs (i.e., the time needed to take wastewater to the disposal facility on site). To perform the cost comparisons between the three sampling methods - low-flow purging and sampling, the Snap Sampler, and the RGC sampler - the following assumptions about this site were made.

- The number of monitoring wells at this site was assumed to be 50 .

- The wells are to be sampled quarterly for a period of 10 years.

- The mean sampling depth used will be the same as that of the 10 wells in this demonstration (36 ft).

Other assumptions made for the cost analyses include the following.

- For low-flow sampling, the field crew would consist of two people.

- Only one individual would be needed to collect samples using a Snap Sampler or a RGC sampler.

- The analytes of interest would be only those examined in this study.

- The minimum sample volume needed was determined by the laboratory.

- The RGC samplers would be constructed by the field technician.

- New Snap Sampler bottles would be used at each deployment (rather than cleaning and reusing bottles).

- An additional trip to the field would not be necessary to deploy the Snap Samplers since they would be routinely re-deployed after each sampling event.

- An additional trip to the field would be necessary to deploy the RGC samplers because of their relatively short shelf life (in-situ).

- No initial well conditioning would be needed for low-flow sampling at the beginning of a 10-year sampling program.

- Initial well conditioning would be needed for the Snap Sampler and the RGC sampler at the beginning of a 10-year sampling program.

- Dedicated equipment would be used in all wells, including pumps for low-flow sampling.

- There would be no replacement of equipment during the 10 years (such as bladder pumps or Snap Sampler bottle holders).

- There would be no periodic redevelopment of the wells during the 10 years.

- There would be no economy of scale factored into sampler costs of either the Snap Sampler or RGC samplers.

All cost values being compared in this discussion allowed for an annual inflation rate of $2.2 \%$. This analysis will be given in more detail in the related Cost and Analysis report associated with this project. 
The total estimated cost for sampling 50 wells quarterly for 10 years using low-flow sampling was projected to be $\sim \$ 907.6 \mathrm{~K}$ (Table 26). As mentioned previously, this assessment is based upon a two-person field crew. The estimated cost for the same number of sampling events using the Snap Sampler came to $\$ 296.1 \mathrm{~K}$, or a $67 \%$ cost savings (Table 25). The estimated cost for using the RGC sampler at this site was $\$ 257.9 \mathrm{~K}$ a cost savings of 71\% (Table 27). For both of the Snap Sampler and the RGC sampler, this assessment was based upon a field crew of one. The cost savings would have been more for the RGC sampler if a second trip to the field was not needed. Clearly, greater savings could be achieved by using a similar diffusion sampler that has a more resilient membrane.

One can see that the number of field technicians and the sampling time associated with low-flow sampling are major reasons for the cost savings associated with passive sampling methods. As an example, if we estimate that the field crew for low-flow sampling consisted of one individual and it took that person 1.5 times the time it takes two to sample, we estimate that the cost of low-flow sampling at the site would be $\sim \$ 491.9 \mathrm{~K}$ or $\sim 45 \%$ less. However, even using this lower cost estimate for low-flow sampling, the cost savings with the Snap Sampler would still be substantial, $~ 39 \%$.

On a per-sample basis, we estimate that over 10 years, the cost per sample at this site would be $\$ 187.70$ with low-flow sampling. In contrast, we estimate that the per-sample cost for the Snap Sampler would be $\$ 62.40$, and for the RGC sampler it would be $\$ 53.95$ (without adding in inflation).

Table 25. Projected monitoring costs using the Snap Sampler for 10 years.

\begin{tabular}{|c|c|c|c|}
\hline Cost Element & $\begin{array}{l}\text { Data Tracked During The } \\
\text { Demonstration }\end{array}$ & Details & Cost (\$) \\
\hline \multirow{3}{*}{ Initial Startup } & $\begin{array}{l}\text { Planning fieldwork, equipment, } \\
\text { supplies, and personnel }\end{array}$ & Project Technician, $64 \mathrm{hr}$ & 3,840 \\
\hline & \multirow{2}{*}{ Well reconditioning } & Contract & 37,500 \\
\hline & & Subtotal & 41,340 \\
\hline \multirow{2}{*}{ Material } & \multirow{2}{*}{ Equipment- non-consumables } & Snap Sampler equipment & 23,405 \\
\hline & & Subtotal & 23,405 \\
\hline \multirow{3}{*}{ Installation } & \multirow{3}{*}{ First-time sampler deployment } & Project Technician, $36 \mathrm{hr}$ & 2,160 \\
\hline & & Supplies & 2,962 \\
\hline & & Subtotal & 5,122 \\
\hline \multirow{3}{*}{$\begin{array}{l}\text { Annual } \\
\text { Sampling }\end{array}$} & \multirow{3}{*}{$\begin{array}{l}\text { Quarterly sampling for remainder of } \\
\text { first year }\end{array}$} & Project Technician, $200 \mathrm{hr}$ & 12,280 \\
\hline & & Sampler bottles, other sply. & 8,344 \\
\hline & & Subtotal & 20,624 \\
\hline
\end{tabular}




\begin{tabular}{|c|c|c|c|}
\hline Cost Element & $\begin{array}{l}\text { Data Tracked During The } \\
\text { Demonstration }\end{array}$ & Details & Cost (\$) \\
\hline \multirow{14}{*}{$\begin{array}{l}\text { Long-term } \\
\text { Monitoring }\end{array}$} & \multirow{3}{*}{ Total Costs, no inflation } & After Year 1 & 88,859 \\
\hline & & After Year 5 & 171,355 \\
\hline & & After Year 10 & 274,475 \\
\hline & $\begin{array}{l}\text { Cumulative Costs, assuming OMB's } \\
2.2 \% \text { annual inflation average }\end{array}$ & $\begin{array}{l}\text { Yearly sampling costs }+ \\
\text { inflation }\end{array}$ & Total Costs \\
\hline & After Year 1 & & 88,859 \\
\hline & After Year 2 & 21,078 & 109,937 \\
\hline & After Year 3 & 21,541 & 131,478 \\
\hline & After Year 4 & 22,015 & 153,494 \\
\hline & After Year 5 & 22,500 & 175,993 \\
\hline & After Year 6 & 22,995 & 198,988 \\
\hline & After Year 7 & 23,501 & 222,488 \\
\hline & After Year 8 & 24,018 & 246,506 \\
\hline & After Year 9 & 24,546 & 271,052 \\
\hline & After Year 10 & 25,086 & 296,138 \\
\hline
\end{tabular}

Table 26. Projected monitoring costs, using low-flow sampling for 10 years.

\begin{tabular}{|c|c|c|c|}
\hline Cost Element & $\begin{array}{l}\text { Data Tracked } \\
\text { During the Demonstration }\end{array}$ & Details & $\begin{array}{l}\text { Cost } \\
(\$)\end{array}$ \\
\hline \multirow{2}{*}{ Initial Startup } & \multirow{2}{*}{$\begin{array}{l}\text { Planning equipment, supplies, } \\
\text { fieldwork, and personnel }\end{array}$} & Project Technician, 64 hrs & 3,840 \\
\hline & & Subtotal & 3,840 \\
\hline \multirow{5}{*}{ Material } & \multirow{5}{*}{$\begin{array}{l}\text { Dedicated sampling equipment \& } \\
\text { supplies }\end{array}$} & $\begin{array}{l}\text { Bladder pumps, tubing, } \\
\text { cable, controller }\end{array}$ & 30,435 \\
\hline & & Purging equipment & 6,365 \\
\hline & & Gas-powered generator & 1,100 \\
\hline & & $\begin{array}{l}\text { Other equipment, tools, \& } \\
\text { supplies }\end{array}$ & 1,195 \\
\hline & & Subtotal & 39,095 \\
\hline \multirow{3}{*}{ Installation } & \multirow{3}{*}{ Deploy pumps } & Project Technicians, 88 hrs & 5,280 \\
\hline & & Decon supplies & 15 \\
\hline & & Subtotal & 5,295 \\
\hline \multirow{3}{*}{ Annual Sampling } & \multirow{3}{*}{ Sampling } & Project technicians, 836 hrs & 74,460 \\
\hline & & Supplies & 3,306 \\
\hline & & Subtotal & 77,766 \\
\hline
\end{tabular}




\begin{tabular}{|c|c|c|c|}
\hline Cost Element & $\begin{array}{l}\text { Data Tracked } \\
\text { During the Demonstration }\end{array}$ & Details & $\begin{array}{l}\text { Cost } \\
(\$)\end{array}$ \\
\hline \multirow{14}{*}{$\begin{array}{l}\text { Long-term } \\
\text { Monitoring }\end{array}$} & \multirow{3}{*}{ Total Costs, no inflation } & After Year 1 & 125,996 \\
\hline & & After Year 5 & 437,060 \\
\hline & & After Year 10 & 825,890 \\
\hline & $\begin{array}{l}\text { Cumulative Costs, assuming OMB's } \\
2.2 \% \text { annual inflation avg. }\end{array}$ & $\begin{array}{l}\text { Yearly bottles and sampling } \\
\text { costs + cumulative inflation }\end{array}$ & Total Costs \\
\hline & After Year 1 & & 125,996 \\
\hline & After Year 2 & 79,477 & 205,473 \\
\hline & After Year 3 & 81,225 & 286,698 \\
\hline & After Year 4 & 83,012 & 369,710 \\
\hline & After Year 5 & 84,839 & 454,549 \\
\hline & After Year 6 & 86,705 & 541,254 \\
\hline & After Year 7 & 88,613 & 629,867 \\
\hline & After Year 8 & 90,562 & 720,429 \\
\hline & After Year 9 & 92,554 & 812,983 \\
\hline & After Year 10 & 94,591 & 907,574 \\
\hline
\end{tabular}

Table 27. Projected monitoring costs, using the RGC sampler for 10 years.

\begin{tabular}{|c|c|c|c|}
\hline Cost Element & $\begin{array}{l}\text { Data Tracked } \\
\text { During the Demonstration }\end{array}$ & Details & $\begin{array}{c}\text { Cost } \\
(\$)\end{array}$ \\
\hline \multirow{3}{*}{ Initial Startup } & $\begin{array}{l}\text { Planning fieldwork, personnel, } \\
\text { ordering }\end{array}$ & Project Technician, $50 \mathrm{hr}$ & 3,000 \\
\hline & \multirow{2}{*}{ Well reconditioning } & Contract & 37,500 \\
\hline & & Subtotal & 40,500 \\
\hline \multirow{4}{*}{ Material } & \multirow{4}{*}{$\begin{array}{l}\text { Purchasing and construction, } \\
\text { personnel }\end{array}$} & Project Technician, $25 \mathrm{hr}$ & 1,500 \\
\hline & & $\begin{array}{l}\text { Reusable equipment, } \\
\text { supplies }\end{array}$ & 949 \\
\hline & & $\begin{array}{l}\text { Sampler materials, } \\
\text { expendable }\end{array}$ & 529 \\
\hline & & Subtotal & 2,978 \\
\hline \multirow{3}{*}{ Installation } & \multirow{3}{*}{$\begin{array}{l}\text { First-time sampler deployment \& } \\
\text { waste disposal }\end{array}$} & Project Technician, $21 \mathrm{hr}$ & 1,260 \\
\hline & & Expendable supplies & 289 \\
\hline & & Subtotal & 1,549 \\
\hline \multirow{2}{*}{ Sampler Retrieval } & \multirow{2}{*}{ Retrieve samplers } & Project Technician, $22 \mathrm{hr}$ & 1,320 \\
\hline & & Subtotal & 1,320 \\
\hline
\end{tabular}




\begin{tabular}{|c|c|c|c|}
\hline Cost Element & $\begin{array}{l}\text { Data Tracked } \\
\text { During the Demonstration }\end{array}$ & Details & $\begin{array}{l}\text { Cost } \\
(\$)\end{array}$ \\
\hline \multirow{14}{*}{$\begin{array}{l}\text { Long-term } \\
\text { Monitoring }\end{array}$} & \multirow{3}{*}{ Total Costs } & After Year 1, no inflation & 61,041 \\
\hline & & After 5 years, no inflation & 139,409 \\
\hline & & After 10 Years, no inflation & 237,369 \\
\hline & $\begin{array}{l}\text { Cumulative Costs, assuming OMB's } \\
2.2 \% \text { annual inflation average. }\end{array}$ & $\begin{array}{l}\text { Yearly sampling costs + } \\
\text { cumulative inflation (\$) }\end{array}$ & Total Costs \\
\hline & After Year 1 & & 61,041 \\
\hline & After Year 2 & 20,023 & 81,064 \\
\hline & After Year 3 & 20,464 & 101,528 \\
\hline & After Year 4 & 20,914 & 122,441 \\
\hline & After Year 5 & 21,374 & 143,815 \\
\hline & After Year 6 & 21,844 & 165,659 \\
\hline & After Year 7 & 22,325 & 187,984 \\
\hline & After Year 8 & 22,816 & 210,800 \\
\hline & After Year 9 & 23,318 & 234,117 \\
\hline & After Year 10 & 23,831 & 257,948 \\
\hline
\end{tabular}




\section{Implementation Issues}

Although this demonstration and our previous studies (Parker et al. 2007) have shown that there does not appear to be any consistent bias associated with using the Snap Sampler for most organic and inorganic analytes, there were a few issues raised in this study that should be mentioned. The first is the applicability of using an equilibrated-grab sampler, such as the Snap Sampler, for collecting samples for total Fe and possibly other reactive species such as arsenic. Although it appears that elevated Fe concentrations resulted from an elevated turbidity in the wells that resulted from the installation of all the sampling equipment in the well, subsequent studies will need to examine whether the Snap Sampler raises turbidity in wells under normal deployment. Another issue that should be examined in subsequent studies is whether analyte concentrations in shallow wells are more apt to be affected by the sampling method, especially where there may be a gradient in concentrations, such as sodium and chloride concentrations near a marine environment.

\subsection{Environmental checklist}

A survey sent to the ITRC's state-level points of contact (POCs) confirmed that there are some regulatory barriers (statutes, regulations, or guidance) that either prohibit or impede the use of passive sampler technologies (ITRC 2007). Of the 16 states responding to the survey, 25\% believed their state prohibited the use of passive sampling technologies because they required either three-well-volume purging or low-flow purging and sampling. Other states require that the wells be purged, which also precludes using passive sampler technologies. However, while all states appear receptive, many request comparison studies to verify a passive sampler's reliability. New Jersey was the only responding state that has published guidance on using a specific passive sampling technology for sampling groundwater.

\subsection{Other regulatory issues}

In addition to participation by the principals involved in sampling at this site (the U.S. EPA Region 1 and NH DES), the PI and four of the project's team members were members of the ITRC Diffusion Passive Sampler 
Team (R. Willey, D. Gronstal, S. Britt, and T. Imbrigiotta). The passive sampler team has been proactive in promoting various passive sampling technologies. In 2006, they published an overview document on 14 passive sampling technologies, including the Snap Sampler and the RGC sampler (ITRC 2006). Subsequently, the team published a protocol document on the use of five passive samplers, including the Snap and RGC samplers (ITRC 20007). This document provides guidance on (a) how to deploy and collect samples using these samplers, and (b) the advantages, applicability, and limitations of these technologies. Both of these documents are available free of charge on the ITRC Web site. Since 2007, the ITRC also has provided a free Internet training class on the use of these devices, with the total number trained over 1,400 (as of July 2009).

In early 2009, Ms. Parker and other colleagues in the sampling arena began drafting an ASTM standard on passive sampling (as part of D.18.21.04 on sample collection for ground water monitoring). Presumably, this document will be ready for initial sub-committee ballot in early 2011.

\subsection{End-user issues}

Federal, state, municipal and tribal regulators, environmental consultants, the DoD and the Department of Energy (DOE) are all potential end users of this technology. As mentioned previously, the ITRC passive sampling team has been proactive in educating interested parties about passive sampling. Participants in the free Internet training on these samplers have included individuals from all of the end-user groups listed. The team believes that many of the user's concerns and decision-making factors have been addressed by the ITRC's documents and Internet training.

Snap Samplers are commercially available, and off-the-shelf devices were used in this demonstration. However, there have been some modifications to this the equipment as a result of this demonstration, and there may be additional changes that result from our next demonstration. The electronic trigger was developed with our next demonstration site in mind because of the depth of those wells (100 to $200 \mathrm{ft}$ bgs). Publication of an ITRC Technical Regulatory document on passive sampling and the availability of ITRC training on passive samplers is expected to increase demand for this sampler. This presumably will drive down the cost of the sampler. 
The RGC sampler currently is not commercially available, but (as of June 2009) a firm 9 is considering manufacturing this device. The publication of an ITRC Technical Regulatory document and the availability of Internet training presumably will facilitate broader use of this device. If the sampler becomes commercially available and is widely used, the price of this sampler also presumably would come down.

${ }^{9}$ Columbia Analytical of Kelso, WA (manufacturer of the PDB and RPP samplers). 


\section{References}

Aggett, J. and G.A. O'Brien. 1985. Detailed model for the mobility of arsenic in lacustrine sediments based on measurements in Lake Ohakuri. Environmental Science and Technology 19 (3): 231-238.

Aggett, J. and L.S. Roberts. 1986. Insight into the mechanism of accumulation of arsenate and phosphate in Hydro Lake sediments by measuring the rate of dissolution with ethylenediaminetetraacetic acid. Environmental Science and Technology 20 (2): 183-186.

ASTM. 2003. Standard practice for low-flow purging and sampling for wells and devices used for ground-water quality investigations. ASTM Standard D 6771. West Conshohocken, PA : ASTM International.

Bailey, R., J. Marchesani, A.C. Marinucci, J. Reynard, and P. Sanders. 2005. Use of sequential filtration for determining transportable lead in ground water. Ground Water Monitoring and Remediation 25(3): 52-62.

Creed, J.T., C.A. Brockhoff, and T.D. Martin. 1994. Method 200.8: Determination of trace elements in waters and wastes by inductively-coupled plasma - mass spectrometry. Environmental Monitoring Systems Laboratory, Office of Research and Development, U.S. Environmental Protection Agency, Cincinnati, OH, Rev. 5.4. Available at (accessed June 2009): http://www.nemi.gov/apex/f?p=237:38:3559224042618507:.::P38_METHOD_ID:4665

Hewitt, A.D. 1989. Leaching of metal pollutants from four well casings used for groundwater monitoring. Special Report 89-32 Hanover, NH U.S. Army Corps of Engineers Cold Regions Research and Engineering Laboratory.

1992. Potential of common well casing materials to influence aqueous metal concentrations. Ground Water Monitoring Review 12(2): 131-136.

1994. Dynamic study of common well casing screen materials. Ground Water Monitoring Review 14(1): 87-94.

Interstate Technology and Regulatory Council (ITRC). 2004. Technical and regulatory guidance for using polyethylene diffusion bag samplers to monitor volatile organic compounds in groundwater. Report by The Diffusion Sampler Team of the Interstate Technology and Regulatory Council, 444 North Capitol Street, NW, Suite 445, Washington, DC 20001. Available at (Accessed June 2009): http://www.itrcweb.org/documents/DSP-3.pdf.

2006. Technology overview of passive sampler technologies. Report by The Diffusion Sampler Team of the Interstate Technology and Regulatory Council, 444 North Capitol Street, NW, Suite 445, Washington, DC 20001. Available at (Accessed June 2009): http://www.itrcweb.org/documents/DSP_4.pdf. 
Jenne, E.A., 1968. Controls on $\mathrm{Mn}, \mathrm{Fe}, \mathrm{Co}, \mathrm{Ni}, \mathrm{Cu}$, and $\mathrm{Zn}$ concentrations in soils and water: The significant role of hydrous $\mathrm{Mn}$ and Fe oxides. Advances in Chemistry Series 73: 337-387.

Korte, N. 1991. Naturally occurring arsenic in groundwater of the Midwestern United States. Environmental Geology and Water Sciences 18 (2):137-141.

, and Q.F. Fernando. 1991. A Review of Arsenic(III) in Groundwater. Critical Reviews in Environmental Control 21 (1):1-39.

— , J. Skopp, W. H. Fuller, E.E. Niebla, and B.A. Alesii. 1976. Trace element movement in soils: Influence of soil physical and chemical properties. Soil Science 122 (6):350-359.

Masse, R., F.J.M.J. Maessen, and J.J.M. DeGeoeij. 1981. Loss of silver , arsenic, cadmium, selenium and zinc traces from distilled water and artificial sea-water by sorption on various container surfaces. Analytica Chimica Acta, 127:181-193.

Mok, W.M. and C.M. Wai. 1990. Distribution and mobilization of arsenic and antimony species in the Coeur D'Alene River, Idaho. Environmental Science and Technology 24 (1):102-108.

MWH Americas, Inc. 2004. Former Pease Air Force Base Five-Year Review Report (1999-2004), prepared for the Air Force Real Property Agency, Limestone, Maine and the Air Force Center for Environmental Excellence, Base Closure Division, Brooks City-Base, Texas. Pike Malvern, PA.: MWH Americas, Inc. Available at (Accessed June 2009): http://www.epa.gov/superfund/sites/fiveyear/f04-01013.pdf

New Jersey Department of Environmental Protection (NJDEP). 2004. Field sampling procedures manual. Trenton, NJ.: New Jersey Department of Environmental Protection,

Nielsen, D.M. and G.L. Nielsen. 2002. Technical guidance on low-flow purging and sampling and minimum-purge sampling. Second edition. Las Cruces, NM: Nielsen Environmental Field School Publication NEFS-TGoo1-02.

Parker, L.V. 1997. Sampling trace-level organics with polymeric tubing: Part I static studies. Ground Water Monitoring and Remediation 17 (4): 115-124.

. 1998. Sampling trace-level organics with polymeric tubing: Part 2 dynamic studies. Ground Water Monitoring and Remediation 18 (1): 148-155.

- 2000. Decontaminating materials used in ground water sampling devices: organic contaminants. Ground Water Monitoring and Remediation 20 (1): 5668.

, and C.H. Clark. 2004. Study of five discrete-interval type ground water sampling devices. Ground Water Monitoring and Remediation 24 (3):111-123.

, A.D. Hewitt, and T.F. Jenkins. 1990. Influence of casing materials on trace-level chemicals in well water. Ground Water Monitoring Review 10 (2): 146-156. 
, and N. Mulherin. 2008. Use of snap sampler in ground water monitoring. ERDC/CRREL TR-08-25. Hanover, NH: U.S. Army Engineer Research and Development Center.

and T.A. Ranney. 1994. Effect of concentration on sorption of dissolved organics by well casings. Ground Water Monitoring and Remediation 14 (3): 139-149.

Parsons Inc. 2003. Final comprehensive results report of the passive diffusion bag demonstration. Contract Number F41624-00-D-8024. Report prepared for the Air Force Center for Environmental Excellence, Science and Engineering Division.

2005. Results report for the demonstration of no-purge groundwater sampling devices at former McClellan Air Force Base, California. Contract No. F4465099-D-005. Prepared for the U.S. Army Corps of Engineers, Omaha District, and Air Force Center for Environmental Excellence, Air Force Real Property Agency. Report available (accessed June 2009) at: http://www.snapsampler.com/images/McClellan_Report_Highlighted.pdf

Powell, R.M., and R.W. Puls. 1993. Passive sampling of ground-water monitoring wells without purging: multilevel well chemistry and tracer disappearance. J ournal of Contaminant Hydrology 12: 51-77

Puls, R.W., and M.J. Barcelona. 1996. Low-flow (Minimal Drawdown) Ground-Water Sampling Procedures. EPA/540/S-95/504. Washington, D.C.: United States Environmental Protection Agency, Office of Research and Development, Office of Solid Waste and Emergency Response.

Ranney, T.A., and L.V. Parker. 1998a. Comparison of fiberglass and other polymeric well casings: Part II. sorption and leaching of trace-level organics. Ground Water Monitoring and Remediation 18 (2): 107-112.

1998b. Comparison of fiberglass and other polymeric well casings: Part III. sorption and leaching of trace-level metals. Ground Water Monitoring and Remediation, 18 (3): 127-133.

Robin, M.H..L., and R.W. Gillham. 1987. Field evaluation of well purging procedures. Ground Water Monitoring Review 7 (4): 85-93.

Ronen, D., M. Magaritz, and I. Levy. 1986. A multi-layer sampler for the study of detailed hydrochemical profiles in groundwater. Water Research 20 (3): 311-315.

Roy. F. Weston, Inc. 1992. Installation restoration program stage 3c, site 32/36 source area remedial investigation, Pease AFB, NH. Report prepared for Headquarters Air Force Base Disposal Agency (HQ AFBDA/BD) The Pentagon, Washington, D.C. 20330 and the Air Force Center for Environmental Excellence Base Closure Branch (AFCEE/ESRB) Brooks Air Force Base, TX.

U.S. Environmental Protection Agency Region 1. 1996. Low stress (low flow) purging and sampling procedure for the collection of ground water samples from monitoring wells, Revision 2.

SOP\# GW 0001. Boston, Massachusetts: U.S. Environmental Protection Agency Region 1. 


\section{Acronyms and Annotations}

$\AA$

AFB

ANOVA

As

ASTM

BFSA

bgs

BRAC

BTEX

$\mathrm{Ca}$

$\mathrm{Cd}$

CERCLA

$\mathrm{Cr}$

CRREL

DI

DO

DOE

DoD

EPA

EPASW

ERDC
Angstrom

Air Force Base

Analysis of Variance test

Arsenic

American Society for Testing and Materials (now known as ASTM International)

Bulk Fuel Storage Area

below ground surface

Base Realignment and Closure

Benzene, Toluene, Ethylbenzene, Xylene

Calcium

Cadmium

Comprehensive Environment Response Compensation \& Liability Act

Chromium

Cold Regions Research and Engineering Laboratory

deionized water

Dissolved Oxygen

U.S. Department of Energy

U.S. Department of Defense

U.S. Environmental Protection Agency

EPA Office of Solid Waste

U.S. Army Engineer Research and Development Center 


\begin{tabular}{|c|c|}
\hline ERDC-EL-MS & ERDC Environmental Laboratory- Vicksburg \\
\hline ERDC-EL-EP & ERCDC Environmental Laboratory- Omaha \\
\hline $\mathrm{Fe}$ & Iron \\
\hline FFA & Federal Facility Agreement \\
\hline $\mathrm{ft}$ & foot \\
\hline $\mathrm{ft}$ bgs & feet below ground surface \\
\hline gal & gallon \\
\hline GPM & Gallons per Minute \\
\hline HDPE & High Density Polyethylene \\
\hline ICP & Inductively Coupled Plasma \\
\hline $\mathrm{ICP} / \mathrm{MS}$ & Inductively Coupled Plasma Mass Spectrometry \\
\hline IRP & Installation Restoration Plan \\
\hline ITRC & Interstate Technology and Regulatory Council \\
\hline $\mathrm{K}$ & Potassium \\
\hline$\$ \mathrm{~K}$ & thousand dollars \\
\hline LS & Lower Sand \\
\hline LTM & Long-term monitoring \\
\hline MCL & Maximum contaminant level \\
\hline MCS & Marine clay and silt \\
\hline $\mathrm{Mg}$ & Magnesium \\
\hline $\mathrm{mL}$ & milliliter \\
\hline Mn & Manganese \\
\hline MS & Matrix spike sample \\
\hline MSD & Matrix spike duplicate sample \\
\hline mXYL & m-Xylene \\
\hline
\end{tabular}




\begin{tabular}{|c|c|}
\hline $\mathrm{Na}$ & Sodium \\
\hline NELAC & $\begin{array}{l}\text { National Environmental Laboratory Accreditation } \\
\text { Conference }\end{array}$ \\
\hline NH DES & New Hampshire Department of Environmental Services \\
\hline $\mathrm{Ni}$ & Nickel \\
\hline NJDEP & New Jersey Department of Environmental Protection \\
\hline NPL & National Priorities List \\
\hline NTU & Nephelometric turbidity units \\
\hline ORP & Redox potential \\
\hline OSHA & U.S. Occupational and Safety Health Administration \\
\hline PAHs & Polycyclic aromatic hydrocarbons \\
\hline $\mathrm{Pb}$ & Lead \\
\hline PCE & Tetrachloroethylene \\
\hline PDB & Polyethylene Diffusion Bag sampler \\
\hline $\mathrm{PE}$ & Polyethylene \\
\hline $\mathrm{pH}$ & measurement of acidity \\
\hline PI & principal investigator \\
\hline $\mathrm{POC}$ & points of contact \\
\hline $\mathrm{PP}$ & Polypropylene \\
\hline $\mathrm{ppb}$ & parts per billion \\
\hline ppm & parts per million \\
\hline psi & pounds per square inch \\
\hline PTFE & polytetrafluoroethylene \\
\hline QA & quality assurance \\
\hline QAPP & Quality Assurance Project Plan \\
\hline
\end{tabular}




\begin{tabular}{|c|c|}
\hline $\mathrm{QC}$ & quality control \\
\hline RDX & cyclotrimethylenetrinitramine \\
\hline RGC & regenerated cellulose \\
\hline RM-ANOVA & Repeated Measures Analysis of Variance test \\
\hline RPD & Relative Percent Difference \\
\hline RPP & Rigid Porous Polyethylene sampler \\
\hline $\mathrm{S}$ & Sulfur \\
\hline SS & Stainless steel \\
\hline TCE & Trichloroethylene \\
\hline TDS & Total Dissolved Solids \\
\hline TNT & Trinitrotoluene \\
\hline US & Upper Sand \\
\hline USACE & United States Army Corps of Engineers \\
\hline UST & underground storage tank \\
\hline VOA & volatile organic analyte \\
\hline VOC & volatile organic compound \\
\hline $\mathrm{Zn}$ & zinc \\
\hline
\end{tabular}




\section{Points of Contact}

\begin{tabular}{|c|c|c|c|}
\hline $\begin{array}{l}\text { Point of contact } \\
\text { Name }\end{array}$ & $\begin{array}{l}\text { Organization Name } \\
\text { Address }\end{array}$ & Phone/Fax/E-mail & Role in Project \\
\hline Louise Parker & $\begin{array}{l}\text { USA ERDC-CRREL } \\
72 \text { Lyme Road } \\
\text { Hanover, NH } 03755\end{array}$ & $\begin{array}{l}\text { Voice 603-646-4393 } \\
\text { Fax 603-646-4640 } \\
\text { Louise.V.Parker@usace.army.mil }\end{array}$ & Principal Investigator (PI) \\
\hline Robert Strainge & $\begin{array}{l}\text { AFRPA/ER-Loring/Pease } \\
154 \text { Development Drive, } \\
\text { Suite G } \\
\text { Limestone, ME } 04750\end{array}$ & $\begin{array}{l}\text { Voice 207-328-7109 } \\
\text { Dave.strainge@afrpa.pentagon.af.mil }\end{array}$ & $\begin{array}{l}\text { Air Force Environmental } \\
\text { Coordinator for Pease AFB }\end{array}$ \\
\hline Michael Daly & $\begin{array}{l}\text { U.S. EPA, Region } 1 \\
1 \text { Congress Street, Suite } \\
\text { 1100, Mail Stop: HBS } \\
\text { Boston, MA 02114-2023 }\end{array}$ & $\begin{array}{l}\text { Voice 617-918-1386 } \\
\text { Daly.Mike@epamail.epa.gov }\end{array}$ & Remediation Site Manager \\
\hline Martin Mistretta & $\begin{array}{l}\text { URS Corp. } \\
20 \text { Short Street } \\
\text { Portsmouth, NH } 03801\end{array}$ & $\begin{array}{l}\text { Voice 603-334-6442 } \\
\text { Martin_Mistretta@URSCorp.com }\end{array}$ & Site manager (contractor) \\
\hline William Major & $\begin{array}{l}\text { NFESC } \\
110023^{\text {rd }} \text { Ave. } \\
\text { Port Hueneme, CA }\end{array}$ & $\begin{array}{l}\text { Voice 805-982-1808 } \\
\text { Fax 805-982- } \\
\text { William.major@navy.mil }\end{array}$ & $\begin{array}{l}\text { Co-PI, } \\
\text { Site POC for Port Hueneme }\end{array}$ \\
\hline Richard Willey & $\begin{array}{l}\text { U.S. EPA, Region } 1 \\
1 \text { Congress Street, Suite } \\
\text { 1100, Mail Stop: HBS } \\
\text { Boston, MA 02114-2023 }\end{array}$ & $\begin{array}{l}\text { Voice 617-918-0266 } \\
\text { Fax 617-918-0266 } \\
\text { Willey.Dick@epamail.epa.gov }\end{array}$ & $\begin{array}{l}\text { Co-PI, hydrologist, regulator } \\
\text { with EPA }\end{array}$ \\
\hline $\begin{array}{l}\text { Thomas } \\
\text { Imbrigiotta }\end{array}$ & $\begin{array}{l}\text { USGS Water Resources } \\
\text { Div., NJ District } \\
810 \text { Bear Tavern Road, } \\
\text { Suite } 206 \\
\text { West Trenton, NJ. } 08628\end{array}$ & $\begin{array}{l}\text { Voice 609-771-3900 } \\
\text { Fax 609-771-3915 } \\
\text { timbrig@usgs.gov }\end{array}$ & $\begin{array}{l}\text { Co-PI, team expert on RGC } \\
\text { samplers, hydrologist }\end{array}$ \\
\hline Dr. Jacob Gibs & $\begin{array}{l}\text { USGS Water Resources } \\
\text { Div., NJ District } \\
810 \text { Bear Tavern Road, } \\
\text { Suite } 206 \\
\text { West Trenton, NJ. } 08628\end{array}$ & $\begin{array}{l}\text { Voice 609-771-3900 } \\
\text { Fax 609-771-3915 } \\
\text { jgivs@usgs.gov }\end{array}$ & $\begin{array}{l}\text { Co-PI, hydrologist, expert on } \\
\text { ground water sampling }\end{array}$ \\
\hline Donald Gronstal & $\begin{array}{l}\text { U.S. Air Force Real Property } \\
\text { Agency } \\
3411 \text { Olson Street } \\
\text { McClellan, CA } 95652\end{array}$ & $\begin{array}{l}\text { Voice 916-643-3672, ext } 211 \\
\text { Fax 916-643-5880 } \\
\text { Donald.Gronstal@afrpa.pentagon.af.mil }\end{array}$ & $\begin{array}{l}\text { Co-PI, site POC for former } \\
\text { McClellan AFB }\end{array}$ \\
\hline Sanford Britt & $\begin{array}{l}\text { ProHydro, Inc. } \\
1011 \text { Fairport Road } \\
\text { Fairport, NY } 14450\end{array}$ & $\begin{array}{l}\text { Voice 585-385-0023 } \\
\text { Fax 585-385-1774 } \\
\text { Sandy.Britt@ProHydrolnc.com }\end{array}$ & $\begin{array}{l}\text { Co-PI, inventor of Snap } \\
\text { Sampler, hydrogeologist, former } \\
\text { state regulator }\end{array}$ \\
\hline
\end{tabular}




\section{Dated Signature of Project Leader}

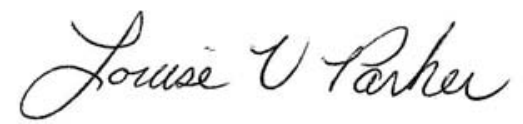

Louise V. Parker

Principal Investigator

U.S. Army Engineer Research and Development Center (ERDC)

Cold Regions Research \& Engineering Laboratory

72 Lyme Rd

Hanover NH 03755-1290

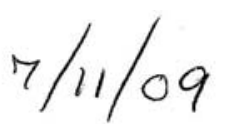

Date 


\section{Appendix A: Sampling Methods Supporting the Experimental Design}

The Interstate Technology and Regulatory Council (ITRC). 2006. Technology Overview of Passive Sampler Technologies. The Diffusion Sampler Team of the Interstate Technology and Regulatory Council, 444 North Capitol Street, NW, Suite 445, Washington, DC 20001. Available at http://www.itrcweb.org/documents/DSP_4.pdf

U.S. Environmental Protection Agency Region I. 1996. Low Stress (low flow) Purging and Sampling Procedure for the Collection of Ground Water Samples From Monitoring Wells, Revision 2. U.S. Environmental Protection Agency Region I SOP \# GW 0o01, U.S. EPA Region I, Boston, Massachusetts. Available at http://www.epa.gov/ne/measure/well/lowflow8.pdf 


\section{Appendix B: Analytical Methods Supporting the Sampling Plan}

U.S. EPA Office of Solid Waste. 1996. SW-846, Test Methods for Evaluating Solid Waste, Physical/Chemical Methods, Office of Solid Waste, U.S. Environmental Protection Agency, Washington, DC, December 1996.

Available at: http://www.epa.gov/epaoswer/hazwaste/test/pdfs/6010b.pdf 


\section{Appendix C: Quality Assurance Project Plan (QAPP)}

\section{C.1. Purpose and scope of the plan}

The objectives of this demonstration are to compare concentrations of inorganic analytes in samples collected from ground water monitoring wells by using several sampling methods. Analytes will include non-metals, transition metals, alkaline earth metals, alkali metals, and a metalloid. Sampling methods will include low-flow purging and sampling, the Snap Sampler, and other passive diffusion samplers. Specifically for this site, samples to be taken with the Snap Sampler will be compared with samples taken using the RGC sampler and a dedicated 3/4-in. diameter bladder pump. Because of the number and size of the samplers installed in each well, larger diameter wells (4-in. and 6-in.) will be needed for this demonstration. Statistical analyses will be used to determine if a statistically significant difference exists between the concentrations of samples collected using the various sampling methods.

\section{C.2. Quality assurance responsibilities}

With respect to ensuring the integrity of the demonstration and the quality of the samples, Louise Parker, Nathan Mulherin, Sandy Britt, Richard Willey, Thomas Imbrigiotta, and the contract laboratory POC will have the following responsibilities.

Louise Parker (CRREL) will oversee all aspects of this project, direct the demonstration in the field including all the sampling events, serve as the QA Officer, review and analyze all data, and serve as primary author of the report.

Nathan Mulherin (CRREL) will be the primary field technician. He will interact with the regulators and site manager prior to the demonstration, make certain that all equipment is operational prior to deployment, conduct all preliminary sampling and develop any wells that need redevelopment, and be responsible for sending all the samples to the laboratory and filling out the chain of custody forms. 
Sandy Britt (ProHydro) will review the draft plan, categorize the hydraulics in the wells prior to sampling, and be present on site during the demonstration to address any problems with the Snap Sampler.

Thomas Imbrigiotta (USGS) will review the draft plan and provide guidance on the construction, storage, and use of the RGC sampler.

Richard Willey (U.S. EPA Region 1) will review the draft plan, provide guidance throughout the demonstration, and review the final report.

The contract lab POC will have all data oversight responsibilities to ensure that samples are analyzed within the holding time, that all calibrations are not suspect, and that analyses agree for standard reference samples.

\section{C.3. Data quality parameters}

To insure data validity, standard laboratory practices for analyses will include the following:

- receiving, log-in, and storage of field samples

- chain-of-custody documentation

- standards preparation and analysis

- Instrument calibration

- instrumentation QC

- duplicate field samples

- matrix spike samples

- field and laboratory blanks

Standard QC samples will be taken at each site, including laboratory and field duplicates, duplicates for spiked recoveries by the lab (to determine matrix effects), and trip blanks.

Trip blanks will be prepared by the contract laboratory using analyte-free reagent water. Trip blanks will be handled, transported, and analyzed using identical procedures as those used for the other groundwater samples. Equipment blanks will be collected from samplers and pumps that have been deployed in DI water for 10 days.

Duplicate field samples will be collected from $10 \%$ of the total number of samples. Duplicate samples will be obtained by using all three sampling methods (low-flow, Snap, and RGC). The results from these analyses will 
provide a measure of the precision (repeatability) of the field sampling methods.

Duplicate samples for spiked recoveries will be collected for $5 \%$ of the total number of samples. These samples will be collected for the purposes of preparing Matrix Spikes (MS) and Matrix Spike Duplicates (MSD). They will be identified with the suffixes MS and MSD on the Chain-of-Custody Forms. These samples will help identify matrix effects on spiked analytes of known quantity, as well as the laboratory's precision in recognizing matrix effects.

Labels on the sample bottles will be marked with a water-insoluble marker. They will be given an identification number, and marked with the time, date, initials of the sampling individual, and whether they samples are to be filtered or not. All information about each sample also will be recorded in the (bound) green lab field book. Each sample bottle will be placed in a zipper-lock plastic bag. Samples will be stored on ice in a cooler until they are delivered to the analytical laboratory.

When the samples are ready to be sent to the contract lab, the cooler will be packed with fresh ice. A Chain-of-Custody Form will be signed, placed in a zipper-lock plastic bag, and sealed; the bag will be placed inside the cooler; and the cooler will be sealed with tape and a Chain-of-Custody Seal (in a manner that the seal must be destroyed before accessing the cooler). The cooler will then be shipped to the laboratory by overnight express (or equivalent) delivery.

Certified reference samples will be used by the laboratory to ensure proper calibration and thus accuracy of the analyses. One out of 40 samples will be a certified reference sample (2.5\%). One out of 20 samples will be a calibration standard (5\%).

\section{C.4. Calibration procedures, quality control checks, and corrective action}

Five percent of the samples will be analyzed in duplicate, to give a measure of the precision of the various analyses.

The analytical laboratory will use standard U.S. EPA protocols for calibrating the analytical instrumentation including: calibration curves with a minimum of three standards at different concentrations, internal and ex- 
ternal standards, and analyses of equipment blanks. Certified reference samples will be used by the laboratory to ensure proper calibration and thus accuracy of the analyses. All reference samples should agree within $\pm 20 \%$ with known concentrations.

All data will be reviewed by a second analyst (or supervisor), using procedures that ensure all calculations are correct and detect any transcription errors. Any issues (including lack of agreement with reference samples) are to be reported immediately to the PI.

\section{C.5. Demonstration procedures}

There will be 10 sampling events and the well water will be analyzed for inorganic analytes. Specific analytes will include As, Ca, Fe, Mg, Mn, K, and Na. For each well, samples will be collected using the Snap Sampler, low-flow purging and sampling (U.S. EPA Region 1 1996), and the RGC sampler. Two sets of samples will be collected; one set of the samples will not be filtered (i.e., will be whole-water samples) and the other set will be filtered.

The Snap and RGC samplers will be deployed at the same depth in the well as the bladder pump (or dedicated tubing for a peristaltic pump) that will be used for low-flow sampling. Two Snap Samplers will be deployed in tandem in each well, one just above the pump intake and one just below the pump intake The samplers will be left in the well for 10 days prior to sampling.

Tentatively, 12 4-in. (or 6-in.) diameter monitoring wells have been selected as potential monitoring wells for this demonstration. Ten wells to be used in this demonstration will be selected from these 12 wells. Prior to selecting the final wells, the site geology will be reviewed and the well hydraulics will be determined for each of the wells to determine the flow patterns in the wells. In addition, all the prospective wells will be sampled prior to conducting the demonstration using low-flow sampling. This is necessary to determine (1) whether the wells have analyte concentrations that are within the desired range, (2) whether any of the wells need redevelopment prior to starting this project, and (3) whether draw down occurs in any of the wells at the sampling rate. In order to evaluate these passive and active sampling systems, it is important that all wells used in this demonstration perform as they were designed. Total depth of the wells will be measured and compared with construction diagrams to determine 
if the wells have silted in. Wells that have silted in or have high turbidity levels will be redeveloped prior to starting the demonstration. In addition, two Snap Sampler samples will be collected ( $\sim 5 \mathrm{ft}$ apart) to determine if there is any contaminant stratification in these wells.

All the bladder pumps will be cleaned prior to installing them in the well. Equipment blanks will be taken prior to deployment to verify there is no leaching of analytes of interest. The length of the suspension lines for the diffusion samplers and the trigger lines will have to be determined exactly, so that the samplers can be deployed at the desired depths in the well (especially with respect to the intake of the bladder pump). The RGC samplers will have to be constructed within a week of the project. The equipment used to monitor the purge parameters will be checked a month before we begin the project and again the week before we go in the field.

\section{C.6. Calculation of data quality indicators}

According to the contract, the laboratory will have in place procedures for demonstrating proficiency of the analytical method for each analyte. The relative percent difference (RPDs) between the laboratory's values for certified reference samples and the known values will be calculated using the same formula given previously in Section 3.5.7.5

\section{C.7. Performance and system audits}

If the contract laboratory is unable to meet the terms of the contract, a second (back-up) laboratory will be selected at the time the contract is awarded.

\section{C.8. Quality assurance reports}

This data will be generated from two sampling events, (i.e., two data sets). The first set of data will be the preliminary data from the 12 candidate wells. The second set of data will be the results from the demonstration comparing the three sampler types in the 10 wells. We anticipate two sets of reports from the laboratory; one after the preliminary sampling is completed and the second after the demonstration is complete. Each report will contain the information on the following: (a) sample preparation and analysis procedures, (b) instrument standardization, (c) sample data, precision and bias, (d) detection and report limits, and (e) results from all 
QA/QC analyses including certified references samples and laboratory duplicates.

Laboratory reports will include all information used in calculations, (e.g., raw data, calibration files, tuning records, results of standard additions, interference check results, and blank or background correction protocols). This will allow the data to be reconstructed if need be.

\section{C.9. Data format}

All field data will be written in a bound, green notebook. It will be written in ink, dated, and initialed or signed by the person making the entry.

Data from the laboratory will be delivered in electronic form (a Microsoft Excel spreadsheet) in a format suitable for easy data analyses (as specified by ERDC-CRREL in the laboratory contract). Any change in automated data entries should not obscure the original entry. Updated entries should also indicate the reason for the change, the date, and the person responsible for making the change. Back-up copies of all data submitted by the contract lab will be kept.

\section{C.10. Data storage and archiving procedures}

The data will be available as an Appendix in the final report, and that report will be available electronically on the CRREL Web site. Nate Mulherin (CRREL) will keep electronic copies of all data reports from the contract lab and records of all correspondence and other documents between CRREL and the contract lab that relate to interpretation and evaluation of the data. In addition, Mr. Mulherin will keep the green book that will be used to document everything done in the field. Ms. Parker will keep an electronic copy of the interim and final report on a CD-ROM. 


\section{Appendix D: Health and Safety Plan (HASP)}

(Available on request.) 


\section{Appendix E: Data Summaries for the Second Laboratory Study.}

Table E1. Recovery of the cations in the second laboratory study.

\begin{tabular}{|c|c|c|c|c|c|c|c|c|c|c|}
\hline Sample & \multicolumn{2}{|c|}{$\mathrm{Ca}$} & \multicolumn{2}{|c|}{$\mathrm{K}$} & \multicolumn{2}{|c|}{$\mathrm{Mg}$} & \multicolumn{2}{|c|}{$\mathrm{Mn}$} & \multicolumn{2}{|c|}{$\mathrm{Na}$} \\
\hline 24-hr & Control & Snap & Control & Snap & Control & Snap & Control & Snap & Control & Snap \\
\hline $\begin{array}{l}\text { Mean concentration } \\
(\mathrm{mg} / \mathrm{L})\end{array}$ & 19.4 & 19.1 & 42.5 & 42.7 & 8.5 & 8.3 & 36.1 & 35.5 & 47.0 & 46.6 \\
\hline $\begin{array}{l}\text { \% recovery of Snap } \\
\text { Sampler }\end{array}$ & & 98.7 & & 100.4 & & 97.4 & & 98.3 & & 99.2 \\
\hline \% RSD & 1.1 & 0.7 & 2.0 & 1.5 & 0.6 & 0.5 & 0.0 & 0.7 & 0.5 & 0.1 \\
\hline 48-hr & Control & Snap & Control & Snap & Control & Snap & Control & Snap & Control & Snap \\
\hline $\begin{array}{l}\text { Mean concentration } \\
(\mathrm{mg} / \mathrm{L})\end{array}$ & 19.1 & 19.2 & 41.8 & 42.6 & 8.3 & 8.3 & 35.7 & 35.5 & 46.2 & 46.4 \\
\hline $\begin{array}{l}\% \text { recovery of Snap } \\
\text { Sampler }\end{array}$ & & 100.3 & & 102.0 & & 99.8 & & 99.4 & & 100.5 \\
\hline$\%$ RSD & 0.7 & 0.4 & 0.5 & 1.3 & 0.3 & 0.1 & 0.2 & 0.6 & 0.8 & 0.6 \\
\hline 72-hr & Control & Snap & Control & Snap & Control & Snap & Control & Snap & Control & Snap \\
\hline $\begin{array}{l}\text { Mean concentration } \\
(\mathrm{mg} / \mathrm{L})\end{array}$ & 19.3 & 19.1 & 42.7 & 42.0 & 8.35 & 8.34 & 35.7 & 35.7 & 46.5 & 46.6 \\
\hline $\begin{array}{l}\% \text { recovery of } \\
\text { Snap Sampler }\end{array}$ & & 99.0 & & 98.5 & & 99.9 & & 100.0 & & 100.0 \\
\hline$\%$ RSD & 0.7 & 1.5 & 1.8 & 0.0 & 2.9 & 2.0 & 1.6 & 0.4 & 0.2 & 0.8 \\
\hline
\end{tabular}

Table E2. Recovery of the anions in the second laboratory study.

\begin{tabular}{|l|c|c|c|c|c|c|c|c|c|c|}
\hline \multicolumn{1}{|c|}{ Sample } & \multicolumn{2}{c|}{ Bromide } & \multicolumn{2}{c|}{ Chloride } & \multicolumn{2}{c|}{ Nitrate } & \multicolumn{2}{c|}{ Perchlorate } & \multicolumn{2}{c|}{ Sulfate } \\
\hline \multicolumn{1}{|c|}{ 24-hr } & Control & Snap & Control & Snap & Control & Snap & Control & Snap & Control & Snap \\
\hline $\begin{array}{l}\text { Mean concentration } \\
\text { (mg/L) }\end{array}$ & 79.5 & 78.8 & 66.0 & 63.5 & 13.3 & 13.3 & 52.9 & 53.3 & 61.0 & 62.0 \\
\hline $\begin{array}{l}\text { \% recovery of } \\
\text { Snap Sampler }\end{array}$ & & 99.1 & & 96.2 & & 100.0 & & 100.8 & \\
\hline \% RSD & 0.9 & 1.3 & 6.4 & 5.6 & 0.5 & 0.5 & 8.2 & 0.9 & 0.0 & 0.0 \\
\hline \multicolumn{1}{|c|}{$48-h r$} & Control & Snap & Control & Snap & Control & Snap & Control & Snap & Control & Snap \\
\hline $\begin{array}{l}\text { Mean concentration } \\
\text { (mg/L) }\end{array}$ & 80.0 & 80.5 & 64.0 & 68.5 & 13.3 & 13.4 & 49.7 & 52.7 & 61.5 & 63.0 \\
\hline $\begin{array}{l}\text { \% recovery of } \\
\text { Snap Sampler }\end{array}$ & & 100.6 & & 107 & & 100.8 & & 106 & 1.1 \\
\hline \% RSD & 0.0 & 0.9 & 0.0 & 9.3 & 0.5 & 0.5 & 0.4 & 3.2 & 1.2 \\
\hline
\end{tabular}




\begin{tabular}{|l|c|c|c|c|c|c|c|c|c|c|}
\hline \multicolumn{1}{|c|}{ 72-hr } & Control & Snap & Control & Snap & Control & Snap & Control & Snap & Control & Snap \\
\hline $\begin{array}{l}\text { Mean concentration } \\
(\mathrm{mg} / \mathrm{L})\end{array}$ & 81.0 & 80.0 & 64.0 & 64.5 & 13.4 & 13.3 & 47.4 & 52.5 & 62.0 & 62.5 \\
\hline $\begin{array}{l}\text { \% recovery of } \\
\text { Snap Sampler }\end{array}$ & & 98.8 & & 100.8 & & 99.6 & & 111 & & 100.8 \\
\hline \% RSD & 0.0 & 0.0 & 0.0 & 3.3 & 0.5 & 0.0 & 0.0 & 0.1 & 0.0 & 1.1 \\
\hline
\end{tabular}




\section{Appendix F: Findings from Parker and Mulherin (2007)}

Table F1. Summary of the findings for the Snap Sampler, exposed to a test solution containing VOCs ${ }^{1}$

\begin{tabular}{|l|c|c|c|}
\hline \multicolumn{4}{|c|}{ Mean Concentration* $(\mathrm{mg} / \mathrm{L})$} \\
\hline \multicolumn{1}{|c|}{ Analyte } & Control & Snap Sampler & Percent Difference \\
\hline tDCE & 0.940 & 0.930 & -1.1 \\
\hline Benzene & 0.994 & 0.989 & -0.5 \\
\hline TCE & 0.970 & 0.965 & -0.5 \\
\hline Toluene & 0.970 & 0.962 & -0.9 \\
\hline oDCB & 1.02 & 1.01 & -1.5 \\
\hline mXYL & 0.958 & 0.947 & -1.2 \\
\hline PCE & 0.906 & 0.895 & -1.2 \\
\hline
\end{tabular}

* Mean of six replicate samples.

1 The Snap Samplers were equilibrated for 24 hours prior to sampling.

Table F2. Summary of the findings for the Snap Sampler, exposed to a test solution containing explosives ${ }^{1}$

\begin{tabular}{|l|c|c|c|}
\hline \multicolumn{4}{|c|}{ Mean Concentration* $(\mathrm{mg} / \mathbf{L})$} \\
\hline \multicolumn{1}{|c|}{ Analyte } & Control & Snap Sampler & Percent Difference \\
\hline HMX & 0.682 & 0.704 & 3.2 \\
\hline TNB & 1.94 & 1.94 & 0.0 \\
\hline RDX & 5.93 & 5.92 & -0.2 \\
\hline 1,3-DNB & 0.133 & 0.132 & -0.8 \\
\hline TNT & 1.40 & 1.39 & -0.7 \\
\hline 2,4-DNT & 0.104 & 0.104 & 0.0 \\
\hline
\end{tabular}

* Mean of five replicate samples.

1 The Snap Samplers were equilibrated for 24 hours prior to sampling. 
Table F3. Summary of the findings from the holding-time studies for VoCs.

\begin{tabular}{|c|c|c|c|c|c|c|c|c|c|c|c|c|c|c|c|c|}
\hline \multirow{3}{*}{$\begin{array}{l}\text { Holding } \\
\text { time } \\
\text { (days) }\end{array}$} & \multirow{3}{*}{$\begin{array}{c}\text { Equili- } \\
\text { bration } \\
\text { Time } \\
\text { (days) }\end{array}$} & \multirow{3}{*}{ 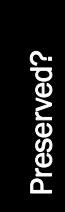 } & \multicolumn{14}{|c|}{ Mean Concentration $(\mathrm{mg} / \mathrm{L})^{1}$} \\
\hline & & & \multicolumn{2}{|c|}{ tDCE } & \multicolumn{2}{|c|}{ Benzene } & \multicolumn{2}{|c|}{ TCE } & \multicolumn{2}{|c|}{ Toluene } & \multicolumn{2}{|c|}{ oDCB } & \multicolumn{2}{|c|}{$m X Y L$} & \multicolumn{2}{|c|}{ PCE } \\
\hline & & & Control & SS & Control & ss & Control & ss & Control & SS & Control & SS & Control & Ss & Control & SS \\
\hline 7 & 1 & No & 0.235 & $0.242 *$ & 0.155 & $0.097^{*}$ & 0.235 & 0.231 & 0.131 & $0.05 *$ & 0.278 & $0.26 *$ & $<\mathrm{DL}$ & $<\mathrm{DL}$ & 0.177 & $0.166 *$ \\
\hline \multicolumn{3}{|c|}{ Percent difference } & & 3.0 & & -38.0 & & -2.0 & & -61 & & -3.9 & & & & -6.1 \\
\hline 7 & 3 & No & 0.417 & $0.435 *$ & 0.27 & 0.254 & 0.378 & $0.388 *$ & 0.191 & 0.172 & 0.328 & 0.328 & 0.111 & $0.008^{*}$ & 0.274 & 0.273 \\
\hline \multicolumn{3}{|c|}{ Percent difference } & & 4.1 & & -0.7 & & 2.8 & & -9.7 & & 0 & & -93.0 & & -0.3 \\
\hline 14 & 1 & Yes & 0.245 & $0.233^{*}$ & 0.206 & 0.205 & 0.245 & $0.230 *$ & 0.195 & $0.184 *$ & 0.298 & $0.271 *$ & 0.05 & $0.032 *$ & 0.192 & $0.162 *$ \\
\hline \multicolumn{3}{|c|}{ Percent difference } & & -4.6 & & -0.5 & & -5.9 & & -5.9 & & -8.9 & & -36.0 & & -16.0 \\
\hline 14 & 3 & Yes & 0.591 & $0.599 *$ & 0.418 & $0.430 *$ & 0.536 & 0.539 & 0.309 & $0.298 *$ & 0.493 & $0.483^{*}$ & 0.243 & $0.187^{*}$ & 0.403 & $0.387 *$ \\
\hline \multicolumn{3}{|c|}{ Percent difference } & & 1.5 & & 2.9 & & 0.5 & & -3.5 & & -2 & & -23.0 & & -3.8 \\
\hline
\end{tabular}

1 Mean of 5 replicate samples.

* Values with a statistically significant difference from control samples. 
Table F4. Results from the holding-time study, using the explosives test solution (with 7-day holding time).

\begin{tabular}{|l|c|c|c|c|}
\hline \multicolumn{1}{|c}{ Analyte } & $\begin{array}{c}\text { Mean Concentration* } \\
(\mathrm{mg} / \mathrm{L})\end{array}$ & $\begin{array}{c}\text { Significant } \\
\text { Difference? }\end{array}$ & $\begin{array}{c}\text { Percent } \\
\text { Difference }\end{array}$ \\
\cline { 2 - 4 } & Control & Snap & & \\
\hline HMX & 0.650 & 0.649 & No $^{1}$ & \\
\hline TNB & 2.71 & 2.69 & No $^{2}$ & \\
\hline RDX & 4.75 & 4.72 & Yes $^{1}$ & 0.63 \\
\hline 1,3-DNB & 0.212 & 0.215 & No $^{1}$ & \\
\hline TNT & 0.976 & 0.970 & Yes $^{1}$ & 0.70 \\
\hline NB & 0.116 & 0.115 & Yes $^{1}$ & 0.86 \\
\hline 2,4-DNT & 0.074 & 0.074 & No $^{1}$ & \\
\hline $\begin{array}{l}\text { * Mean of 5 replicate samples } \\
\text { 1 Paired t-test } \\
\text { 2 Wilcoxon signed rank test }\end{array}$ & & & \\
\hline
\end{tabular}




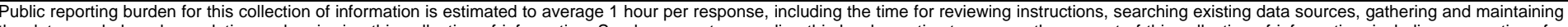

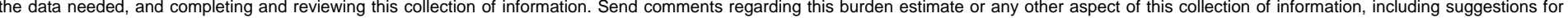

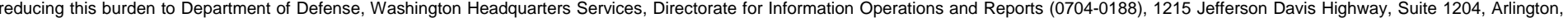

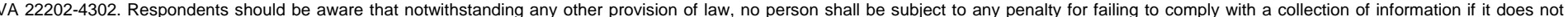
display a currently valid OMB control number. PLEASE DO NOT RETURN YOUR FORM TO THE ABOVE ADDRESS.

\begin{tabular}{|l|l|}
\hline $\begin{array}{l}\text { 1. REPORT DATE (DD-MM-YYYY) } \\
\text { July 2009 }\end{array}$ & $\begin{array}{c}\text { 2. REPORT TYPE } \\
\text { Final }\end{array}$ \\
\hline 4. TITLE AND SUBTITLE
\end{tabular}

Demonstration/Validation of the Snap Sampler Passive Ground Water Sampling Device for Sampling Inorganic Analytes at the Former Pease Air Force Base
3. DATES COVERED (From - To)

Feb 2007 to Feb 2009 5a. CONTRACT NUMBER

5b. GRANT NUMBER

5c. PROGRAM ELEMENT NUMBER

\section{5d. PROJECT NUMBER}

ER-0630

Louise Parker, Nathan Mulherin, Gordon Gooch, William Major, Richard Willey, Thomas Imbrigiotta, Jacob Gibs, and Donald Gronstal

5f. WORK UNIT NUMBER

\section{PERFORMING ORGANIZATION NAME(S) AND ADDRESS(ES)}

U.S. Army Engineer Research and Development Center (ERDC)

Cold Regions Research \& Engineering Laboratory (CRREL)

72 Lyme Road

Hanover, NH 03755-1290

\section{SPONSORING I MONITORING AGENCY NAME(S) AND ADDRESS(ES)}

Environmental Security Technology Certification Program (ESTCP)

901 North Stuart Street, Suite 303

Arlington, VA 22203

\section{SPONSOR/MONITOR'S ACRONYM(S) ESTCP}

11. SPONSOR/MONITOR'S REPORT NUMBER(S)

Environmental Restoration Project ER-0630

\section{DISTRIBUTION I AVAILABILITY STATEMENT}

Approved for public release; distribution is unlimited.

\section{SUPPLEMENTARY NOTES}

\section{ABSTRACT}

Laboratory studies and a field demonstration were conducted to determine the ability of the Snap Sampler to recover representative concentrations of several types of inorganic analytes from ground water. Analytes included non-metals, transition metals, alkaline earth metals, alkali metals, and a metalloid. In the laboratory studies, concentrations of analytes in Snap Sampler samples were comparable with concentrations of the analytes in samples collected from a standpipe (i.e., control samples). For the field demonstration, there were sampling events at the former Pease Air Force Base. Samples taken using a Snap Sampler were compared with samples collected using conventional low-flow purging and sampling and a regenerated cellulose passive diffusion sampler. Based upon statistical analyses, analyte concentrations were found to be equivalent to those in the low-flow samples with one exception - unfiltered iron, where concentrations were significantly higher in the Snap Sampler samples. Differences were most pronounced in samples collected from the two stainless steel wells and from wells with higher turbidity levels. Elevated turbidities may have resulted from installing additional sampling equipment (including the baffle, pump, samplers, and bottom weight) in the well before sampling. We will examine this issue further at our next test site.

\section{SUBJECT TERMS}

dialysis membrane sampler, equilibrated-grab sampler, low-flow purging and sampling, no-purge sampling, passive ground water sampling, passive sampling, regenerated cellulose sampler, Snap Sampler

\section{SECURITY CLASSIFICATION OF:}

\section{a. REPORT}

Unclassified

b. ABSTRACT
Unclassified

c. THIS PAGE

Unclassified

\section{LIMITATION}

\section{OF ABSTRACT}

\section{NUMBER} OF PAGES

U
115

\section{9a. NAME OF RESPONSIBLE}

PERSON Louise Parker

19b. TELEPHONE NUMBER (include area code) 